Politics and Health Care Spending in the United States

Zack Cooper, Amanda E Kowalski, Eleanor N Powell, and Jennifer Wu

NBER Working Paper No. 23748

August 2017, Revised in September 2020

JEL No. D72,H51,I10,I18,P16

\begin{abstract}
We uncover political dynamics that reward and reinforce increases in US health spending by studying the passage of the 2003 Medicare Modernization (MMA). We focus on a provision added to the MMA, which allowed hospitals to apply for temporary Medicare payment increases. Hospitals represented by members of Congress who voted 'Yea' to the MMA were more likely to receive payment increases. The payment increases raised local health spending and led to suggestive increases in health sector employment. Members of Congress representing hospitals that got a payment increase received large increases in campaign contributions before and after the program was extended.

Zack Cooper

Yale Institution for Social and Policy Studies

77 Prospect Street

New Haven, CT 06511

and NBER

zack.cooper@yale.edu

Amanda E Kowalski

Department of Economics

University of Michigan

611 Tappan Ave.

Lorch Hall 213

Ann Arbor, MI 48109-1220

and NBER

aekowals@umich.edu

Eleanor N Powell

University of Wisconsin-Madison

1050 Bascom Mall

Madison, Wisconsin, 53706

eleanor.powell@wisc.edu

Jennifer $\mathrm{Wu}$

Yale University

jennifer.wu@yale.edu
\end{abstract}




\title{
Politics and Health Care Spending in the United States*
}

\author{
Zack Cooper, Yale University and the NBER \\ Amanda Kowalski, University of Michigan and the NBER \\ Eleanor Neff Powell, University of Wisconsin-Madison \\ Jennifer Wu, Yale University
}

September 2020

\begin{abstract}
We uncover political dynamics that reward and reinforce increases in US health spending by studying the passage of the 2003 Medicare Modernization (MMA). We focus on a provision added to the MMA, which allowed hospitals to apply for temporary Medicare payment increases. Hospitals represented by members of Congress who voted 'Yea' to the MMA were more likely to receive payment increases. The payment increases raised local health spending and led to suggestive increases in health sector employment. Members of Congress representing hospitals that got a payment increase received large increases in campaign contributions before and after the program was extended.
\end{abstract}

Key Words: Health Care Spending, Political Economy, Congress, Lobbying JEL Codes: I10, I18, H51, D72, P16

*Acknowledgements: This work began when all four coauthors were affiliates of the Institution for Social and Policy Studies (ISPS) at Yale University and we thank ISPS and Jacob Hacker for the tremendous support. This project also received financial support from the Tobin Center for Economic Policy at Yale University. We thank Steven Berry, Andrea Harris, Neale Mahoney, Joshua Gottlieb, David Mayhew, Mark McClellan, Fiona Scott Morton, Jonathan Skinner, Ebonya Washington, and participants at various seminars for helpful feedback. We also thank Leemore Dafny, Jonathan Gruber, and Adam Sacarny for help with accessing data. Antoine Arnoud, Eugene Larsen-Hallock, Charles Gray, Harriet Jeon, Jonathan Kroah, Hao Nguyen, Lachi Singh, and Stuart Craig provided excellent research assistance. All mistakes are our own. 
"In the past, decisions on health care delivery were largely professional ones. Now the decisions will be largely political.” - John G. Veneman, undersecretary of the Department of Health, Education and Welfare (HEW) in the Nixon administration, discussing the effect of the growing role of the federal government in the US health care system. ${ }^{1}$

\section{Introduction}

In 2018, the United States (US) spent \$3.6 trillion on health care, of which more than \$1 trillion was funded by the federal government (Centers for Medicare and Medicaid Services 2018). From the 1970 s to present, in each successive decade, health spending has grown more quickly than gross domestic product (GDP) (Kamal and Cox 2018). Both because of the scale of government spending on health care in the US and evidence that the US health system is inefficient relative to other countries, the level of health spending and the growth in health spending over time represent significant policy challenges domestically (Garber and Skinner 2008). However, until now, most research has focused on studying the influence of demand and supply side factors-e.g., patient demographics, cost sharing, provider incentives, the diffusion of new technologies, and provider consolidation - on the variation and growth in U.S. health spending. ${ }^{2}$ In this paper, we present some of the first work to formally explore how congressional politics influence health care spending in the US. We show that members of Congress receive benefits-increases in health spending, jobs in their districts, and campaign contributions - in the wake of votes they took that raised Medicare reimbursement rates for hospitals in their districts. We also illustrate the lobbying and political dynamics that allow provisions that raise health spending to get added to laws and persist as policy. As a result, this paper both is informative about factors that influence health spending in the US and adds to the wider political economy literature assessing the

\footnotetext{
${ }^{1}$ Quoted in Iglehart (1971) as cited in Starr (1983).

${ }^{2}$ See Finkelstein, Gentzkow, and Williams (2016), Chandra and Skinner (2011), Smith, Newhouse, and Freeland (2009), and Cutler et al. (2013) as examples.
} 
relationship between legislators' actions, local benefits, and campaign contributions.

To analyze the influence of politics on health spending, we study events leading up to and following passage of the Medicare Modernization Act (MMA) of 2003, a law which gave government-funded prescription drug coverage to seniors via the introduction of the Medicare Part D program. The MMA of 2003 was politically fraught and challenging to pass. It involved a large increase in government spending and required support from Democratic legislators reticent about supporting an initiative championed by a Republican president and support from Republican lawmakers who were not naturally in favor of expansions of government programs. The MMA of 2003 was ultimately approved by Congress in November 2003 by a five-vote margin in a vote that involved significant political bartering (Oliver, Lee, and Lipton 2004).

Whereas most of the literature on the MMA of 2003 has analyzed the impact of the law on individuals who received Part D drug insurance (for example, see Abaluck and Gruber (2011), Abaluck and Gruber (2016), Joyce et al. (2009)), we use the law to examine how the political process necessary to pass sweeping health care legislation impacts long-run health spending, local employment, lobbying, and campaign contributions. We focus on the impact of a provision inserted into the MMA of 2003-Section 508-which created a process through which hospitals could apply to receive an increase in their regulated Medicare payments. Crucially, the rules governing which hospitals received increases in their reimbursements from Section 508 were written by the executive branch after the MMA was passed. This allowed officials to potentially steer funds to specific hospitals and regions (that would then benefit specific politicians) after seeing how members voted.

Our analysis proceeds in four stages. First, we present evidence that Medicare hospital payment increases generated by the Section 508 program were used as a bartering tool to win political support. We identify, via a Freedom of Information Act (FOIA) request, the hospitals that applied for and were granted a Section 508 waiver. We find evidence that 
hospitals represented by a member of the House of Representatives who voted 'Yea' to the MMA of 2003 were more likely to receive a payment increase than hospitals represented by a member of the House who voted 'Nay' to the law. These empirical findings are consistent with press reporting about efforts to win votes during the passage of the MMA of 2003 (Lee 2003).

Second, we show that these Medicare payment increases generated by the Section 508 program materially impacted hospital behavior and led to a large aggregate increase in health care spending. We identify, via difference-in-difference analysis, that hospitals that received a payment bump generated by the Section 508 program increased the number of inpatient Medicare cases they delivered by approximately seven percent and raised their inpatient Medicare payments by 11 percent. We also find suggestive evidence that hospitals that received this payment increase - particularly those with the largest monetary gains from the program - invested in new technology and increased their staffing and payroll. It is notable that original language in Section 508 in the MMA only allocated $\$ 900$ million to fund the program for three years. Nevertheless, the program was repeatedly extended by Congress, lasted for eight years, and, as we illustrate, resulted in the federal government spending many multiples more than was initially allocated.

Third, we show that the Section 508 program brought tangible benefits to members' districts. This is informative about why the Section 508 program (and programs like it) are added to laws in the first place. We find that local federal health spending went up by millions per congressional district and we observe suggestive evidence that there was the creation of hundreds of new health care jobs in congressional districts with a Section 508-recipient hospital. The impact of the Section 508 program was greatest in the districts that were the most exposed to the Section 508 program.

Finally, we show how provisions like the Section 508 program, once signed into law, become extremely difficult to eliminate. While the payment changes created by the Section 
508 program were originally written to expire three years after they were introduced, the hospitals and wider constituencies that benefited from the waivers had considerable interest in seeing the program extended. Indeed, their shared financial interest in the continuance of the program was so great that Section 508-recipient hospitals joined together to form a political action committee (PAC) called the Section 508 Hospital Coalition. ${ }^{3}$ Using data from the Center for Responsive Politics, we find that the Section 508 Hospital Coalition spent significant resources lobbying members of Congress to extend the Section 508 program. Using data on campaign contributions from the Database on Ideology, Money in Politics, and Elections (DIME), we find that members of Congress representing Section 508-recipient hospitals received large increases in campaign contributions after the program was reauthorized. Likewise, we observe suggestive evidence that there were large increases in campaign contributions to members representing Section 508-recipient hospitals from individuals working in the hospital sector immediately before the vote to reauthorize the Section 508 program and again after the law was passed. We do not find corresponding increases in campaign contributions from individuals working in sectors that were plausibly wholly unexposed to changes in hospital Medicare reimbursements - individuals working in the agriculture sector and the oil and gas industry.

This paper makes three distinct contributions to the literature. First, we present some of the first work to formally show a link between the US political process and domestic health spending. While it is assumed that politics influences health spending, this is largely based on conjecture, theory, and reporting from journalists. We study a specific setting that allows for robust identification and provide evidence of how political dynamics and the actions of Congress influence health spending.

This analysis provides suggestive evidence of a feedback loop that illustrates why provisions like the Section 508 program get added to laws and then become exceedingly

\footnotetext{
${ }^{3}$ See: https : //www . opensecrets . org/lobby/clientsum.php?id=D000056560\&year=2012.
} 
hard to eliminate. Our evidence suggests that politicians use Medicare payment increases as a tool to win votes from members of Congress. It is clear from our analysis that increases in Medicare payments can lead to large increases in hospital spending and substantive changes in local labor markets. The benefits of narrow provisions, like the Section 508 program, are substantive enough that they precipitate the formation of PACs and substantial lobbying efforts to see them extended. Moreover, members of Congress see an increase in campaign contributions once these types of programs are extended. This feedback loop may help explain, in part, why it is so challenging to reduce US health spending in the long run. Simply put, we observed that legislators were rewarded for votes that raised health spending in their districts.

While we focus on a program that impacted approximately 100 hospitals, the dynamics we observe-health spending generating local benefits and leading to increases in donations for members of Congress - can inform our understanding of the wider allocation of tens of billions of dollars in health spending. Indeed, the Medicare program alone spends approximately $\$ 750$ billion annually. There are a myriad of other programs similar to Section 508, which were added to wider pieces of legislation, were rumored to be political, and which led to billions of dollars in higher Medicare spending via increasing the rates that hospitals get reimbursed by the government. ${ }^{4}$ Focusing on the Section 508 program in particular provides a useful setting that affords clean identification.

The political dynamics we observe also help explain how seemingly inefficient Medicare programs remain funded despite widespread concerns about differentially high health spending in the US. ${ }^{5}$ Our evidence suggests that providers need to spend relatively little in

\footnotetext{
${ }^{4}$ For example, the Frontier State program was introduced as part of the Affordable Care Act (ACA). It raised the Medicare reimbursements to hospitals in five states: Montana, Nevada, North Dakota, South Dakota, and Wyoming. Ultimately, nearly 40 percent of hospitals have received an adjustment similar to the Section 508 adjustment, which increased their Medicare payment rates (Institute of Medicine 2012).

${ }^{5} \mathrm{~A}$ classic example is the funding of long-term care hospitals, as noted by Einav, Finkelstein, and Mahoney (2018). Einav, Finkelstein, and Mahoney (2018) study the efficacy of Medicare funding for long-term care hospitals (LTCHs). The authors find that LTCHs offer no clinical benefits relative to other providers, but lead
} 
lobbying dollars and on campaign contributions in exchange for exceptionally large increases in health spending. These results are particularly notable because from 2000 to 2019, the health care industry (physicians, hospitals, and device and pharmaceutical manufacturers) spent more on lobbying annually than any other industry and have spent more than double what other industries have spent during that period (The Center for Responsive Politics 2019a).

Second, we add to the literature analyzing the link between legislators' actions and campaign contributions. A large body of theoretical work has posited that campaign contributions are directly linked to legislators' actions (e.g., that they facilitate access to politicians, that they induce legislators to act, or that they influence legislators' votes). ${ }^{6}$ However, the empirical evidence on the relationship between legislators' actions and campaign contributions is extremely mixed and null findings are more common in the literature than significant effects (Ansolabehere, Figueiredo, and Snyder Jr. 2003; Stratmann 2005). In part, this reflects the challenge of finding institutional settings that allow for causal inference (Powell 2014). We show that directly affected donors (individuals working in the hospital sector) increased their donations in the quarter leading up to the re-authorization of the Section 508 program and after the program was reauthorized. Likewise, members of the House who had a 508 hospital in their district received a large increase in overall campaign contributions after the program was extended.

Third, while not the primary focus of this analysis, we add to the literature assessing how hospitals respond to payment increases. ${ }^{7}$ Because Section 508 waivers appeared to be politically motivated, the payment increases they generated can be viewed as plausibly

to approximately $\$ 30,000$ in higher costs per admission. Eliminating the program and reimbursing LTCHs at the same rate as other post-acute providers could save approximately $\$ 5$ billion annually. However, despite numerous attempts, policymakers have not been able to eliminate differentially high payments to LTCHs.

${ }^{6}$ See, for example, (Coate 2004; Grossman and Helpman 1994; Grossman and Helpman 1996; Grossman and Helpman 2001).

${ }^{7}$ Other papers in this literature include Baicker and Staiger (2005), Dafny (2005), Kaestner and Guardado (2008), Foo, Lee, and Fong (2017), Duggan (2000), Chang and Jacobson (2011). 
exogenous. We use the receipt of a Section 508 waiver to show that hospitals respond to a Medicare payment increase by increasing their activity. We also find suggestive evidence that our sample of hospitals (which were mostly non-profits) also responded to the payment increase by raising their payroll and acquiring more technology.

This paper is structured as follows. In Section 2, we provide background information on the Medicare program and the Medicare Modernization Act of 2003. In Section 3, we describe the Section 508 program, identify recipient hospitals, and quantify the payment increases they received from receiving a Section 508 waiver. Section 4 describes the impact of the 508 program on hospital behavior. In Section 5, we analyze how the Section 508 program impacted congressional districts. In Section 6, we explore whether members of the House were rewarded for reauthorizing the Section 508 program. We conclude in Section 7.

\section{Background}

\subsection{The Medicare Program and the Medicare Modernization Act of 2003}

The Medicare program provides health insurance coverage to individuals age 65 and older and to a subset of individuals with disabilities who are under age 65. Most Medicare funds are allocated across the US via formula-based payment reimbursement programs for physicians and hospitals. The majority of hospitals in the US are paid for treating Medicare patients under the formula-based prospective payment system (PPS). The PPS reimburses hospitals a fixed payment per inpatient case. Medicare payments vary across hospitals in the US by a factor of approximately three and are set to approximate hospital input costs for delivering care (Institute of Medicine 2012).

On December 8, 2003, President George W. Bush signed the MMA into law, which, for the first time, provided prescription drug coverage to seniors via the creation of the Medicare Part D program. The MMA was the largest expansion in the Medicare program's 38-year 
history. The law, which was expected to cost approximately $\$ 400$ billion over 10 years, was a political priority for the George W. Bush White House who thought the coverage expansion would bolster the senior vote that he had lost to $\mathrm{Al} \mathrm{Gore} \mathrm{in} \mathrm{the} 2000$ presidential election (Oliver, Lee, and Lipton 2004). According to Bruce Bartlett, "George W. Bush strongly supported this effort [to pass Medicare Part D]. Looking ahead to a close re-election in 2004 , he thought a new government giveaway to the elderly would increase his vote share among this group" (Bartlett 2013).

The passage of the MMA of 2003 was politically fraught. The bill was introduced in the US House of Representatives by Speaker Dennis Hastert on June 25, 2003. Early roll call votes in the House indicated that the bill was unlikely to pass. The key vote that moved the bill from the House to the Senate (roll call vote 332) passed by a one-vote margin, 216 to 215 , and was split along party lines. Democrats voted 9 'Yea' and 195 'Nay' while Republicans voted 207 'Yea' and 19 'Nay.' This vote, in breach of congressional rules, was kept open for an abnormally long period during which time Vice President Cheney visited the House floor, and there was substantial arm-twisting (Oliver, Lee, and Lipton 2004). Ultimately, passage of the law hinged on keeping Republican members of the House from voting against the legislation and mustering support from conservative Democrats (Oliver, Lee, and Lipton 2004). As a result, because the vote was so close, every member's vote could be considered a marginal vote. Section 508 was added immediately after this vote. ${ }^{8}$ We focus on this vote and examine whether there are links between members' votes and whether hospitals in the members' districts received Section 508 waivers.

After the Senate passed the bill, the final vote on the reconciled legislation in the House of Representatives (roll call vote 669) was also extremely close. As was the case during the first House vote, rather than adhering to the standard 15-minute vote period and in

\footnotetext{
${ }^{8}$ We spoke to individuals working on the staffs of members of Congress during the passage of the MMA, who indicated that Section 508 waivers were used as sweeteners during roll call vote 332.
} 
contravention of the Rules of the House of Representatives, the vote was kept open for an extended window during which time Health and Human Services (HHS) Secretary Tommy Thompson visited the House floor and President Bush phoned reluctant members of Congress (Oliver, Lee, and Lipton 2004). In the end, the law passed by a vote of 220 to 215 .

Consistent with Evans' 2004 argument that targeted policies can be inserted to garner votes in the passage of sweeping legislation, the MMA contains a number of provisions, in addition to Section 508, that provide targeted benefits in an effort to win over particular legislators (Lee 2003; Abelson 2003). As Christopher Lee wrote in The Washington Post in 2003:

“The $\$ 395$ billion Medicare bill passed by the House yesterday, advertised as a way to provide a long-awaited prescription drug benefit for seniors, also has become a vehicle for scores of narrower provisions tailored to benefit special interests. Such measures, dubbed 'rifle shots' for their narrowly targeted effects, are commonly attached to complex, high-profile legislation in the crunch as a way to both build support for the larger bill and to provide an avenue to passage for provisions that likely would not succeed on their own.” (Lee 2003)

Lee (2003) notes a number of specific provisions including a large increase in funding added to the MMA for physicians in Alaska, the home state of Senator Ted Stevens, the chairman of the Senate Appropriations Committee. Another provision, championed by Senator Charles Grassley from Iowa, contained significant funding for trials to determine whether the Medicare program should fund chiropractic services. Iowa is the home of a leading chiropractic educational institution (Lee 2003).

\subsection{The Medicare Program and Political Logrolling}

While the Medicare program is supposed to allocate funding based on local needs and not politics, the control and influence that Congress has over the program allows members to 
narrowly focus funds to specific districts and key constituencies. There are a number of examples of where legislators have used the Medicare program to reward their constituents. For example, within the 1999 federal budget, Representative Rob Portman successfully lobbied for an increase in Medicare payments for brachytherapy, a treatment for prostate cancer in which radioactive seeds are implanted in the prostate. The radioactive seeds subjected to the funding increase were produced by Indigo Medical, a firm based in Congressman Portman's district (Pear 1999). Similarly, the 1999 budget also increased funding for radioactive dye used to sharpen the precision of imaging studies (Pear 1999). The provision for this funding increase was inserted by William Roth, the junior senator from Delaware, the state where the largest manufacturer of this product is headquartered.

Policymakers and journalists have argued that these types of narrowly directed funds have been used to curry favor from lawmakers and nudge them to vote for laws that were successfully passed including the Children's Health Insurance Program, the Affordable Care Act (ACA), and the MMA (Vladeck 1999; Aaron and Reischauer 2015; Pear 1999; Cohn 2010; Abelson 2003). These kinds of logrolling efforts can involve significant sums of money. For example, a recent article on Senate Majority Leader Mitch McConnell's efforts to repeal the ACA and pass the Better Care Reconciliation Act of 2017 (BCRA) stated, "Using a combination of hardball politics, personal persuasion and lots of money hundreds of billions of dollars were available to pay for more add-ons to the bill in order to get some votes - the Kentucky Republican scrambled to round up 50 Republicans to support the motion to proceed to the bill" (Bresnahan 2017).

Hospital payment rules, in particular, have been used to steer additional funding to particular hospitals and regions. While payment changes cannot be explicitly political, officials at CMS can write rules at the direction of legislative leaders that are crafted to steer funds narrowly to specific hospitals or groups of hospitals. Indeed, a significant portion of hospitals paid under the Medicare PPS have experienced a payment change. Between 
1997 and 2012, 16 statutory provisions were introduced that raised hospital reimbursements for small groups of providers (Government Accountability Office 2013). ${ }^{9}$ As a result, by 2012, 29.7 percent of hospitals received some form of wage index reclassification that raised their reimbursement rate above what was originally set by the PPS formula (Government Accountability Office 2013).

While some of these changes were merit based, a number of provisions have produced large changes in hospital payments that are often credited to a particular lawmaker or were used to direct funds very narrowly. ${ }^{10}$ For example, "Lugar counties," authorized by and named after Indiana Senator Richard Lugar, were introduced in the Omnibus Reconciliation Act of 1987 and generated 10 percent increases in hospital payments for providers located in a small number of counties (American Hospital Association 2011). Likewise, within the 1999 budget, hospitals in districts represented by Representative Tom DeLay, the House Republican Whip and Representative Dennis Hastert, the Speaker of the House, were reclassified into other regions, which significantly increased the hospitals' Medicare payment rates (Pear 1999). These changes resulted in annual increases in hospital funding of $\$ 380,000$ and $\$ 750,000$, respectively (Pear 1999). More recently, in what became popularly known as the "Bay State Boondoggle," John Kerry, then Senator from Massachusetts, lobbied to prohibit Medicare from paying urban hospitals below the rate paid to the rural hospital with the highest reimbursement rate in the state (Keane 2013; Jan 2013). Because the only rural hospital in Massachusetts is located in Nantucket, a wealthy island town, urban hospitals across the state saw a substantial increase in payments from this change. ${ }^{11}$

\footnotetext{
${ }^{9}$ For a detailed description of the statutory provisions that have increased hospital payments, see the US 2013 Government Accountability Offices report to Congress that describes all the policies that have increased Medicare hospital payments between 1997 and 2012 (Government Accountability Office 2013).

${ }^{10}$ For example, because hospital payments are, to a large extent, based on the metropolitan statistical area (MSA) where the hospital is located, hospitals located near one another but on other sides of an MSA border can face substantial differences in payment rates. To address this issue, for example, the Omnibus Budget Reconciliation Act of 1989 created a process for hospitals to apply to have their wage index changed if the hospital was located within a short distance of another hospital that was paid at a substantially higher rate.

${ }^{11}$ Ironically, in 2016, CMS discovered a mistake in calculating the wage index for Massachusetts that
} 
There have also been larger-scale payment changes similar to the Section 508 program that were inserted into wider legislation and designed to win votes from reluctant legislators. For example, the ACA created the Frontier States provision, which raised the minimum wage index of hospitals in Montana, Nevada, North Dakota, South Dakota, and Wyoming. This payment change was reported to be a vehicle to win support for the Affordable Care Act from senators in these rural states (Cohn 2010).

\section{The Section 508 Program}

\subsection{Background on the Section 508 Program}

The main factor that determines the level of hospitals' regulated payments is their wage index. A hospital's wage index is based on the hospital's physical location and is a measure of the local labor costs a hospital faces. The Section 508 program created a process through which, in the months after the MMA was passed, hospitals could appeal their current wage index assignment and receive a time-limited change in their wage index that would increase their PPS payment rate. The provision was open to hospitals that were paid using the PPS that did not qualify for other changes in their wage index. According to the Federal Register (2004a), "a qualifying hospital... does not qualify for a change in wage index classification under paragraphs (8) or (10) of section 1886(d) of the Act on the basis of requirements relating to distance or commuting" (pg. 7341). The legislation did not specify the specific criteria hospitals would need to meet to qualify. Instead, the law stated that a qualifying hospital "meets other criteria, such as quality, as the Secretary may specify by instruction or otherwise." Ultimately, the specific rules and regulations that determined

accidentally led to higher hospital payments for Nantucket than should have been allowed. When the mistake was discovered and subsequently corrected, because of the 2012 law that linked statewide urban hospital payments to the payment rate for Nantucket, updating Nantucket's hospital payment rate led to cuts in hospital funding across all of Massachusetts that totaled approximately \$160 million (Kuhn and Schencker 2016). 
how Section 508 waivers were to be granted were written after the MMA was passed and members of Congress had cast their votes. The broad language in Section 508 of the MMA created flexibility for the executive branch to write rules that favored specific hospitals. ${ }^{12}$ Originally, the law budgeted $\$ 900$ million to fund the wage index changes from the Section 508 waivers, which were to run from April 1, 2004 to March 31, 2007. However, the program was extended several times until it finally expired on March 31, 2012 (Government Accountability Office 2013).

Approximately two months after the MMA was passed, the first set of rules for judging Section 508 waiver requests was published in the Federal Register (Federal Register 2004a). A month later, the rules were updated with more detail and justification (Federal Register 2004b). In practice, the Section 508 program relaxed the criteria for hospitals to get their wage index changed. Historically, the Medicare Geographic Classification Review Board, the body responsible for assessing hospital wage index appeals, would allow hospitals to reclassify their wage index to an adjacent region if an urban hospital was within 15 miles of another hospital that was paid substantially more or a rural hospital was within 35 miles of a hospital that was paid substantially more (Federal Register 2004a). The Section 508 program allowed hospitals that did not meet those standard criteria to get a wage index change based on one of eight new criteria (Federal Register 2004a). These new criteria were quite specific and allowed policymakers to target funds narrowly to specific groups of hospitals. For example, the program allowed urban hospitals in states with fewer than 10 people per square mile to get a reclassification. Likewise, the program allowed hospitals to change their assigned wage index to a wage index from a region in another state if the hospital's average hourly wages were at least 108 percent of the average hourly wages at a hospital in the area where the hospital was arguing it should be reclassified. ${ }^{13}$ While

\footnotetext{
${ }^{12}$ In 2014, we spoke to officials at CMS when the Section 508 program was introduced. They described how the program allowed them to write 'rifle shot' provisions to target funds at specific hospitals.

${ }^{13}$ The Federal Register, Volume 69, Number 30, printed on February 13, 2004 includes a detailed description
} 
the Section 508 program was written with very specific criteria that allowed benefits to be directed to specific hospitals, other hospitals that were represented by politicians who were not part of the logrolling process around the MMA could apply and potentially get a waiver.

\subsection{Quantifying Medicare Payments and Gains from the Section 508 Program}

We submitted a FOIA request to CMS and requested the criteria on which hospitals that applied for a Section 508 waiver were judged, a definitive list of hospitals that applied for and received a Section 508 waiver, and a list of hospitals that applied for but were rejected for a Section 508 reclassification. Within a year of our submission, we received a detailed reply from CMS with the information we requested including the identities of the 498 hospitals that applied for a waiver and the 120 hospitals that had their applications approved.

We followed the CMS payment rules presented in the Federal Register to construct hospital PPS payments for each inpatient case for each hospital in each year from 2001 through 2010. ${ }^{14}$ Using this formula to calculate hospitals' Medicare PPS payments allowed us to create counterfactual payments and identify what hospitals would have been paid with and without the wage index change generated by the Section 508 program. In Figure 1, we show Section 508-recipient hospitals' base Medicare PPS payment rate with and without the wage index change generated by the program. Because of the immediate payment rules change, as we illustrate in the figure, the Section 508 program created a sharp and immediate increase in hospitals' payments in 2005 that persisted for the next five years. We find that the mean Section 508-recipient hospital received a 6.90 percent increase in their Medicare PPS payment rates in 2005.

of the quality criteria hospitals had to meet to receive a Section 508 waiver. Per federal law, the Federal Register also includes justifications for these changes.

${ }^{14}$ See Appendix A.2 for more details about how we calculated Medicare PPS payments per hospital. 


\section{Figure 1: The Impact of Medicare Payment Increases on Hospitals' Base PPS Payment Rates}

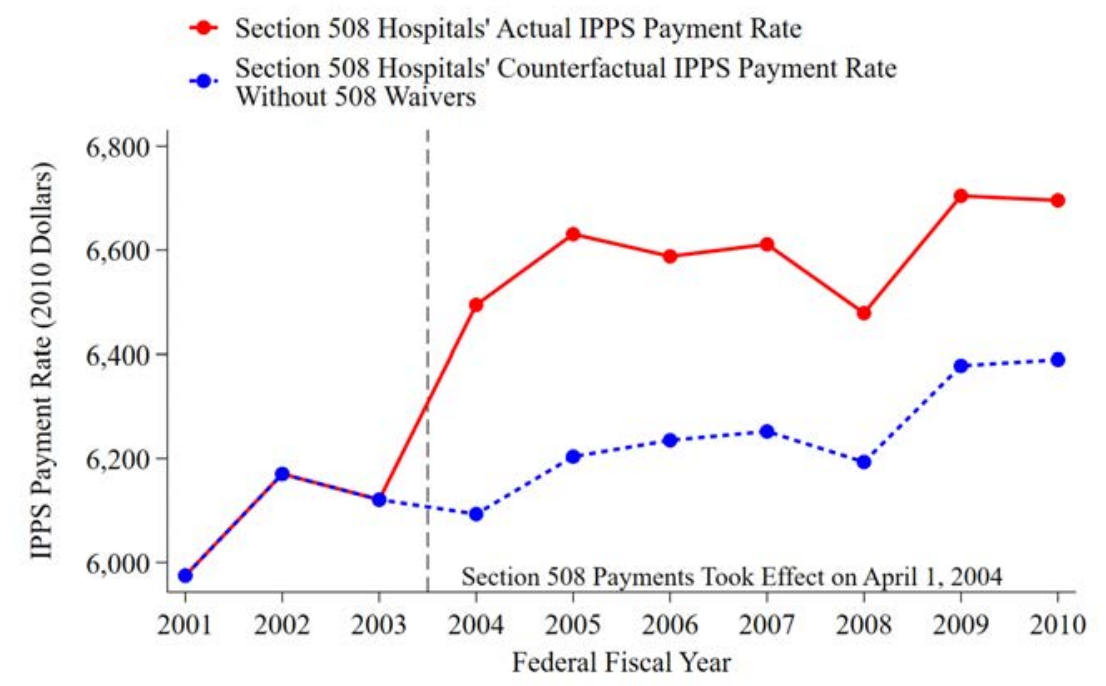

Notes: This figure shows the annual mean Medicare inpatient PPS payment rates in 2010 dollars for the 88 hospitals in our balanced analytic sample that received a Section 508 waiver. We show the actual PPS payment rates (red solid line) and the estimated payment rates the hospitals would have received without a 508 waiver (blue dashed line). To construct the latter, we recalculate payment rates using the wage index for each Section 508 hospital's pre-reclassification labor market area (CBSA), holding all other payment adjustments constant. (These wage indexes are from Tables 4A and 4B of the annual IPPS Final Rules published in the Federal Register.) Because of data limitations, the "actual IPPS payment rate" in 2004 is based on each hospital's 2005 post-reclassification wage index; the "counterfactual IPPS payment rate" in 2004 is based on each hospital's 2004 wage index from the 2004 Impact File, which does not incorporate the Section 508 policy.

\subsection{Hospital Receipt of Section 508 Waivers and Votes for Medicare Modernization Act of 2003}

In Table 1, we examine the relationship between the vote on the MMA by each member of Congress and whether the hospitals in their district received a Section 508 waiver. Data on members' votes were obtained from Voteview, and data on whether hospitals received a 508 waiver came from our FOIA request (details on our data sources are included in Appendix A.1). Note that this table examines 118 Section 508-recipient hospitals because two hospitals with a Section 508 waiver were represented by members of Congress who did not vote in roll call vote 332 . Among the universe of hospitals paid using the PPS in 2005, 3.0 percent received a Section 508 waiver. Among the universe of hospitals eligible 
to receive a waiver (e.g. those that did not already have a wage index reassignment), 5.0 percent received a Section 508 waiver. Of hospitals that applied for a waiver (498 hospitals), 24.1 percent (120) had their application approved.

In Columns (1) and (2) in Table 1, we find that, among all hospitals in our sample eligible to receive a Section 508 waiver, hospitals represented by a member of Congress who voted 'Yea' to roll call vote 332 on the MMA were more likely to receive a waiver than hospitals represented by a member of Congress who voted 'Nay' ( 6.0 percent versus 4.2 percent; $p<$ 0.10). Among hospitals that applied for a waiver, hospitals represented by a member who voted 'Yea' to the MMA were 1.4 times more likely to have their applications approved than hospitals represented by a member who voted 'Nay' (27.6 percent/19.9 percent; $p<$ $0.05) \cdot{ }^{15}$

The political calculus and electoral risks associated with voting in favor of the legislation varied substantially by party with Republicans choosing between angering fiscal conservatives in their base and opposing a president from their own party, while Democrats who may have liked the policy were loath to provide legislative support that could help re-elect the Republican president. Therefore, we also split the analysis by the political party of the congressional representative in each hospital district. In Columns (4) and (5) in Table 1, we find that among hospitals that were eligible to receive a waiver, hospitals represented by a Republican member of Congress who voted 'Yea' to the MMA were nearly seven times more likely to receive a Section 508 waiver than those represented by a Republican member of Congress who voted 'Nay' $(=5.6$ percent $/ 0.8$ percent; $p<0.01)$. Among hospitals that applied for a Section 508 waiver, those represented by a Republican member of Congress who voted 'Yea' were four times more likely $(=26.3$ percent / 6.7 percent; $p<0.01)$ to receive a waiver than those represented by a Republican member of Congress who voted

\footnotetext{
${ }^{15}$ Note that two hospitals that received a Section 508 waiver were excluded from this analysis because the members representing those hospitals abstained from voting in roll call vote 332 . We lose three additional hospitals that applied for a waiver because their members also abstained from voting.
} 
Table 1: Congressional Votes for the Medicare Modernization Act of 2003 and Section 508 Waivers

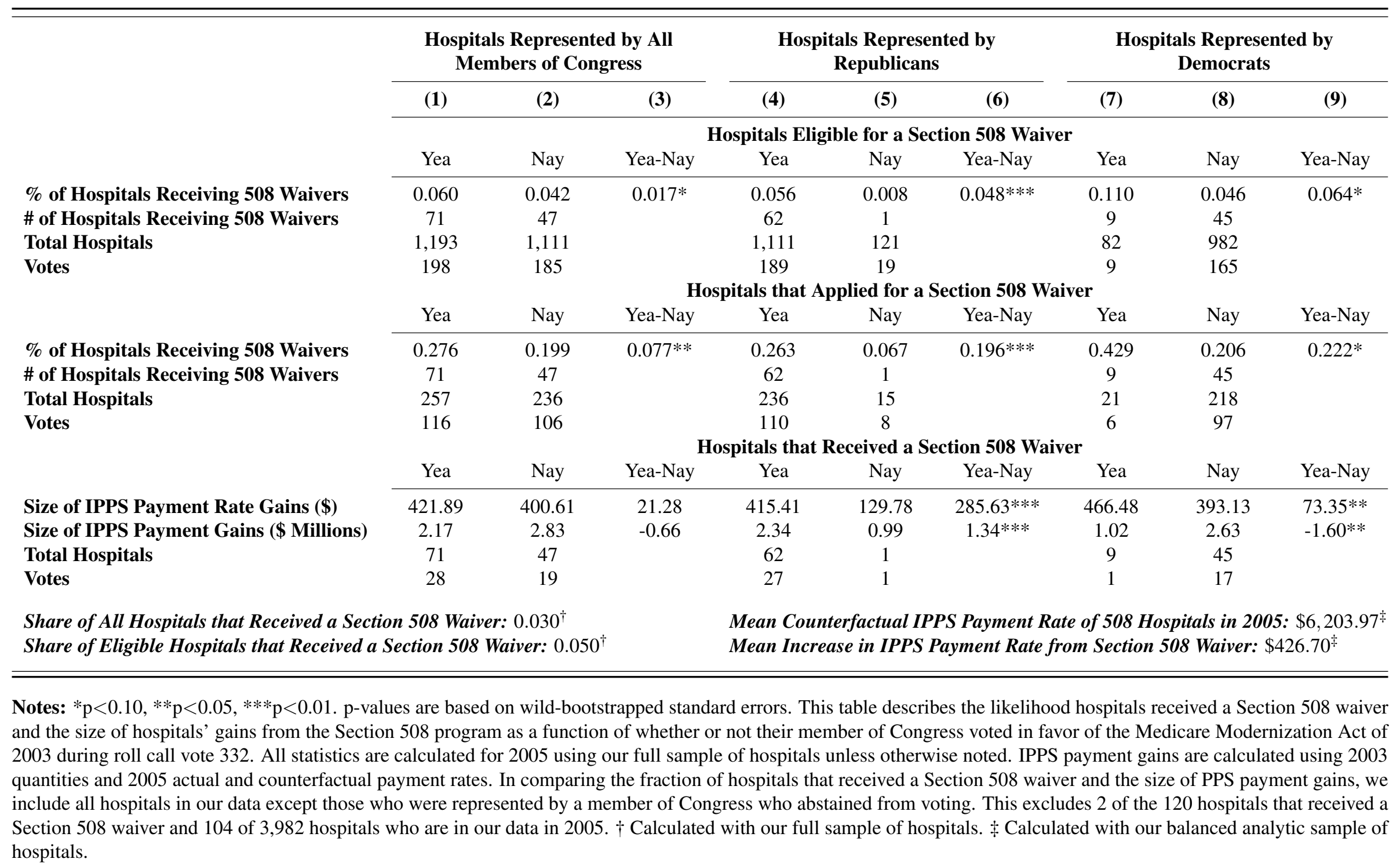


'Nay'. Likewise, hospitals represented by a Democratic member of Congress who voted 'Yea' were also significantly more likely to receive a waiver than hospitals represented by a Democratic member who voted 'Nay' $(p<0.10)$. Note that in Columns (4) through (9), we rely on a sample of 117 Section 508-recipient hospitals because one recipient hospital was represented by a member of Congress that was not registered as a Democrat or a Republican.

While the average gain in IPPS payments for hospitals that received a Section 508 waiver were $\$ 426.70$ off of a mean PPS base payment rate of $\$ 6,203.97$ in 2005 , there was significant heterogeneity in the size of the PPS payment gains. According to the MMA, the Secretary of HHS had influence over the size of the gains hospitals could obtain from a Section 508 waiver. Within the rules for the MMA, the Federal Register (2004a) stated, "Under this [Section 508] process, a qualifying hospital may appeal the wage index classification otherwise applicable to the hospital and apply for reclassification to another area of the State in which the hospital is located (or, at the discretion of the Secretary, to an area within a contiguous State)" (pg. 7341). Therefore, the Secretary of HHS was able to decide whether hospitals that received a Section 508 waiver could be reclassified to areas in other states with higher wage indexes.

In Table 1, we also examine whether there were larger PPS payment gains among Section 508-recipient hospitals represented by members of Congress who voted 'Yea' relative to 'Nay.' In Columns (1) and (2), we show that hospitals represented by a member of Congress who voted 'Yea' received larger gains in base IPPS payment rates than those represented by a member who voted 'Nay' ( $\$ 421.89$ versus $\$ 400.61 ; p<0.63)$. These differences are statistically significant when we analyze the votes by party. The 62 Section 508-recipient hospitals represented by Republican members who voted 'Yea' gained an average of $\$ 285.63$ more than the lone Section 508-recipient hospital represented by a Republican member who voted 'Nay' $(p<0.01)$. Likewise, we also find that hospitals represented by Democratic members of Congress who voted 'Yea' to the MMA received $\$ 73.35$ more from the program 
than hospitals represented by Democratic members of Congress who voted 'Nay' $(p<0.05)$.

\section{Section 508 Waivers and Hospital Behavior}

\subsection{Estimating the Impact of the Section 508 Medicare Payment Increases}

In this section, we examine the impact of the Medicare payment increase generated by the Section 508 program on hospital activity, hospital spending, and hospital investments. We use difference-in-difference regression to identify the outcomes for the hospitals that received a Section 508 waiver before and after they received their April 1, 2004 onward payment increase relative to the outcomes at various groups of control hospitals. Our difference-in-difference specification takes the form:

$$
\text { Outcome }_{h, t}=\beta_{t} \text { Section_508_Recipient }_{h} \cdot \tau_{t}+\vartheta_{h}+\tau_{t}+\varepsilon_{h, t}
$$

where we measure outcomes Outcome ${ }_{h, t}$, such as inpatient Medicare discharges, at hospital $h$ in year $t$. We interact our treatment indicator $\left(\right.$ Section_508_Recipient ${ }_{h}$ ) with a vector of year fixed effects $\tau_{t}$. We also include a vector of year fixed effects $\tau_{t}$ and hospital fixed

effects $\vartheta_{h}$, which capture the main effects of each interaction. Following Cameron, Gelbach, and Miller (2008), we report wild-bootstrapped standard errors (although our results are robust to clustering our standard errors around hospitals). We present our estimates of Equation (1) graphically and in tables.

Our FOIA request revealed that 498 hospitals applied for a Section 508 waiver. Of those hospitals that applied for a waiver, 378 had their applications rejected and 120 hospitals had their applications approved. Among the 120 hospitals that had their waiver applications approved, we lose 17 hospitals from our analysis because they were not registered with the American Hospital Association (AHA) in at least one year. A further 15 hospitals dropped 
out during our sample period because they either were involved in a merger, closed during our period of analysis, or ceased being listed in the CMS Impact Files (which identify how hospitals are paid). This leaves 88 hospitals in our treated sample that remained registered with the AHA, and were reimbursed by the Medicare program from 2001 through 2010. While we rely on a balanced panel of hospitals in our main analysis, we also illustrate that our results are robust when we rely on an unbalanced panel of hospitals. ${ }^{16}$

In any difference-in-difference analysis, the identifying assumption is that the control group represents what would have occurred at the treated group absent any intervention (in our setting, the intervention is the payment increase generated by the Section 508 program). Because the payment increases generated by the Section 508 program were not a function of random assignment, there is no "perfect" control group. The main control group we use in this analysis includes the 284 hospitals in our balanced sample that applied for a Section 508 waiver, but had their application rejected. As we illustrate in Appendix Table A.1, these hospitals have similar characteristics to treated hospitals, but are less likely to be represented in Congress by a member of Congress who voted 'Yea' to the MMA of $2003(p<0.10) .{ }^{17}$ In addition, we estimate Equation (1) using three alternative control groups: 1) hospitals that were eligible to apply for the Section 508 program, but did not submit an application; 2) hospitals that were ineligible for the Section 508 program; and 3) all hospitals that did not receive a Section 508 waiver. We also use propensity score matching to construct a control group drawn from hospitals that were eligible for a Section 508 waiver but did not receive

\footnotetext{
${ }^{16}$ There are 20 hospitals in our treatment group and 115 hospitals in our "applied but rejected" control group that have missing or zero outcomes in one year or another. We dummy out these missing values and zeros. Our results are also robust to excluding these observations from our analysis.

${ }^{17}$ In Appendix Table A.1, we compare the characteristics of Section 508-recipient hospitals, hospitals that applied for a waiver and were rejected, those that were eligible but did not apply, ineligible hospitals, and all hospitals registered with the AHA from 2001 to 2010 that were paid using the PPS. Section 508-recipient hospitals were slightly larger than the average AHA hospital, more likely to be a non-profit, teaching hospital, and less likely to be located in a rural area. Hospitals that unsuccessfully applied for a Section 508 waiver were larger than Section 508-recipient hospitals, had more Medicaid discharges, and were less likely to be non-profit providers.
} 
one.

We also illustrate how our treatment effects vary as a function of hospitals' potential gains from and exposure to the Section 508 program. As we document in Appendix Table A.2, there was significant heterogeneity in payment increases generated by the Section 508 program. Ultimately, hospitals' potential gains from and hence exposure to the Section 508 program were a function of both the number of Medicare patients they treated and the payment increases they received via the receipt of a waiver. To capture this heterogeneity, we created a measure of hospitals' Section 508 treatment exposure, measured in dollars, which we estimate as the product of a hospital's pre-treatment (2003) Medicare inpatient patient volume multiplied by a treated hospital's change in Medicare reimbursement rates generated by the Section 508 program for those procedures. ${ }^{18}$ This exposure measure captures hospitals' predicted revenue gains from the Section 508 program ignoring any expansion of hospital activity induced by the Section 508 program. As we illustrate in Appendix Table A.2, the median Section 508 recipient hospital had a potential exposure (predicted revenue gains) of $\$ 1.52$ million from the 508 program. The hospitals in the 10th and 90th percentiles had potential exposure from the program of $\$ 0.16$ million and $\$ 5.90$ million, respectively.

To test the impact of the increase in Medicare payments on hospital activity and health care spending, we utilize data from the Medicare Provider Cost Report Public Use Files maintained and accessible via the Healthcare Provider Cost Reporting Information System

\footnotetext{
${ }^{18}$ In practice, we calculated Section 508-recipient hospitals' treatment exposure as follows. First, for each Section 508 hospital, we calculated actual and counterfactual inpatient PPS payment rates in 2005 (the first full fiscal year in which the Section 508 program was active). The actual rate includes the wage index boost from the Section 508 program, while the counterfactual rate uses the wage index from each Section 508-recipient hospital's pre-reclassification labor market area. Second, we estimated inpatient PPS payments without the Section 508 policy by applying the counterfactual rate from 2005 to inpatient case counts and DRG payment weights from 2003 (the year before Section 508 took effect, so as to exclude any supply effects of the payment

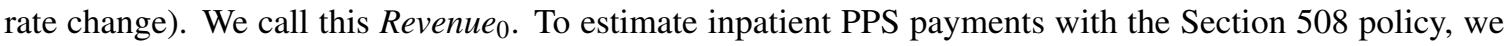
repeated this step using the actual payment rates from 2005. We call the results Revenue 508 . Finally, we identify hospitals' exposure to the Section 508 program as Exposure $_{508}=$ Revenue $_{508}-$ Revenue $_{0}$.
} 
(HCRIS). ${ }^{19}$ We analyze how the Medicare payment increases generated by the Section 508 program impacted hospitals' outputs including their inpatient Medicare discharges, inpatient Medicare prospective payment system (PPS) payments, and total revenue. ${ }^{20} \mathrm{We}$ also measure how the receipt of a Section 508 waiver impacted hospitals' inputs for care including their acquisition of technology, payroll, and staffing. We measure the amount of technology per hospital by following the approach of Acemoglu and Finkelstein (2008) using data from the AHA. The AHA data includes binary indicators for whether a hospital has various technologies, such as computed-tomography (CT) scanners, electron beam computed tomography, or proton beam therapy. We sum the number of these technologies present at each hospital to arrive at a count of technologies per hospital per year. We also measure hospital staffing counts and payroll using data from the AHA.

\subsection{Section 508 Waivers, Inpatient Discharges, and Medicare Inpatient Spending}

Within our sample, as we illustrate in Appendix Table A.1, 88 percent of Section 508recipient hospitals are non-profit facilities. Newhouse (1970) has argued that private, non-profit hospitals maximize output and prestige. If hospitals maximize output, then an increase in Medicare payment rates should also generate movement along the supply curve and an increase in the number of Medicare patients treated at Section 508-recipient hospitals, assuming Medicare reimbursements are greater than hospital per case marginal costs.

Consistent with these predictions, while there was a national reduction in the share of hospital services performed in an inpatient setting in the 2000s, the event study on the left of Panel A of Figure 2 shows that inpatient quantities went down less at Section 508-recipient hospitals than they did in control hospitals (McDermott, Elixhauser, and Sun 2017).

\footnotetext{
${ }^{19} \mathrm{We}$ accessed cleaned Cost Report data files from the RAND Corporation. For more information, see https://www . hospitaldatasets . org/about.

${ }^{20}$ We inflation-adjust our spending measure into 2010 dollars using the seasonally-adjusted Consumer Price Index for All Urban Consumers (CPI-U).
} 


\section{Figure 2: The Impact of Section 508 Waivers on Hospitals' Inpatient Medicare Admissions and Spending}

\section{Panel A: Medicare Inpatient Admissions}
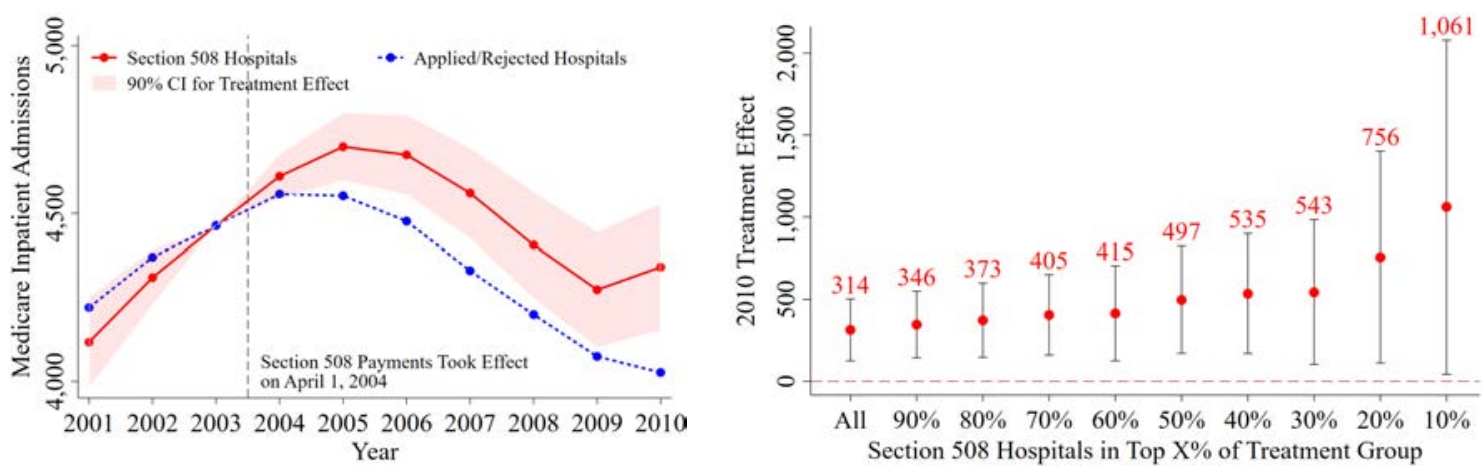

Panel B: Medicare Inpatient PPS Payments (\$ Millions, 2010 Dollars)
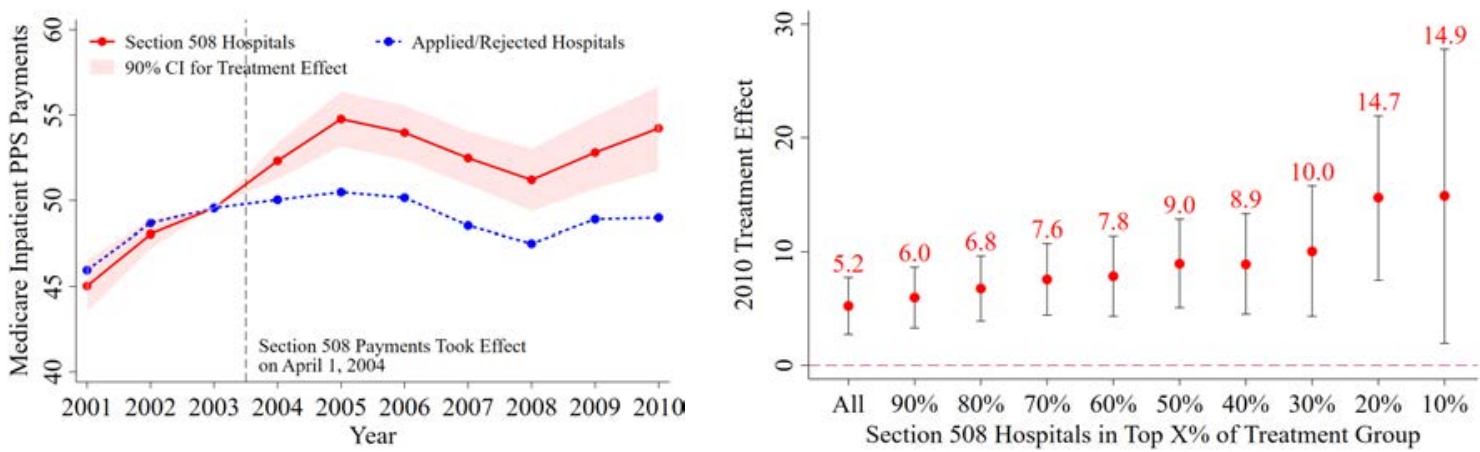

Notes: These panels present estimates of Equation (1) where we regress hospital outcomes on a vector of hospital fixed effects, year dummies, and interactions between the Section 508-recipient hospital indicator and year dummies. 2003 is our omitted year. 90\% confidence intervals are based on wild-bootstrapped standard errors clustered around hospitals. Control hospitals include those that applied for the Section 508 waiver but were rejected. The rightmost figures plot the coefficient of the 2010 interaction term from Equation (1) as we vary the definition of the treatment group. Moving left to right in each figure, each specification involves a treated group composed of hospitals that received increasingly large gains in total IPPS payments (based on quantities in 2003 and actual and counterfactual payment rates in 2005) due to the Section 508 program. Medicare inpatient admissions and PPS payments are from the RAND Medicare Cost Reports (HCRIS) data.

Estimates of Equation (1) presented in Column (1) of Table 2 show that the number of inpatient discharges were 313.94 higher in treated hospitals by 2010 than what occurred at hospitals that applied for a Section 508 waiver, but had their applications rejected $(p<0.01)$. The mean number of discharges in our treated group in the base year (2003) was 4,420.34, implying a difference in inpatient discharges between treated and control hospitals of approximately 3.3 percent in 2005 and 7.1 percent in 2010. Notably, we do not observe any 
meaningful or significant differences in pre-trends between treated and control hospitals prior to the introduction of the Section 508 program.

For each outcome, we also show how the scale of the 2010 treatment effects vary as a function of hospitals' exposure to the Section 508 program. To do so, we alter the composition of our treated group and illustrate the treatment effects from the Section 508 program when we focus on the treatment groups composed of hospitals that received increasingly large predicted revenue gains from the Section 508 program. We refer to these as our "dose response" estimates and they appear on the right side of each panel. In the dose response estimates on the right of Panel A of Figure 2, each point represents an estimate of Equation (1) with inpatient admissions as the dependent variable. Moving left to right, the treated group in each of the point estimates is composed of hospitals that had increasingly large exposure to the Section 508 program. The point estimate closest to the Y-axis shows the 2010 treatment effects when all Section 508-recipient hospitals are included in the treatment group (All). The next point estimate is the treatment effect including the top 90 percent of hospitals (e.g. those that had exposure in the 10th percentile and upwards). The next point includes the top 80 percent of hospitals (e.g. those that had exposure in the 20th percentile and upwards), and so forth. The control group remains the same across all our estimates.

The dose response estimates on the right of Panel A of Figure 2 illustrate that the magnitude of the effect of the Section 508 program on inpatient volume in 2010 is increasing as hospitals' exposure to the program increases (although these differences are not statistically significant). The dose response estimates illustrate that the treatment effect size goes up by 73 percent when we focus on the 30 percent of hospitals with greatest exposure to the Section 508 program and more than triples when we focus on the 10 percent of hospitals with the highest potential exposure.

The Section 508 program also led to large increases in inpatient Medicare spending. As 
we illustrate in Panel B of Figure 2 and Column (2) of Table 2, in 2005, the first year the Section 508 payment increases were in effect for the full calendar year, inpatient Medicare spending at treated hospitals increased by $\$ 4.28$ million off of mean spending at treated hospitals of $\$ 48.86$ ( $p<0.01)$ in 2003 (the year before the payment increases took effect). Treated and control hospitals also had nearly identical pre-trends in the period before the Section 508 payments were introduced. As we illustrate in Panel A of Appendix Figure A.1, this result is robust to measuring the impact of the program on hospitals' total Medicare spending (inpatient plus outpatient spending).

The scale of hospitals' increases in Medicare spending generated by the Section 508 program varied considerably across hospitals (see the dose response estimates on the right side of Panel B of Figure 2). For the 50 percent of hospitals with the largest exposure to the Section 508 program, the payment increases raised inpatient Medicare spending by $\$ 8.95$ million in 2010. For the ten percent of hospitals most exposed to the Section 508 program, the payment increases raised inpatient Medicare spending by $\$ 14.86$ million in 2010. This treatment effect is nearly three times larger than the treatment effect we observe from estimates relying on the full sample of treated hospitals (though this difference is not statistically significant).

Collectively, from 2005 to 2010, the Section 508 program raised inpatient Medicare spending at treated hospitals by approximately $\$ 25$ million per hospital. ${ }^{21}$ Across the 88 treated hospitals in our analysis, this resulted in more than $\$ 2.1$ billion in additional inpatient Medicare spending from 2005 to $2010 .{ }^{22}$ This amount is notable because the original legislative language in Section 508 of the MMA only authorized $\$ 900$ million in spending on the program that was to occur between April 1, 2004 and April 1, 2007.

\footnotetext{
${ }^{21}$ This number is obtained by summing the 2005 to 2010 interaction terms.

${ }^{22}$ We obtain this by multiplying 88 (the number of treated hospitals) by the $\$ 24.87$ million in added spending per treated hospital.
} 
Table 2: The Impact of Section 508 Waivers on Hospitals' Outputs and Inputs

\begin{tabular}{|c|c|c|c|c|c|}
\hline & \multicolumn{2}{|c|}{ Hospital Outputs } & \multicolumn{3}{|c|}{ Hospital Inputs } \\
\hline & $\begin{array}{l}\text { Medicare Inpatient } \\
\text { Admissions } \\
\text { (1) }\end{array}$ & $\begin{array}{c}\text { Medicare Inpatient PPS } \\
\text { Payments (\$ Millions, } 2010 \\
\text { Dollars) } \\
(2)\end{array}$ & $\begin{array}{c}\text { Total Facility Payroll } \\
\text { Expenses (\$ Millions, } 2010 \\
\text { Dollars) } \\
(3)\end{array}$ & $\begin{array}{l}\text { Full-Time Total Personnel } \\
\text { (4) }\end{array}$ & $\begin{array}{c}\text { Number of Technologies } \\
\text { (5) }\end{array}$ \\
\hline $\begin{array}{l}2001 * \text { Treated } \\
\text { Group } \\
2002 * \text { Treated } \\
\text { Group }\end{array}$ & $\begin{array}{l}-103.29 \\
(82.94) \\
-60.22 \\
(51.40)\end{array}$ & $\begin{array}{l}-0.92 \\
(0.96) \\
-0.64 \\
(0.55)\end{array}$ & $\begin{array}{c}3.10 \\
(3.27) \\
0.93 \\
(3.34)\end{array}$ & $\begin{array}{c}39.06 \\
(38.17) \\
32.05 \\
(36.08)\end{array}$ & $\begin{array}{c}-1.13 \\
(1.15) \\
0.16 \\
(0.82)\end{array}$ \\
\hline \multicolumn{6}{|c|}{$\begin{array}{c}2003 \text { - Pre-Treatment Year - Omitted Category } \\
\text { (Section } 508 \text { Payments Took Effect on April 1, 2004) }\end{array}$} \\
\hline $\begin{array}{l}\text { 2004*Treated } \\
\text { Group } \\
2005^{*} \text { Treated } \\
\text { Group } \\
2006 * \text { Treated } \\
\text { Group } \\
2007 * \text { Treated } \\
\text { Group }\end{array}$ & $\begin{array}{c}53.14 \\
(41.26) \\
146.33^{* *} \\
(62.11) \\
197.77 * * * \\
(73.06) \\
230.36 * * * \\
(82.98)\end{array}$ & $\begin{array}{c}2.28 * * * \\
(0.67) \\
4.28 * * * \\
(1.00) \\
3.81 * * * \\
(1.00) \\
3.95 * * * \\
(0.99)\end{array}$ & $\begin{array}{c}-1.11 \\
(0.78) \\
0.12 \\
(3.53) \\
4.43 \\
(5.75) \\
7.27 \\
(6.40)\end{array}$ & $\begin{array}{c}-11.83 \\
(17.91) \\
-2.15 \\
(37.22) \\
13.79 \\
(47.91) \\
-24.42 \\
(59.20)\end{array}$ & $\begin{array}{c}-0.29 \\
(0.78) \\
-0.02 \\
(1.04) \\
-0.10 \\
(1.22) \\
1.87 \\
(1.46)\end{array}$ \\
\hline \multicolumn{6}{|c|}{ Section 508 Program Reauthorized on December 19, 2007} \\
\hline $\begin{array}{l}2008 * \text { Treated } \\
\text { Group } \\
2009 * \text { Treated } \\
\text { Group } \\
2010 * \text { Treated } \\
\text { Group }\end{array}$ & $\begin{array}{c}206.02 * * \\
(96.82) \\
198.82 * \\
(105.31) \\
313.94 * * * \\
(114.89)\end{array}$ & $\begin{array}{c}3.70 * * * \\
(1.13) \\
3.90 * * * \\
(1.32) \\
5.23 * * * \\
(1.53)\end{array}$ & $\begin{array}{c}6.43 \\
(6.68) \\
5.44 \\
(7.01) \\
4.95 \\
(7.27)\end{array}$ & $\begin{array}{c}-36.30 \\
(66.76) \\
1.61 \\
(91.55) \\
-9.36 \\
(83.79)\end{array}$ & $\begin{array}{c}2.95 * \\
(1.57) \\
1.57 \\
(1.82) \\
1.32 \\
(1.81)\end{array}$ \\
\hline $\begin{array}{l}\text { Hospital FEs } \\
\text { Year FEs } \\
\text { N }\end{array}$ & $\begin{array}{c}X \\
X \\
3,720\end{array}$ & $\begin{array}{c}X \\
X \\
3,720\end{array}$ & $\begin{array}{c}X \\
X \\
3,720\end{array}$ & $\begin{array}{c}X \\
X \\
3,720\end{array}$ & $\begin{array}{c}X \\
X \\
3,720\end{array}$ \\
\hline \multicolumn{6}{|c|}{ Mean of the Dependent Variable in 2003} \\
\hline $\begin{array}{l}508 \text { Hospitals } \\
\text { Control Hospitals }\end{array}$ & $\begin{array}{l}4,420.34 \\
4,476.76\end{array}$ & $\begin{array}{l}48.86 \\
49.77\end{array}$ & $\begin{array}{l}78.00 \\
78.22\end{array}$ & $\begin{array}{l}1,148.85 \\
1,285.70\end{array}$ & $\begin{array}{l}51.79 \\
49.63\end{array}$ \\
\hline
\end{tabular}

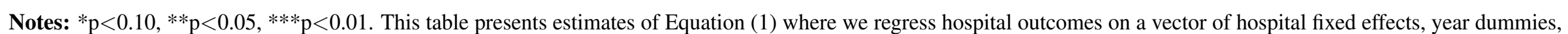

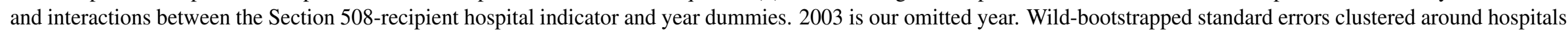

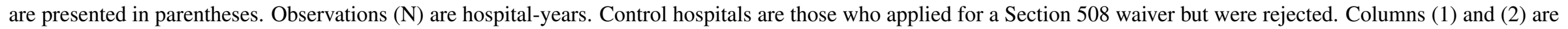
from the RAND Medicare Cost Reports (HCRIS) data. Columns (3), (4), and (5) are derived from the American Hospital Association's Annual Survey data. 
The Medicare payment increases generated by the Section 508 program also created large spillover effects and raised total hospital revenue at the hospitals most exposed to the Section 508 program (see Panel B of Appendix Figure A.1). According to data from the Medicare Cost Reports, mean hospital revenue in 2010 was approximately \$208 million (across all hospitals in our balanced sample). While we do not observe precisely estimated treatment effects on total revenue across the universe of treated hospitals, when we focus on the 50 percent of hospitals with the highest exposure to the program (Panel C of Appendix Figure A.1), we observe that the program led to a $\$ 33$ million increase in total revenue in $2010(p<0.11)$. When we focus on the 20 percent of hospitals with the most exposure to the Section 508 program (Panel D of Appendix Figure A.1), we observe a \$102 million increase in hospital revenue $(p<0.05)$.

\subsection{Section 508 Waivers and Hospital Inputs}

The increase in Medicare reimbursements, hospital activity, and hospital revenue should also have precipitated an increase in hospital inputs. The AHA estimates that labor and benefits account for approximately 60 percent of hospital costs (American Hospital Association 2016). As a result, it is likely that the increase in hospital activity and revenue generated by the Section 508 program should lead to a proportional increase in hospital payroll and staffing.

However, some hospitals stood to gain very little from the Section 508 program (see Appendix Table A.2). Indeed, ignoring a supply response, we estimate that hospitals in the 10th percentile of exposure to the program would only gain $\$ 160$ thousand in Medicare inpatient revenue, hospitals in the 25 th percentile would gain $\$ 510$ thousand, and hospitals in the 50th percentile of exposure would gain $\$ 1.52$ million. It is unlikely that a hospital that received a marginal increase in revenue of $\$ 160$ thousand would meaningfully alter their 
Figure 3: The Impact of Section 508 Waivers on Hospitals' Payroll, Staffing, and Technology

\section{Panel A: Total Facility Payroll Expenses (\$ Millions, 2010 Dollars)}
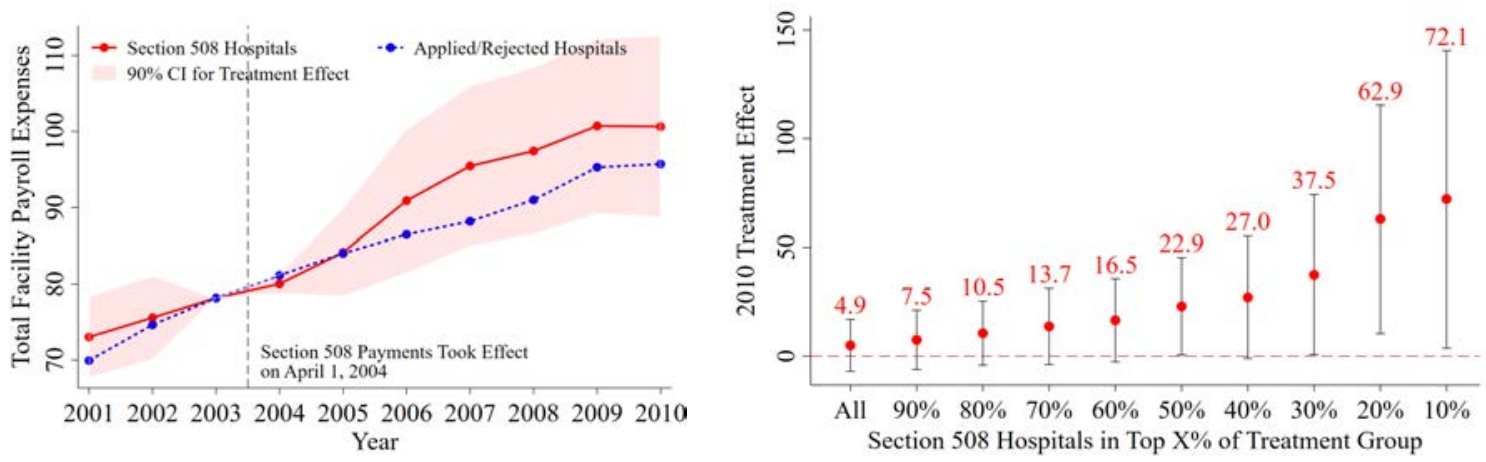

Panel B: Full-Time Total Personnel
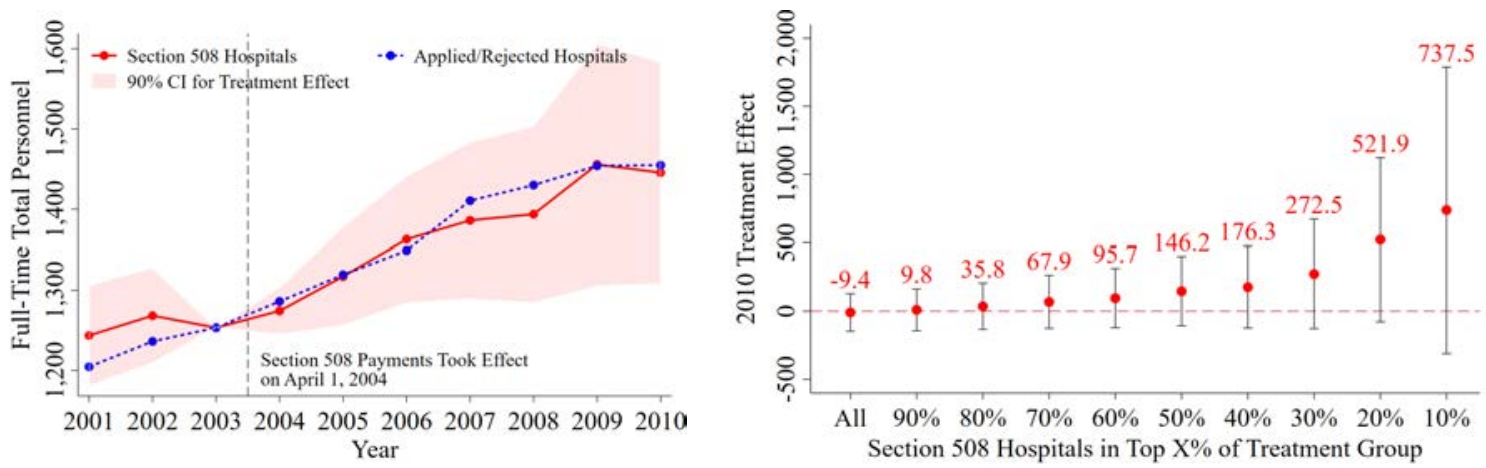

\section{Panel C: Number of Technologies}
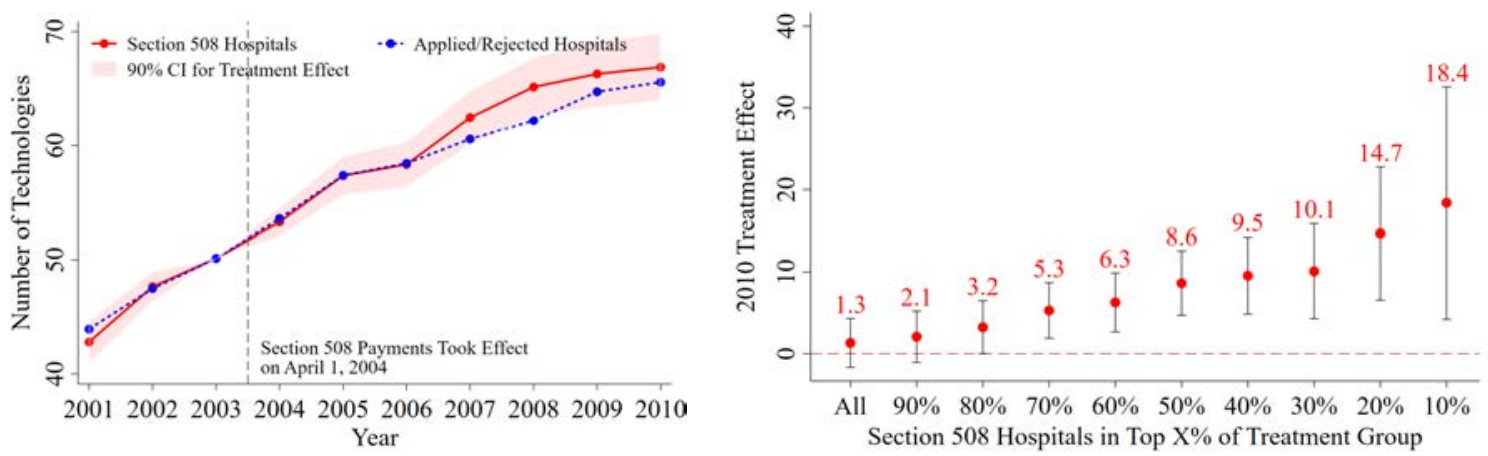

Notes: These panels present estimates of Equation (1) where we regress hospital outcomes on a vector of hospital fixed effects, year dummies, and interactions between the Section 508-recipient hospital indicator and year dummies. 2003 is our omitted year. $90 \%$ confidence intervals are based on wild-bootstrapped standard errors clustered around hospitals. Control hospitals include those that applied for the Section 508 waiver but were rejected. The rightmost figures plot the coefficient of the 2010 interaction term from Equation (1) as we vary the definition of the treatment group. Moving left to right in each figure, each specification involves a treated group composed of hospitals that received increasingly large gains in total IPPS payments (based on quantities in 2003 and actual and counterfactual payment rates in 2005) due to the Section 508 program. Payroll expenses, full-time personnel, and technology counts are derived from the American Hospital Association's Annual Survey data. 
staffing. By contrast, hospitals that received tens of millions of dollars in gains would be more likely to increase their staffing and staff pay.

Consistent with these predictions, as results in Panel A of Figure 3 illustrate, there is a notable increase in hospital payroll that is concentrated among the Section 508 recipient hospitals that were the most exposed to the program. While there is not a precisely estimated increase in payroll across the universe of Section 508-recipient hospitals, among the half of hospitals most exposed to the program, there is a $\$ 22.9$ million increase in payroll in $2010(p<0.1)$. As we illustrated in Panel B of Figure A.1, the total revenue gains from the Section 508 program in this cohort were approximately $\$ 33$ million, so the gains in payroll as a share of revenue gains (70 percent) approximate the AHA's estimates of the share of hospital costs that are driven by labor. Likewise, as results in Panel B of Figure 3 illustrate, there is also a suggestive increase in total, full-time staff at the hospitals most exposed to the Section 508 program, although the point estimates are not precisely estimated.

At non-profit hospitals that cannot distribute profits to shareholders, as Newhouse (1970) predicts, an increase in Medicare payments could also result in an increase in hospitals' adoption of new technology. To test this hypothesis, we measure hospital's use of technology annually following the approach of Acemoglu and Finkelstein (2008), which counts technologies per hospital. Panel C of Figure 3 presents trends in the hospital technology count generated from estimates of Equation (1). Consistent with predictions from Newhouse (1970), there is suggestive evidence that the introduction of the Section 508 program led hospitals to adopt more technology. Treated and untreated hospitals had nearly identical pre-trends before the passage of the MMA of 2003. After treatment hospitals received the payment increase generated by the Section 508 program, there was an increase in the count of technology among the most treated hospitals. These changes are generally not precisely estimated at conventional levels across the universe of treated hospitals. However, as we illustrate in the dose response estimates on the right of Panel $\mathrm{C}$ of Figure 3, these 
effects become precisely estimated $(p<0.10)$ when the treated group is restricted to the 80 percent of Section 508-recipient hospitals with the largest exposure to the Section 508 program. These results imply that in the 80 percent of hospitals with the largest exposure to the Section 508 program, hospitals added approximately three new technologies by 2010 .

\subsection{Section 508 Waivers and Hospital Behavior - Robustness}

We conducted a large number of robustness tests, some of which we describe here. First, as we illustrate in Appendix Figure A.2, our main results remain robust when we rely on an unbalanced panel of treated hospitals. Second, in lieu of using hospitals that applied for a Section 508 waiver, but had their applications rejected as our control group, we show the robustness of our results to using three alternative control groups. In Appendix Figure A.3, we show event studies derived from estimates of Equation (1) and dose response graphs for the 2010 Section 508 treatment effects when we construct a control group that is composed of hospitals that were eligible to apply for the Section 508 program but did not submit an application. In Appendix Figure A.4, we show event study graphs and dose response estimates for the 2010 treatment effects when the control group is composed of hospitals ineligible for the Section 508 program because they already received a wage index increase. In Appendix Figure A.5, we construct a control group composed of the universe of hospitals paid via the inpatient PPS that did not receive a Section 508 waiver. Our main results are qualitatively unchanged when we use these three alternative control groups. Finally, we show in Appendix Figure A.6 that our treatment effects remain similarly scaled and precisely estimated when we use propensity score matching to construct our control group from the universe of hospitals eligible for a Section 508 waiver that did not receive one. ${ }^{23}$

\footnotetext{
${ }^{23} \mathrm{We}$ use a probit model to construct propensity scores that match Section 508-recipient hospitals to their 10 nearest neighbors. We estimate our probit to predict Section 508 receipt based on 2001-2003 mean Medicare discharges, Medicaid discharges, for-profit status, teaching hospital status, the bed count, a rural indicator, and the 2001-2003 (pre-treatment) mean value of the dependent variables (inpatient Medicare spending, Medicare
} 


\section{Section 508 Waivers and Congressional District-Level Outcomes}

\subsection{Estimating the Gains to Congressional Districts}

A large body of work has found that members of Congress devote substantial time and effort to steering benefits (e.g. jobs and federal dollars) to their district (Mayhew 1974; Weingast 1979; Shepsle and Weingast 1982; Weingast, Shepsle, and Johnsen 1981; Levitt and Snyder Jr. 1997). In this section, we focus on testing whether the Section 508 program led to increases in Medicare inpatient spending and new jobs in congressional districts with one or more hospitals that received a Section 508 waiver.

To estimate the effect of the Section 508 program on congressional districts, we again rely on a difference-in-difference estimator that takes the form:

$$
\text { Outcome }_{d, t}=\beta_{t} C D \_ \text {With_Section_508_Hospital }{ }_{d} \cdot \tau_{t}+\vartheta_{d}+\tau_{t}+\varepsilon_{d, t}
$$

and analyze changes in outcomes Outcome $_{d, t}$ in each district $d$ by year $t$. We interact our treatment indicator, CD_With_Section_508_Hospital , which denotes whether a congressional district has one or more Section 508-recipient hospitals, with a vector of year fixed effects $\tau_{t}$. We also include a vector of year fixed effects $\tau_{t}$ and congressional district fixed effects $\vartheta_{d}$. We identify a district as treated if it included one or more Section 508-recipient hospitals that are in the data from 2001 to 2010. We again report wild-bootstrapped standard errors (although our results are robust to clustering around congressional districts).

We focus on three dependent variables. First, we use Medicare Cost Reports data to aggregate Medicare inpatient spending across every hospital annually in each congressional district (including hospitals that did not receive a Section 508 waiver) in order to admissions, the technology count, payroll and full-time personnel). 
get an annual measure of Medicare inpatient spending per district. ${ }^{24}$ This allows us to analyze whether there was an aggregate increase in health spending per district, rather than substitution in health spending across hospitals. Second, we use AHA data to aggregate hospital-level full-time staff counts across all hospitals per congressional district to generate an aggregate, annual measure of hospital jobs per district. ${ }^{25}$ Third, using AHA data, we aggregate hospital payroll across all hospitals in each congressional district to get an annual measure of congressional district-level, aggregate hospital payroll. There are two distinct advantages to using AHA data to generate measures of hospital staffing and payroll. First, they allow us to aggregate precisely to the congressional district-level because we we can utilize the address of each hospital (rather than, for example, aggregating county-level data). ${ }^{26}$ Second, many employment databases censor county-level hospital data because small values would be revealing of individual firms.

We compare outcomes in treated districts (e.g. those with one or more hospitals that received a Section 508 waiver) with outcomes in four sets of control districts: 1) districts with one or more hospitals that applied for a Section 508 waiver but had their application rejected; 2) districts with one or more hospitals that were eligible for the Section 508 program, but did not apply; 3) districts with one or more hospitals that were ineligible for the Section 508 program; 4) and districts without any hospitals that were awarded a Section 508 waiver, but had one or more hospitals paid via the PPS. We also use propensity score matching to construct a control group of congressional districts without a Section

\footnotetext{
${ }^{24}$ The Cost Reports categorize hospitals as "general short-term", "general long-term", “cancer", "psych", "rehab", "religious nonmedical", "children's", "alcohol \& drug", and "other" in each year. Some hospitals are categorized differently year-to-year. We restrict the data to hospitals that are marked as "general short-term" in half or more of the period 2001-2010.

${ }^{25}$ We restrict the AHA data to "general medical and surgical" facilities, which excludes surgical, psychiatric, long-term care, and other types of hospitals.

${ }^{26}$ In practice, we identify each hospital's congressional district based on its ZIP code as reported in the Medicare Cost Reports (in the case of Medicare inpatient spending) or the AHA Survey (in the case of payroll and full-time staffing). We use ZIP-to-congressional district crosswalks from the Missouri Census Data Center's Geocorr application (http://mcdc.missouri.edu/applications/geocorr.html). If a ZIP intersects with multiple districts, we use the district with the largest share of the ZIP's population.
} 
508-recipient hospital. ${ }^{27}$

As we did in the hospital-level analysis, we also describe how our treatment effects vary as a function of congressional districts' exposure to the Section 508 program. This is particularly important in our congressional-district-level analysis because there was so much heterogeneity in exposure to the program across districts.

To measure each congressional district's exposure, we take our estimates of treated hospitals' predicted revenue gains from the Section 508 program, as described in Section 4.1, and sum these across hospitals in each district. As a result, our measure of a district's treatment exposure captures the potential dollars each district could receive from the Section 508 program, ignoring any supply responses. There were 42 congressional districts with at least one Section 508 recipient hospital. Among treated districts, as we note in Appendix Table A.2, the minimum predicted one-year increase in Medicare inpatient spending was $\$ 80,000$, the 50th percentile was $\$ 3.09$ million, and the maximum was $\$ 38.19$ million. The median treated congressional district had a single Section 508 recipient hospital. There were 17 districts (40 percent) that had more than one Section 508 hospital. The predicted gains in districts with multiple Section 508 hospitals - median gains of $\$ 6.23$ million - were substantially larger than the gains in districts with only one Section 508 recipient hospital.

\subsection{The Section 508 Program and Congressional District-Level Hospital Spending}

Figure 4 presents event-study estimates of Equation (2) and illustrates that there was a large increase in aggregate Medicare inpatient spending in congressional districts with one or more hospitals that received a Section 508 waiver. The point estimates presented in Column (1) in Table 3 show that the Section 508 program led to a $\$ 8.03$ million increase in Medicare inpatient spending per treated congressional district in $2005(p<0.05)$. By 2010, treated districts were receiving $\$ 11.51$ million more $(p<0.1)$ annually than districts with one or

\footnotetext{
${ }^{27}$ We treated congressional districts with both treated and control hospitals exclusively as treated districts.
} 
more hospitals that applied to the 508 program but had their application rejected. To give a sense of the magnitude of the effect of the Section 508 program, Medicare spending in treated districts was $\$ 308$ million in 2003. So, the 2005 average treatment effect implies that the Section 508 program led to an increase in Medicare inpatient spending in congressional districts of approximately 3 percent in the first year post-implementation and approximately 4 percent by 2010. Notably, there is no meaningful difference in Medicare inpatient spending between treated and control congressional districts prior to the introduction of the Section 508 program.

The gains from the Section 508 program were concentrated in a small group of congressional districts. For example, as we illustrate in the dose response estimates presented on the right of Panel A of Figure 4, the 30 percent of congressional districts (12 districts) with the largest predicted revenue increases saw an increase in Medicare inpatient spending of $\$ 25$ million in 2010. All but three of these districts had two or more Section 508 recipient hospitals. Likewise, the ten percent of congressional districts with the largest predicted exposure to the Section 508 program had a $\$ 40$ million increase in Medicare inpatient spending in 2010.

As we illustrate in Panels A and B of Appendix Figure A.7, we also observe large, precisely estimated increases in total hospital revenue among the 20 percent of congressional districts that were the most exposed to the Section 508 program. Among that group, total revenue increased by approximately $\$ 266$ million in 2010 . In the ten percent of treated congressional districts with the highest exposure to the Section 508 program, total revenues increased by over $\$ 281$ million. For reference, across congressional districts, the mean total hospital revenue per district was $\$ 1.6$ billion in 2010. ${ }^{28}$

\footnotetext{
${ }^{28}$ We present event study estimates for the 20 percent of congressional districts with the highest exposure to the Section 508 program in Panel B of Appendix Figure A.7.
} 


\section{Figure 4: The Impact of the Section 508 Program on Congressional District-Level Inpatient Medicare Spending, Hospital Payroll, and Hospital Personnel}

\section{Panel A: Medicare Inpatient Spending (\$ Millions, 2010 Dollars)}
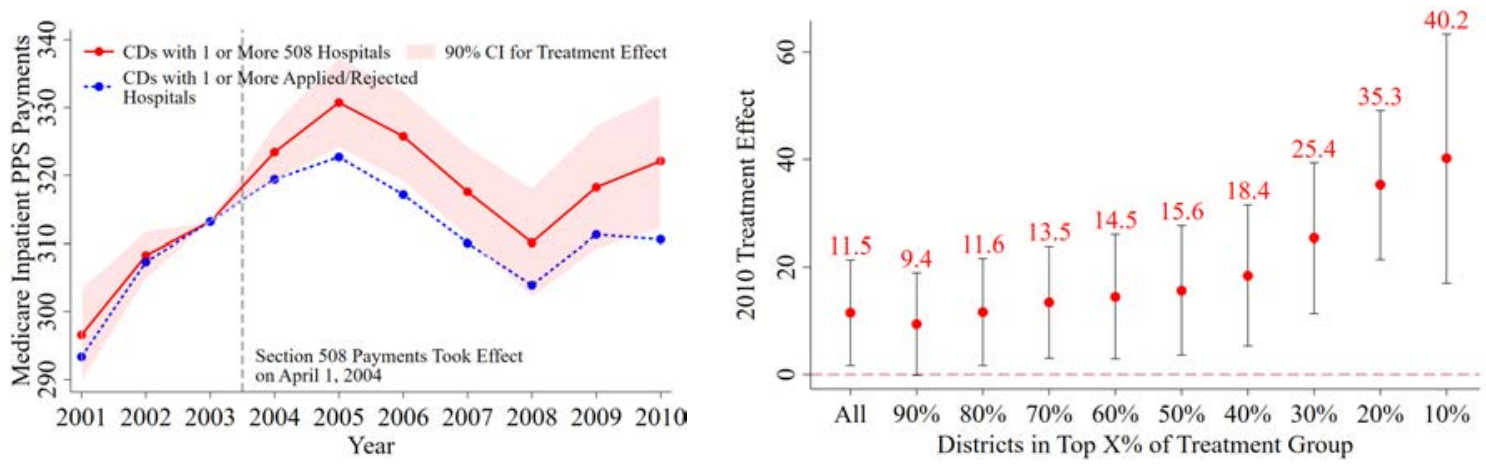

\section{Panel B: Full-Time Total Personnel}
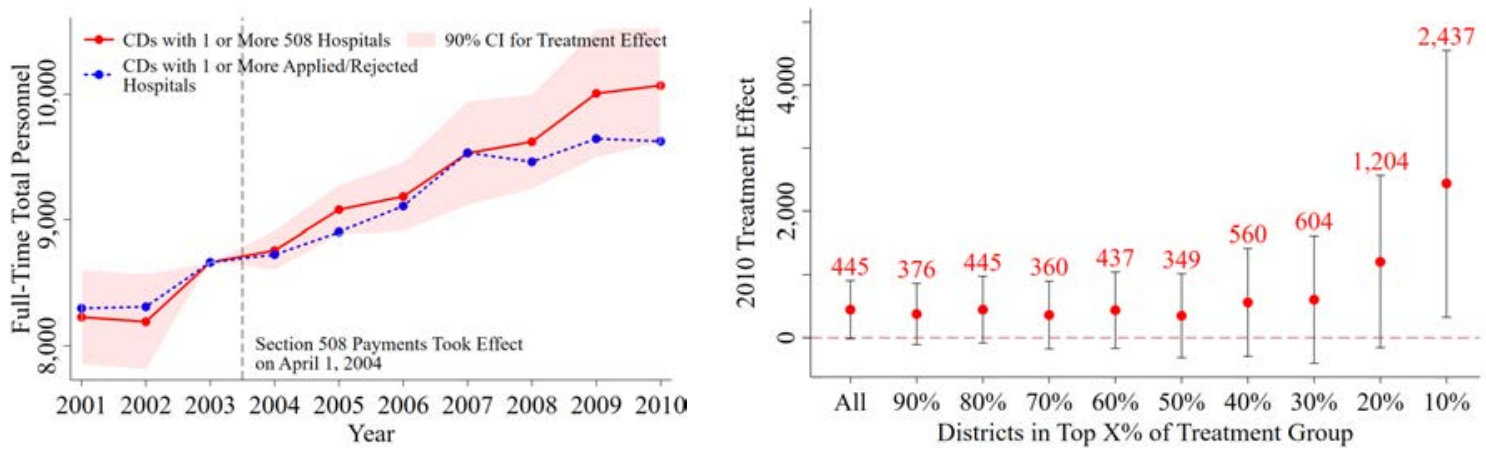

Panel C: Total Facility Payroll Expenses (\$ Millions, 2010 Dollars)

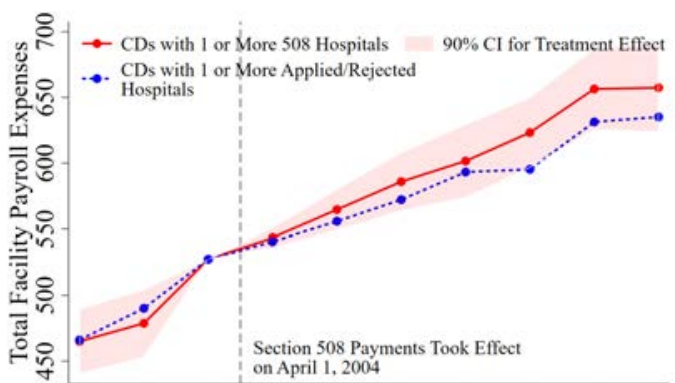

2001200220032004200520062007200820092010 Year

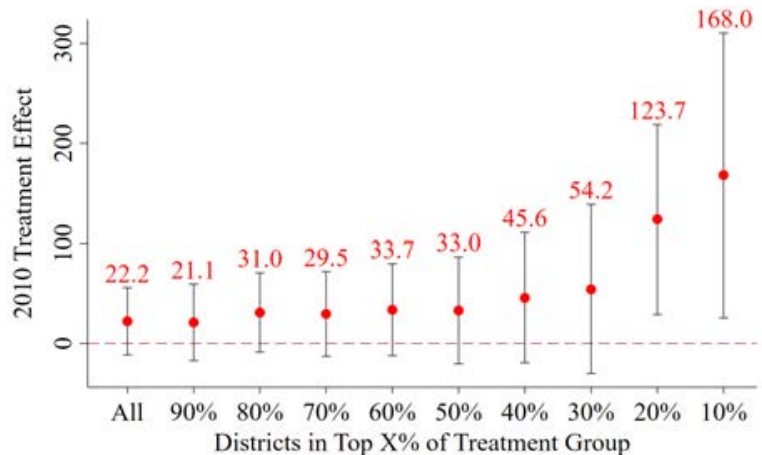

Notes: These panels present estimates of Equation (2) where we regress congressional district outcomes on a vector of congressional district fixed effects, year dummies, and interactions between the treated congressional district indicator and year dummies. 2003 is our omitted year. Control congressional districts are those with one or more hospitals that applied for a Section 508 waiver but were rejected. $90 \%$ confidence intervals are based on wild-bootstrapped standard errors clustered around congressional districts. The rightmost figures plot the coefficient of the 2010 interaction term from Equation (2) as we vary the definition of the treatment group. Moving left to right in each figure, each specification involves a treated group composed of congressional districts with increasingly large gains in total IPPS payments (based on quantities in 2003 and actual and counterfactual payment rates in 2005) due to the Section 508 program. Medicare inpatient PPS payments are from the RAND Medicare Cost Reports (HCRIS) data. Payroll expenses and full-time personnel are derived from the American Hospital Association's Annual Survey. 


\subsection{The Section 508 Program and Congressional District-Level Hospital Employ- ment}

We also observe suggestive evidence that hospital employment and payroll increased in treated congressional districts. In the event study included in Panel B of Figure 4, we present estimates of Equation (2) and focus on testing the impact of the Section 508 program on the count of employees working at hospitals in each congressional district. Our results show that the Section 508 program raised hospital employment in treated congressional districts. As we illustrate in Column (2) of Table 3, across the universe of treated districts, by 2010, hospital employment increased by $444.65(p<0.12)$ off of a mean count of total hospital jobs in treated districts of 8,400.24 in 2003.

The gains in employment appear to be driven by the large changes experienced in the most treated districts. As our dose response estimates in Panel B of Figure 4 illustrate, the 10 percent of congressional districts with the largest exposure to the Section 508 program gained more than five times as many jobs in the hospital sector in 2010 as we observed when we estimated our treatment effects across the universe of treated districts.

Likewise, as we illustrate in Panel C of Figure 4, beginning in 2005, the aggregate hospital payroll in treated and control districts began to diverge. As we illustrate in Column (3) of Table 3, which presents estimates of Equation (2), by 2010, aggregate hospital payroll was \$22.22 million higher in treated districts $(p<0.3)$ off of a mean payroll among treated districts in 2003 of $\$ 537.34$ million. We also observe that the scale of our treatment effects is increasing as districts' exposure to the Section 508 program increases. For example, among the 20 percent of treated districts with the highest exposure to the Section 508 program, payroll increased by approximately $\$ 124$ million ( $p<0.05$; Panel $\mathrm{C}$ of Figure 4$)$. This represents 47 percent of the total hospital revenue gain from the program among the same 20 percent of treated districts (Panel A of Appendix Figure A.7). 


\subsection{Section 508 Waivers and Congressional District-Level Outcomes - Robustness}

Our main results presented in Figure 4 rely on a control group of congressional districts with one or more hospitals that applied for a Section 508 waiver, but had their application rejected. Below, we show that our main results - that the most treated third of congressional districts saw substantial increases in Medicare spending and suggestive evidence of employment increases - are robust across alternative control groups. In Appendix Figure A.8, we present an event study graph and our dose response estimates for our main outcomes when we rely on a control group composed of congressional districts that have one or more hospitals that were eligible for the Section 508 program, but did not apply. In Appendix Figure A.9, we repeat this exercise, but rely on a control group composed of congressional districts with one or more hospitals that were ineligible for the 508 program. In Appendix Figure A.10, we construct a control group of congressional districts that do not include any Section 508-recipient hospitals. Again, we find that our results remain qualitatively unchanged using these alternative control groups. Finally, in Appendix Figure A.11, we construct a control group drawn from districts without a Section 508-recipient hospital using propensity score matching. ${ }^{29}$

\section{Section 508 Waivers and Political Donations}

\subsection{Background, Data, and Estimation}

The Medicare payment increases created by the Section 508 program were written to expire on March 31, 2007, three years after they were introduced. Were the Section 508 program to have expired, it would have cost hospitals millions in annual revenue. In this section, we

\footnotetext{
${ }^{29} \mathrm{We}$ construct propensity scores of each district's probability of being treated (e.g. having a Section 508-recipient hospital) using probit. Our probit estimator includes the number of hospitals per district, the share of non-profit hospitals per district, the share of teaching hospitals per district, and the 2001-2003 (pre-treatment) average of the district-level dependent variables (Medicare inpatient spending, payroll and full-time personnel).
} 


\section{Table 3: The Impact of the Section 508 Program on Congressional District-Level Inpatient Medicare Spending, Hospital Payroll, and Hospital Personnel}

\begin{tabular}{|c|c|c|c|}
\hline & $\begin{array}{l}\text { Medicare Inpatient PPS } \\
\text { Payments (\$ Millions, } \\
2010 \text { Dollars) } \\
\text { (1) }\end{array}$ & $\begin{array}{l}\text { Full-Time Total } \\
\text { Personnel } \\
\text { (2) }\end{array}$ & $\begin{array}{c}\text { Total Facility Payroll } \\
\text { Expenses (\$ Millions, } \\
2010 \text { Dollars) } \\
\text { (3) }\end{array}$ \\
\hline $2001 *$ Treated & 3.22 & -71.08 & -1.19 \\
\hline Group & $(4.21)$ & (230.88) & (14.99) \\
\hline $2002 *$ Treated & 0.95 & -119.16 & -11.40 \\
\hline Group & $(2.17)$ & $(233.31)$ & $(15.66)$ \\
\hline \multicolumn{4}{|c|}{$\begin{array}{c}2003 \text { - Pre-Treatment Year - Omitted Category } \\
\text { (Section } 508 \text { Payments Took Effect on April 1, 2004) }\end{array}$} \\
\hline $2004 *$ Treated & 4.00 & 33.03 & 2.85 \\
\hline Group & $(2.59)$ & (98.20) & $(4.65)$ \\
\hline $2005 *$ Treated & $8.03 * *$ & 175.82 & 8.84 \\
\hline Group & $(4.04)$ & (121.79) & $(9.52)$ \\
\hline $2006 *$ Treated & $8.59 * *$ & 76.25 & 13.71 \\
\hline Group & $(4.05)$ & (170.79) & (13.46) \\
\hline $2007 *$ Treated & $7.48^{*}$ & -3.27 & 8.36 \\
\hline Group & $(4.11)$ & $(253.08)$ & $(16.93)$ \\
\hline \multicolumn{4}{|c|}{ Section 508 Program Reauthorized on December 19, 2007} \\
\hline $2008 *$ Treated & 6.22 & 160.18 & $27.95^{*}$ \\
\hline Group & $(4.87)$ & (231.90) & (16.26) \\
\hline $2009 *$ Treated & 6.94 & 361.37 & 25.07 \\
\hline Group & (5.53) & (313.52) & (18.86) \\
\hline $2010 *$ Treated & $11.51 *$ & 444.65 & 22.22 \\
\hline Group & $(5.99)$ & $(280.52)$ & $(20.45)$ \\
\hline CD FEs & $\mathrm{X}$ & $\mathrm{X}$ & $\mathrm{X}$ \\
\hline Year FEs & $\mathrm{X}$ & $\mathrm{X}$ & $\mathrm{X}$ \\
\hline $\mathrm{N}$ & 1,960 & 1,960 & 1,960 \\
\hline \multicolumn{4}{|c|}{ Mean of the Dependent Variable in 2003} \\
\hline Treated CDs & 308.17 & $8,400.24$ & 537.34 \\
\hline Control CDs & 314.55 & $8,737.77$ & 524.76 \\
\hline
\end{tabular}

Notes: $* \mathrm{p}<0.10, * * \mathrm{p}<0.05, * * * \mathrm{p}<0.01$. This table presents estimates of Equation (2) where we regress congressional district outcomes on a vector of congressional district fixed effects, year dummies, and interactions between the treated congressional district indicator and year dummies. 2003 is our omitted year. Wild-bootstrapped standard errors clustered around congressional districts $(\mathrm{CDs})$ are in parentheses. Observations $(\mathrm{N})$ are $\mathrm{CD}$-years. Control congressional districts are those with at least one hospital that applied for a Section 508 waiver but was rejected. Column (1) is derived from the RAND Medicare Cost Reports (HCRIS) data. Columns (2) and (3) are derived from the American Hospital Association's Annual Survey data. 
explore lobbying efforts to extend the Section 508 program, describe the votes in the House for the re-authorization of the program, and test whether the members of the House who had a Section 508-recipient hospital in their district received larger campaign donations after the Section 508 program was reauthorized.

This analysis is directly related to the wider political science literature that has examined whether members of Congress receive benefits when they use distributive policies to steer funds to their district. As Levitt and Snyder Jr. (1997) note, it is widely accepted by academics, the media, and politicians that members of Congress are rewarded for bringing additional federal funding to their districts. However, few studies have established a causal link between distributive policies championed by members of Congress and changes in fundraising. From an identification perspective, establishing a causal link between donations and distributive policies is challenging because donations could both lead members to push for specific policies that benefit donors and come as a reward for past actions. ${ }^{30}$ However, the Section 508 program offers a unique opportunity to test the link between campaign contributions and targeted distributive policies because we can look at donations before and after the re-authorization of the program, which, as we illustrate, was salient to politicians and many of their constituents.

Lee (2003) and Rocca and Gordon (2013) have argued the extent to which a particular distributive policy will yield electoral gains and increases in campaign contributions is a

\footnotetext{
${ }^{30}$ Two studies have used instrumental variable (IV) analysis to get around endogeneity issues and have found a causal link between federal funding and donations, and federal funding and votes. Rocca and Gordon (2013) analyze whether representatives who allocate more defense-related earmarks receive more donations from political action committees (PACs) representing defense manufacturers. The authors instrument for defense industry earmarks using the total number of earmarks a representative makes, and they find that every $\$ 10,000$ in defense earmarks raises PAC campaign contributions by $\$ 3.00$. It is debatable whether instrumenting for defense earmarks using total earmarks (including defense earmarks) satisfies the exclusion restriction. Levitt and Snyder Jr. (1997) analyze whether increasing federal funding for a district raises vote margins for the incumbent. The authors instrument for federal funding in the district using federal spending outside the district but inside the state and find that a $\$ 100$ increase in per-capita federal spending (approximately $\$ 50$ million per district) leads to a two percent gain in the popular vote for incumbents. We add to this literature by analyzing the impact of the Section 508 program on campaign contributions.
} 
function of the extent to which legislators can claim credit for the benefits (e.g. whether a legislator's efforts are salient to voters). While formula-based distributive policies are often opaque to constituents (such as the initial passage of the Section 508 program), extending the Section 508 program was remarkably important and easily observable to hospitals that previously received a Section 508 payment increase. For example, a 2007 Modern Healthcare article noted that "selected hospitals and systems stand to lose millions of dollars under a provision of the Medicare Modernization Act of 2003 that is set to expire in September [2007]" (Lubell 2007). The author continued, "Executives for hospitals and systems say that losing that extra Medicare reimbursement under Section 508 would be devastating. Layoffs and cutbacks would likely occur at St. Luke's Cornwall Hospital, said Allan Atzrott, president and CEO of the 282-bed hospital, which has campuses in Cornwall and Newburgh, N.Y.". There is also evidence that politicians were aware of the Section 508 program and that they viewed supporting it as politically advantageous. ${ }^{31}$

In general, the academic literature is divided about the extent to which donations serve as ex ante inducements to sway votes or ex post rewards for bringing home local benefits. Some literature suggests that interested parties may donate in advance of legislation in an effort to persuade legislators to shift their votes (Grossman and Helpman 1994, Grossman and Helpman 1996, Chamon and Kaplan 2013). By contrast, interest groups, such as political action committees, both sway legislators and seek to mobilize the public to reward legislators for their actions (Stratmann 2005, Fox and Rothenberg 2011). Rocca and Gordon (2013) have found, for example, that donations tend to be rewards for previous votes. Going forward, we test whether members of the House representing hospitals that received a

\footnotetext{
${ }^{31}$ For example, as the 508 program was coming up for a re-authorization vote in 2007, Senator Charles Schumer's office issued a press release that stated, "In light of todays [sic] announcement that Senate leaders will pursue an extension of Section 508 of the Medicare Modernization Act, US Senator Charles E. Schumer, a member of the Senate Finance Committee, pledged today to work to include all New York Section 508 hospitals..." (Office of Senator Charles Schumer 2006). In the remainder of the statement, the senator's office reiterated his commitment to increasing funding for New York hospitals.
} 
Section 508 waiver received increases in donations in the run up to and in the wake of the re-authorization of the program.

\subsection{Section 508-Recipient Hospitals and Political Lobbying}

According to data from the Center for Responsive Politics, over the last 20 years, the US health care industry spent more annually in absolute dollars on lobbying than was spent by virtually any other industry (for more details on this data set, see Appendix A.1). In 2006, for example, cumulatively, hospitals and nursing homes, pharmaceutical and device manufacturers, and health professionals spent over $\$ 338$ million on lobbying activities. By contrast, that same year, the oil and gas industry spent approximately $\$ 75$ million, the real estate industry spent approximately $\$ 82$ million, and the auto industry spent approximately \$59 million (The Center for Responsive Politics 2019a). In particular, the American Hospital Association spent approximately \$18 million in 2006 lobbying on behalf of hospitals' interests (The Center for Responsive Politics 2019b).

In 2005, two years before the Section 508 program was slated to expire, hospitals that received Section 508 waivers came together to form the Section 508 Hospital Coalition PAC. The stated goal of the PAC was to lobby on behalf of Section 508-recipient hospitals. We obtained the amount the Section 508 Hospital Coalition spent lobbying members of Congress each year from 2005 through 2012 (see Appendix Figure A.12). In 2005, 2006, and 2007, the period before the Section 508 program was reauthorized, the coalition cumulatively spent approximately $\$ 829$ thousand lobbying members of Congress (The Center for Responsive Politics 2019c). The American Hospital Association spent approximately \$54 million on lobbying throughout that same period (although the AHA funding included lobbying for the extension of the Section 508 program and lobbying on behalf of the interests of nonSection 508-recipient hospitals) (The Center for Responsive Politics 2019b). Rocca and 
Gordon (2013) note that although individual voters may not observe and reward members of Congress for contributing to distributive policies that benefit their district, interest groups, such as the Section 508 Hospital Coalition, can sharpen the incentives for members of Congress to act.

\subsection{Estimating the Impact of the Section 508 Re-authorization On Campaign Con- tributions}

After a short extension, on September 31, 2007, the Section 508 program expired and payment increases to hospitals were eliminated. In the intervening months, there was an intense lobbying effort to extend the program. On December 29, 2007, the President signed S.2499 - the Medicare, Medicaid, and SCHIP Extension Act of 2007. This law included a long-term extension of the Section 508 program and also restored the Section 508 payment increases retrospectively for October, November, and December.

The law passed out of the House of Representatives via a 411 to 3 margin (roll call vote 1184). Forty of the 42 members of the House with a Section 508-recipient hospital in their district voted for the long-term extension of the Section 508 program. Two members of the House with Section 508-recipient hospitals in their districts abstained from voting for the re-authorization; those members had among the smallest gains from the Section 508 program. $^{32}$

To analyze whether members of the House with a hospital in their district received an increase in campaign contributions in the run up to and in the wake of the vote to reauthorize the Section 508 program, we estimate:

$$
\text { Donations }_{c, t}=\beta_{t} \text { Candidate_With_Section_508 }{ }_{c} \cdot \tau_{t}+\vartheta_{c}+\tau_{t}+\varepsilon_{c, t}
$$

\footnotetext{
${ }^{32}$ The members who abstained from voting for the Section 508 extension represented districts that gained $\$ 96.8$ thousand and $\$ 797.9$ thousand respectively from the program. The mean gain across all recipients was \$5.54 million.
} 
where we observe campaign contributions Donations D $_{c, t}$ from donors to a candidate for the House of Representatives $c$ in each quarter $t$, all measured in 2010 dollars. We include a vector of quarter fixed effects $\tau_{t}$ and a vector of candidate fixed effects $\vartheta_{c}$. We interact a vector of year dummies with our treatment indicator Candidate_With_Section_508 $8_{c}$ which takes a value of "1" when a candidate has a Section 508-recipient hospital in her district. We focus on the votes taken during roll call vote 1184 . Our omitted category is the first quarter of 2007 (the quarter before the Section 508 program was slated to expire).

We obtain data on campaign contributions from the DIME database, which synthesizes data from the Federal Elections Commission (see Appendix A.1 for more information on the data source). We analyze the campaign contributions to members of the House from all donors, individual donors, and donors working in the hospital industry. We are able to identify donors' industry of employment by looking at the contributor categorization code in the DIME data and analyzing the self-reported "employer" or "organization" field in the DIME data and tagging a donor as working in the hospital industry if words such as "hospital" are included in their employer/organization field.

We limit our analysis to candidates for office from 2001 to 2010 that were serving as members of the House in 2003 when the Section 508 program was initially authorized and were serving again in 2007 when the Section 508 program was reauthorized (later we show our results are robust to not including the 2003 restriction). We observe candidates even if they did not win and remain as members of the House between 2003 and 2007. ${ }^{33} \mathrm{We}$ calculate wild-bootstrapped standard errors (although our results are robust to clustering

\footnotetext{
${ }^{33}$ There is no statistically significant difference between the rates members of the House with and without a Section 508-recipient hospital were reelected to office. Likewise, among those voted out of office, there is no statistically significant difference in the rates that they run again as a function of whether or not they have a Section 508-recipient hospital in their district. Finally, there is no statistically significant difference in whether a member of the House decides to no longer seek reelection as a function of whether or not a member had a Section 508-recipient hospital in her district. Our results are robust to limiting our analysis to candidates who were in the House or ran for office each electoral cycle or including candidates who decided not to seek reelection. When a candidate is not in the data for a given year, we dummy out their missing observation.
} 
around candidates).

As was the case in previous sections, there is no 'perfect' control group, so we show our main results are robust across different control groups. Our main control group is composed of candidates who were in office in 2003 (when Section 508 was initially authorized), had a hospital in their district that unsuccessfully applied for a Section 508 waiver, and were in office in 2007 when the Medicare, Medicaid, and SCHIP Extension Act of 2007 was passed. We also compare our treated group to several alternative control groups including: 1) candidates for the House who were sitting members in 2003 and 2007 with hospitals in their district that were paid using the PPS program, but no Section 508 hospitals; 2) candidates for the House who were sitting members in 2003 and 2007 with one or more hospitals that were eligible for the Section 508 program but did not apply; and 3) candidates for the House who were sitting members in 2003 and 2007 with one or more hospitals in their district that were ineligible for the Section 508 program. We also show our results are robust to limiting our analysis to candidates who were in office in 2007. Finally, we construct a control group of candidates using propensity score matching. As we illustrate, our treated and control groups have virtually identical trends in campaign contributions from 2001 to 2007.

As we did in previous analysis, we also describe how our treatment effects vary as a function of congressional districts' exposure to the Section 508 program. In this setting, our dose response estimates allow us to test whether members of Congress representing more heavily treated districts received larger increases in campaign contributions. To measure each congressional district's exposure, again we take our estimates of treated hospitals' predicted revenue gains from the Section 508 program, as described in Section 4.1, and sum these across hospitals in each district. As a result, our measure of a district's treatment exposure captures the potential dollars each district could receive from the Section 508 program, ignoring any supply responses. 


\subsection{Section 508 Re-Authorization And Campaign Contributions}

Table 4: Yearly Average Total Campaign Contributions Per Member of the House of Representatives (\$ Thousands, 2010 Dollars)

\begin{tabular}{|c|c|c|c|c|c|c|}
\hline \multirow{3}{*}{ From: } & \multirow[b]{2}{*}{ All Donors } & \multirow[b]{2}{*}{$\begin{array}{l}\text { Individual } \\
\text { Donors }\end{array}$} & \multicolumn{4}{|c|}{ Individual Donors in Same State } \\
\hline & & & $\begin{array}{c}\text { All } \\
\text { Industries }\end{array}$ & Hospitals & $\begin{array}{c}\text { Crop } \\
\text { Production } \\
\text { \& Basic } \\
\text { Processing }\end{array}$ & Oil \& Gas \\
\hline & (1) & (2) & (3) & (4) & (5) & (6) \\
\hline 2001 & 427.31 & 211.24 & 161.33 & 1.66 & 1.32 & 1.24 \\
\hline 2002 & 733.19 & 355.38 & 264.07 & 3.06 & 2.69 & 1.75 \\
\hline 2003 & 495.10 & 264.25 & 194.06 & 2.26 & 1.54 & 1.72 \\
\hline 2004 & 943.67 & 419.15 & 295.98 & 3.04 & 2.90 & 2.02 \\
\hline 2005 & 576.16 & 277.64 & 204.07 & 2.53 & 1.65 & 1.32 \\
\hline 2006 & $1,018.11$ & 434.71 & 316.16 & 3.18 & 2.65 & 1.93 \\
\hline 2007 & 706.57 & 337.71 & 217.92 & 2.40 & 1.75 & 1.20 \\
\hline 2008 & $1,063.26$ & 425.18 & 309.36 & 3.27 & 2.39 & 1.91 \\
\hline 2009 & 589.79 & 280.76 & 211.37 & 2.50 & 2.18 & 1.79 \\
\hline 2010 & $1,141.02$ & 500.75 & 355.74 & 4.21 & 3.65 & 2.58 \\
\hline
\end{tabular}

Notes: This table presents the total campaign contributions received by the average member of the House of Representatives each year from 2001 to 2010. Column (1) measures campaign contributions from all donors, column (2) from individual donors, column (3) from individual donors in the same state as the member and column (4) to (6) from individual donors in same state broken down by industry.

From 2001 to 2010, as we illustrate in Table 4, an average member of the House of Representatives raised approximately $\$ 1.54$ million per two-year election cycle. Campaigns tend to bring in substantially larger campaign contributions as in the immediate run-up to an election (e.g. in years with an election). In general, the majority of a candidate's campaign contributions come from committees, groups, or political action committees and not from individual donors. Indeed, across our sample, only 42 percent of campaign contributions come from individual donors. Approximately 71 percent of contributions from individuals come from individual donors living in the same state as the candidate to whom they are donating. Individual donors that report working for a hospital accounted for approximately 
1.05 percent of the contributions from individuals from 2001 to 2010 .

We observe that total contributions to members of the House representing Section 508recipient hospitals increased after the program was extended. The event study in Figure 5 shows estimates of Equation (3) where the dependent variable is the total campaign contributions to members of the House from all donors. The solid red line shows contributions to candidates and members of the House with one or more Section 508 hospitals in their districts; the hashed blue line shows contributions to members of the House and candidates with a hospital that applied, but had their application rejected. As results in Figure 5 illustrate, contributions to members of the House with a Section 508-recipient hospital in their districts looked nearly identical to contributions to members without a Section 508-recipient hospital throughout the period before the Section 508 program was reauthorized on December 19, 2007. However, during the year after the program was extended, campaign contributions increased markedly for members with a Section 508 hospital in their districts. The point estimates imply that in the third quarter of 2008 (the quarter leading up to the congressional election), across all members of the House with a Section 508 recipient hospital in their district, total campaign contributions increased by $\$ 190.56$ thousand off a mean of $\$ 227$ thousand in that same quarter that year $(p<0.05)$. We present full results in Appendix Table A.4.

One concern might be that more powerful members of the House were more likely to have hospitals in their district granted Section 508 waivers and more powerful members receive larger campaign contributions. However, it is notable that from 2001 to 2010, the lone meaningful difference in contributions between our treated group and control group occurs after the Section 508 program was reauthorized. In general, if one believed our results simply captured powerful politicians having the ability to raise more contributions, one would expect more powerful members of the House to receive larger campaign contributions throughout our sample period from 2001 to 2010 and not exclusively after the Section 508 
program was reauthorized.

\section{Figure 5: The Impact of the Re-Authorization of the Section 508 Program on Campaign Contributions from All Donors Nationwide}
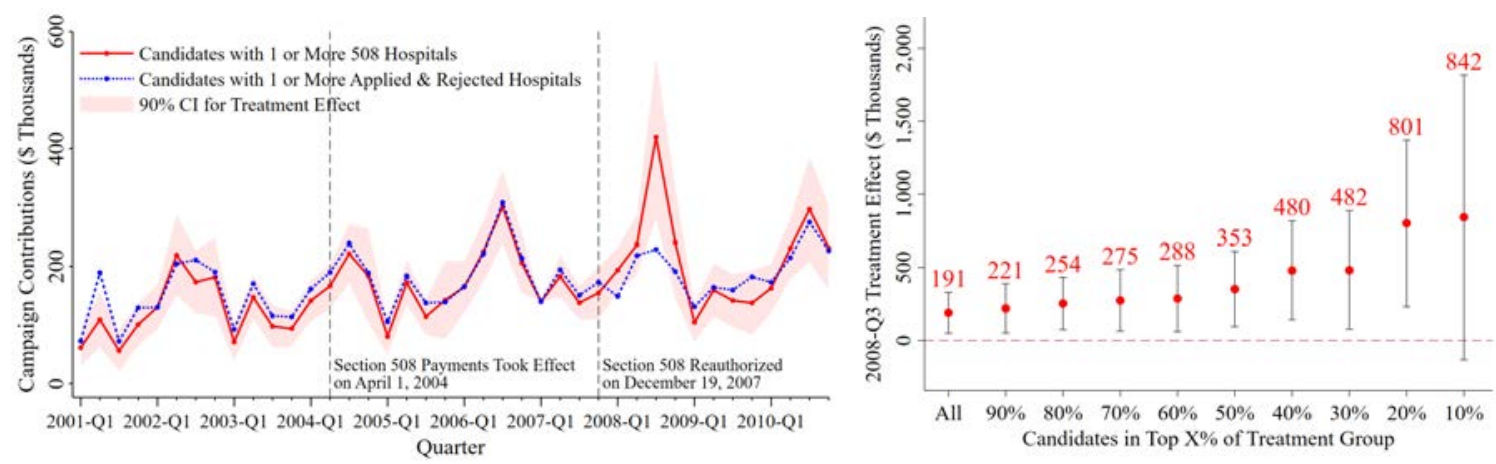

Notes: These figures present estimates of Equation (3) where we regress campaign contributions (in constant 2010 dollars) from all donors nationwide on a vector of candidate fixed effects, quarter dummies, and interactions between the treated candidate indicator and quarter dummies. Control candidates are those with one or more hospitals in their district that applied for a Section 508 waiver but were rejected. 2007-Q1 is our omitted time period. $90 \%$ confidence intervals are based on wild-bootstrapped standard errors clustered around candidates. The rightmost figure plots the coefficient of the 2008-Q3 interaction term from Equation (3) as we vary the definition of the treatment group. Moving left to right, each specification involves a treated group composed of candidates from congressional districts with increasingly large gains in total IPPS payments (based on quantities in 2003 and actual and counterfactual payment rates in 2005) due to the Section 508 program.

Recall that approximately a third of treated congressional districts saw outsized gains from the Section 508 program. The dose response estimates on the right side of Figure 5 show suggestive evidence that members representing these most heavily treated districts saw the largest increases in campaign contributions in the third quarter of 2008. Among the half of congressional districts most exposed to the program, campaign contributions increased by $\$ 353$ thousand in the third quarter of $2008(p<0.05)$. Likewise, among the 20 percent of districts with the most exposure to the program, donations increased by $\$ 801$ thousand that same quarter $(p<0.05)$. However, the differences in contributions across groups are not statistically significant. We show the dose response estimates for each quarter in 2007 and 2008 in Appendix Figure A.13.

Our results are robust to restricting our analysis to contributions from different subsets of donors. In Panel A of Appendix Figure A.14, we show results when we restrict our 
analysis to contributions from donors from the same state as the member to whom they donated. In Panel B, we limit our analysis to contributions from individual donors. In Panel $\mathrm{C}$, we focus on contributions from individual donors from the same state as the candidate to whom they are donating. In Panel D, we focus on contributions excluding those from individual donors (e.g. we focus on campaign contributions from organizations and political action committees).

\subsection{Section 508 Re-Authorization And Campaign Contributions by Industry Group}

To illustrate that the donation increases we observe are a function of the Section 508 program, we analyze changes in campaign contributions from individuals plausibly impacted and unaffected by changes in hospitals' Medicare reimbursements. In Figure 6, we estimate Equation (3) and focus on campaign contributions from individual donors living in the same state as the member of the House of Representatives to whom they contributed, broken down by the industry of the donors. We focus on individuals likely to be directly impacted by the Section 508 program - individuals working in the hospital sector - and individuals working in two industries that should not be impacted by changes in hospital payments - the crop production and basic processing industry and the oil and gas industry.

In Panel A, we focus on contributions from individuals working in the hospital industry. As the event study graph in Panel A illustrates, we observe suggestive evidence that members of the House with a Section 508 in their district saw an increase in campaign contributions from individuals working in the hospital industry in the fourth quarter of 2007 (the quarter when the vote occurred to reauthorize the Section 508 program $)(p<0.12)$ and in the third quarter of 2008 (when there were elections after the program was reauthorized) $(p<0.13)$. On the right of Panel A, we present dose response estimates for the point estimates in the 
Figure 6: The Impact of the Re-Authorization of the Section 508 Program on Campaign Contributions from Individual Donors in Same State Broken Down By Donors' Sector of Employment

\section{Panel A: Individual Donors in the Same State from the Hospital Sector}
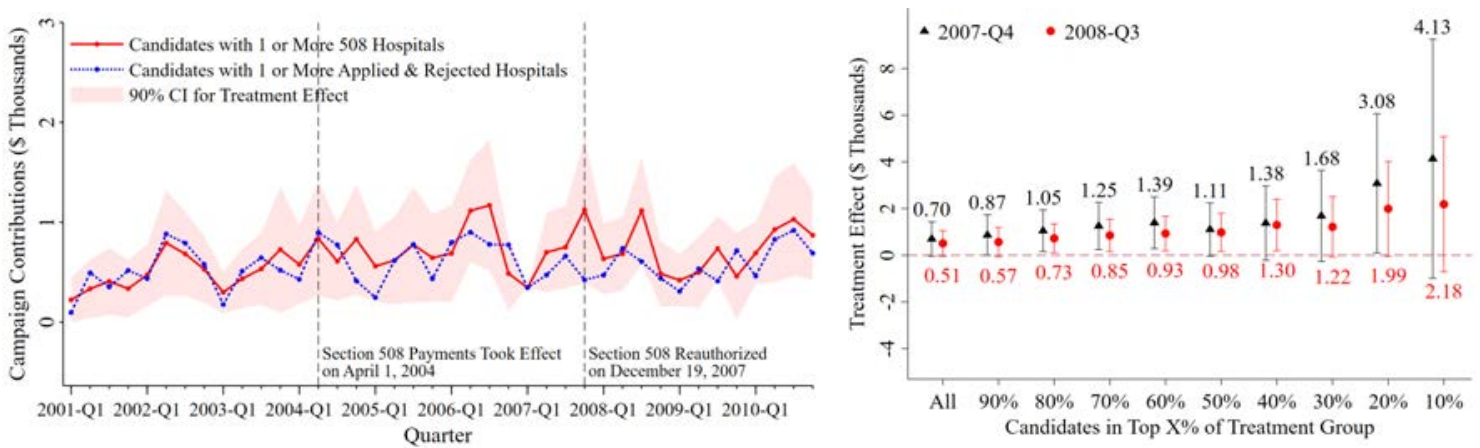

Panel B: Individual Donors in the Same State from the Crop Production \& Basic Processing Sector
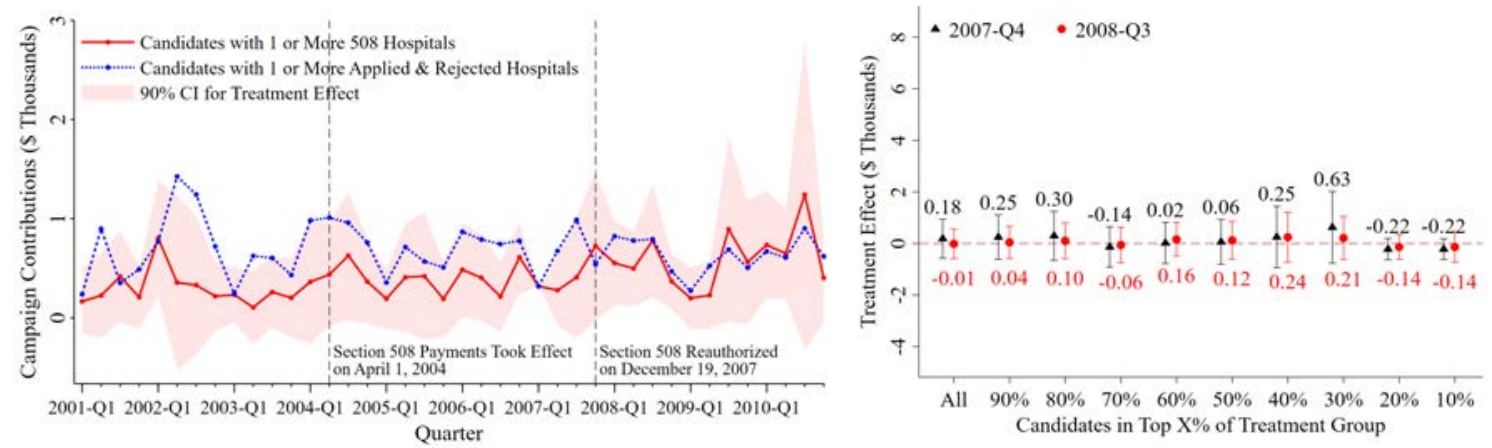

Panel C: Individual Donors in the Same State from the Oil \& Gas Sector
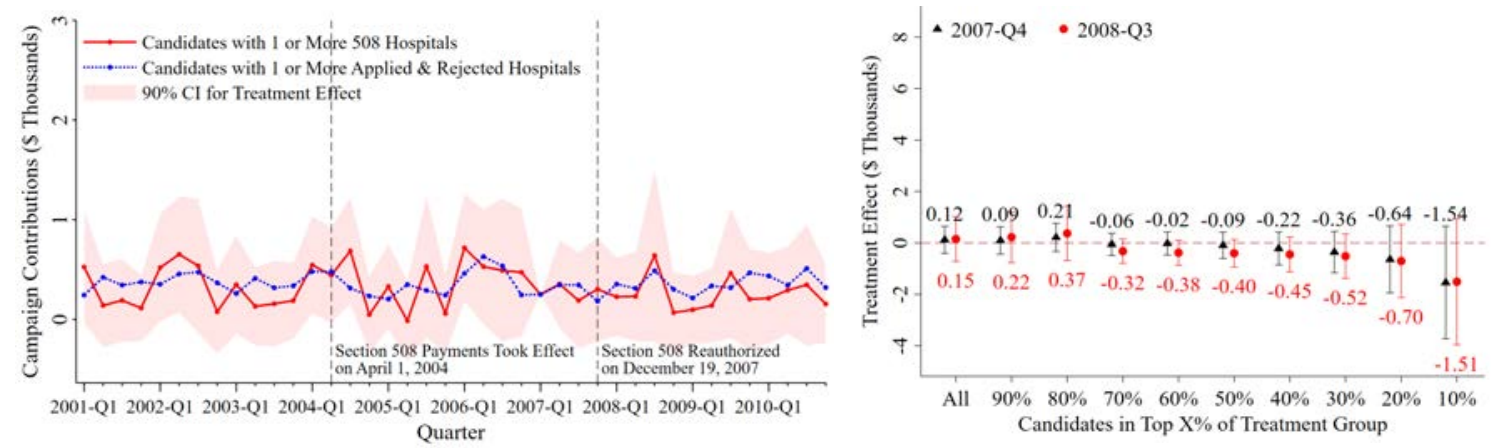

Notes: These panels present estimates of Equation (3) where we regress campaign contributions (in constant 2010 dollars) to candidates from individuals in the same state on a vector of candidate fixed effects, quarter dummies, and interactions between the treated candidate indicator and quarter dummies. Control candidates are those that have one or more hospitals in their district that applied for a Section 508 waiver but were rejected. 2007-Q1 is our omitted time period. 90\% confidence intervals are based on wild-bootstrapped standard errors clustered around candidates. The rightmost figures plot the coefficients of the 2007-Q4 and 2008-Q3 interaction terms from Equation (3) as we vary the definition of the treatment group. Moving left to right in each figure, each specification involves a treated group composed of candidates from congressional districts with increasingly large gains in total IPPS payments (based on quantities in 2003 and actual and counterfactual payment rates in 2005) due to the Section 508 program. The 2007-Q4 and 2008-Q3 coefficients are reported above and below the error bars, respectively. 
fourth quarter of 2007 (included in black) and the third quarter of 2008 (included in red). During both periods, the treatment effects were larger and were statistically significant in districts more exposed to the Section 508 program.

We observe markedly different effects when we analyze campaign contributions to members of the House from individuals working in industries that were largely unaffected by the Section 508 program. In Panels B and C, we focus on contributions from individuals in the same state as the member to whom they donated who were working in the crop production industry (Panel B) and the oil and gas industry (Panel C). ${ }^{34}$ We do not observe that members of the House with Section 508-recipient hospitals in their districts received increases in donations from individuals in these unaffected industries. Likewise, we do not observe any meaningful difference in our treatment effects among these two unrelated groups that is correlated with the exposure of each congressional district to the Section 508 program.

\subsection{Robustness of Our Campaign Contribution Analysis to Different Sample Restric- tions and the Use of Alternative Control Groups}

In our main analysis, we limited our sample to candidates for the House who were in office in 2003 (when the Section 508 program was introduced) and in 2007 (when the program was reauthorized). In Panel A of Appendix Figure A.15, we show estimates of Equation (3) where we relax that assumption and only require that an individual was a sitting member of the House when the Section 508 program was reauthorized in December 2007. As we illustrate, this does not qualitatively change our results. We also illustrate our results are robust across several alternative control groups. In Panel B of Appendix Figure A.15, we

\footnotetext{
${ }^{34} \mathrm{We}$ chose these two industries because individuals in each sector gave at similar levels as individuals working in the hospital industry. Likewise, these were two industries that do not have meaningful engagement with the hospital sector and would not benefit from increased hospital output, increased health sector salaries, or increased employment in the hospital sector.
} 
show an event study graph for estimates of Equation (3) and our dose response estimates for 2008 Q3 when we construct a control group composed of candidates for the House who were in office in 2003 and 2007, had hospitals in their district that were paid using the PPS program, but had no Section 508-recipient hospitals. In Panel C of Appendix Figure A.15, we construct a control group composed of candidates for the House that were in office in 2003 and 2007 and had one or more hospitals in their district that were eligible for the Section 508 program but did not apply. In Panel D of Appendix Figure A.15, we construct a control group composed of candidates for the House who were in office in 2003 and 2007 and had one or more hospitals in their district that were ineligible for the Section 508 program. Finally, we construct a control group of candidates matched using propensity scores and present results in Panel E of Appendix Figure A.15. ${ }^{35}$ Across these alternative control groups, we observe that our main result - that members of the House with a Section 508-recipient hospital in their district received an increase in campaign contributions after the program was reauthorized - remains qualitatively unchanged.

\section{Conclusion}

In the long term, improving the productivity of spending on the Medicare program represents one of the most significant policy priorities in the US. Until now, most academic research on health care spending has focused on the influence of demand and supply side factors on the variation and growth in domestic health spending. In this paper, we present, to our knowledge, some of the first work that assesses empirically how political dynamics in the US influence health care spending. We show that policies that raised hospitals' Medicare reimbursements were used to win members' votes on controversial legislation and that

\footnotetext{
${ }^{35} \mathrm{We}$ construct our control group using propensity score matching where we use a probit model to estimate a candidate's probability of having a hospital in her district that received a Section 508 waiver. In our probit, we control for the party of the candidate, the winning vote share in the 2001/2002 House election, the number of hospitals per district, the share of non-profit hospitals per district and the share of teaching hospitals per district.
} 
politicians received larger campaign contributions when they voted on the extension of these higher payments. In short, we show that legislators were rewarded for votes that raised health spending and we illustrate the political dynamics that make reducing health spending difficult.

Legislators struggled to pass the Medicare program in 1965 and, in the ensuing decades, there have been numerous political fights over altering and expanding the program (Marmor 2000). The pressure members of Congress face to be re-elected makes it challenging for Congress to pass large pieces of sweeping legislation (Mayhew 1974). Evans (2004) argues that logrolling is imperative to pass sweeping legislation in Congress. Nowhere was the role of logrolling more visible than in efforts to pass the MMA of 2003 (Lee 2003). We study how one distributive policy added to the MMA of 2003 - the Section 508 program affected hospital behavior and health spending and influenced campaign contributions.

We show that hospitals represented by a member of Congress who voted 'Yea' to the MMA were more likely to receive a Section 508 waiver. Section 508 waivers increased hospitals' Medicare reimbursement rates substantially. In turn, we observe that hospitals that received a waiver increased their activity. This, together with their payment increase, led hospitals that received a Section 508 waiver to dramatically increase their Medicare inpatient spending in the six years after the program was introduced. Hospitals that received these payment increases invested in new technology and increased their payroll. We also show that congressional districts with Section 508-recipient hospitals had large increases in health spending and an increase in hospital employment.

The Section 508 program was written to expire three years after it was introduced. However, we show that hospitals spent millions lobbying to have the Section 508 program extended. The bill to extend the Section 508 payments was passed by a substantial margin in the House of Representatives and members with a Section 508-recipient hospital in their districts were more likely to vote for the extension of the program. In the run-up to the 
vote to reauthorize the Section 508 program, members of Congress representing a district with a Section 508-recipient hospital received an increase in campaign contributions from individuals working in the hospital sector in their state. After the program was extended, members of Congress with a Section 508-recipient hospital in their district received large increases in campaign contributions from all donors, including those outside the health sector. The gains from the Section 508 program and the subsequent increases in campaign contributions were concentrated in the congressional districts that were the most exposed to the Section 508 program.

The extension of the Section 508 program highlights one explanation for how inefficient and/or cost increasing programs continue to be readily funded by Medicare. We observe that the total dollars spent lobbying for the extension of the Section 508 program and the added campaign contributions to members after the program was extended was in the tens of millions of dollars. By contrast, we estimate that the extension of the Section 508 program raised inpatient Medicare spending by more than $\$ 2.1$ billion. This is consistent with work by Ansolabehere, Figueiredo, and Snyder Jr. (2003) questioning why there is not more money in politics.

The critical finding from this work is that there is a close link between electoral politics and the Medicare program. While we focus on a narrow program that was inserted into the MMA to illustrate the relationship between politics and health spending, the type of provision we analyzed in this paper is present in virtually every piece of major health care legislation. For example, the Government Accountability Office identified 16 statutory provisions passed between 1997 and 2012 that modified Medicare payment policies and increased payments to specific subsets of hospitals (Government Accountability Office 2013). Moreover, while we focus this analysis on the impact of politics on spending in the Medicare program, lawmakers vote on provisions that impact private insurance markets, the pricing of pharmaceuticals, and the regulation of medical devices. As a result, there is scope 
for politics to have a large impact on US health spending in aggregate. Going forward, we hope this paper motivates future work in this area, including testing how lobbying dollars influence health care spending, examining which stakeholders benefit from health care spending growth, and considering how political dynamics impact the variation and growth in US health spending. 


\section{References}

Aaron, Henry J. and Robert Reischauer (2015). “The Transformation of Medicare, 2015 to 2030”. In: Forum for Health Economics and Policy. Vol. 18. 2. De Gruyter, pp. 119-136.

Abaluck, Jason and Jonathan Gruber (2011). "Choice Inconsistencies Among the Elderly: Evidence from Plan Choice in the Medicare Part D Program". In: American Economic Review 101.4, pp. 1180-1210.

— (2016). "Evolving Choice Inconsistencies in Choice of Prescription Drug Insurance”. In: American Economic Review 106.8, pp. 2145-84.

Abelson, Reed (2003). Narrow Interest in a Broad Measure. New York Times.

Acemoglu, Daron and Amy Finkelstein (2008). "Input and Technology Choices in Regulated Industries: Evidence from the Health Care Sector". In: Journal of Political Economy 116.6, pp. 837-880.

American Hospital Association (2011). Wage Index Chart Pack. URL: https : //www . aha . org/system/files/content/11/11nov-wgindexchartpk.pdf.

- (2016). Trendwatch Chartbook 2016: Chart 6.10: Percent of Hospital Costs by Type of Expense, 2015. URL: https://www . aha.org/system/files/research/reports/ tw/chartbook/2016/chart6-10.pdf.

Ansolabehere, Stephen, John M. de Figueiredo, and James M. Snyder Jr. (2003). "Why is There so Little Money in U.S. Politics?" In: Journal of Economic Perspectives 17.1, pp. $105-130$.

Baicker, Katherine and Douglas Staiger (2005). "Fiscal Shenanigans, Targeted Federal Health Care Funds, and Patient Mortality”. In: Quarterly Journal of Economics 120.1, pp. 345-386.

Bartlett, Bruce (2013). Medicare Part D: Republican Budget Busting. New York Times. 
Bresnahan, John (2017). McConnell Gets a Win in Obamacare Repeal Opening Round. Politico.

Cameron, A. Colin, Jonah B. Gelbach, and Douglas L. Miller (2008). "Bootstrap-Based Improvements for Inference with Clustered Errors". In: Review of Economics and Statistics 90.3, pp. 414-427.

Centers for Medicare and Medicaid Services (2018). National Health Expenditures Fact Sheet. URL: https://www.cms.gov/research-statistics-data-and-systems/ statistics - trends - and - reports / nationalheal thexpenddata / nhe - fact sheet.html.

Chamon, Marcos and Ethan Kaplan (2013). "The Iceberg Theory of Campaign Contributions: Political Threats and Interests Group Behavior". In: American Economic Journal: Economic Policy 5.1, pp. 1-31.

Chandra, Amitabh and Jonathan Skinner (2011). Technology Growth and Expenditure Growth in Health Care. Working Paper. NBER.

Chang, Tom and Mireille Jacobson (2011). What do Nonprofit Hospitals Maximize? Evidence from California's Seismic Retrofit Mandate. Working Paper. NBER.

Coate, Stephen (2004). "Political Competition with Campaign Contributions and Informative Advertising". In: Journal of the European Economic Association 2.5, pp. 772-804.

Cohn, Jonathan (2010). How they Did it: The Inside Account of Health Reform's Triumph. The New Republic.

Cutler, David et al. (2013). Physician Beliefs and Patient Preferences: A New Look at Regional Variation in Health Care Spending. Working Paper. NBER.

Dafny, Leemore (2005). "How Do Hospitals Respond to Price Changes?" In: American Economic Review 95.5, pp. 1525-1547.

Duggan, Mark (2000). "Hospital Ownership and Public Medical Spending”. In: Quarterly Journal of Economics 115.4, pp. 1343-1373. 
Einav, Liran, Amy Finkelstein, and Neale Mahoney (2018). Long-Term Care Hospitals: A Case Study In Waste. Working Paper. NBER.

Evans, Diana (2004). Greasing the Wheels: Using Pork Barrel Projects to Build Majority Coalitions in Congress. Cambridge University Press.

Federal Register (2004a). Medicare Program; Notice of One-Time Appeal Process for Hospital Wage Index Classifications. Department of Health and Human Services.

- (2004b). Medicare Program; Revisions to the One-Time Appeal Process for Hospital Wage Index Classifications. Department of Health and Human Services.

Finkelstein, Amy, Matthew Gentzkow, and Heidi Williams (2016). "Sources of Geographic Variation in Health Care: Evidence from Patient Migration”. In: Quarterly Journal of Economics 131.4, pp. 1681-1726.

Foo, Patricia K., Robin S. Lee, and Kyna Fong (2017). "Physician Prices, Hospital Prices, and Treatment Choice in Labor and Delivery”. In: American Journal of Health Economics 3.3, pp. 422-453.

Fox, Justin and Lawrence Rothenberg (2011). "Influence without Bribes: A Noncontracting Model of Campaign Giving and Policymaking”. In: Political Analysis 19.3, pp. 325-341.

Garber, Alan M. and Jonathan Skinner (2008). "Is American Health Care Uniquely Inefficient?” In: Journal of Economic Perspectives 22.4, pp. 27-50.

Government Accountability Office (2013). Medicare: Legislative Modifications Have Resulted in Payment Adjustments for Most Hospitals. United States Government Accountability Office.

Grossman, Gene M. and Elhanan Helpman (1994). "Protection for Sale”. In: American Economic Review 84.4, pp. 833-850.

— (1996). "Electoral Competition and Special Interest Politics". In: Review of Economic Studies 63.2, pp. 265-286.

— (2001). Special Interest Politics. MIT Press. 
Iglehart, John K. (1971). "Prepaid Group Medical Practice Emerges as Likely Federal Approach to Health Care". In: National Journal 3, pp. 1443-1452.

Institute of Medicine (2012). Geographic Adjustment in Medicare Payment: Phase I: Accuracy. The National Academics of Sciences, Engineering, and Medicine.

Jan, Tracy (2013). 21 States Take Aim at Mass. Hospitals' Medicare Windfall. The Boston Globe.

Joyce, Geoffrey F. et al. (2009). “Medicare Part D After Two Years”. In: American Journal of Managed Care 15.8, pp. 536-544.

Kaestner, Robert and Jose Guardado (2008). "Medicare Reimbursement, Nurse Staffing, and Patient Outcomes”. In: Journal of Health Economics 27.2, pp. 339-361.

Kamal, Rabak and Cynthia Cox (2018). How Has U.S. Spending on Healthcare Changed Over Time? Kaiser Family Foundation. URL: https : //www . healthsystemtracker. org / chart - collection/u-s - spending - healthcare - changed - time/\#item start.

Keane, Tom (2013). Bay State Boondoggle. The Boston Globe.

Kuhn, Herb and Lisa Schencker (2016). End the "Bay State's Boondoggle”. The Hill.

Lee, Christopher (2003). Medicare Bill Partly a Special Interest Care Package. The Washington Post.

Levitt, Steven D. and James M. Snyder Jr. (1997). “The Impact of Federal Spending on House Election Outcomes". In: Journal of Political Economy 105.1, pp. 30-53.

Lubell, Jennifer (2007). Section 508 nearing expiration: Loss of MMA wage index could spell trouble. Modern Healthcare.

Marmor, Theodore R. (2000). The Politics of Medicare. Aldine de Gruyter.

Mayhew, David (1974). The Electoral Connection. Yale University Press. 
McDermott, Kimberly W., Anne Elixhauser, and Ruirui Sun (2017). Trends in Hospital Inpatient Stays in the United States, 2005-2014. HCUP Statistical Brief 225. Agency for Healthcare Research and Quality.

Newhouse, Joseph P. (1970). “Toward a Theory of Nonprofit Institutions: An Economic Model of a Hospital". In: American Economic Review 60.1, pp. 64-74.

Office of Senator Charles Schumer (2006). Schumer Demands Orange and Dutchess County Hospitals Be Included in Hospital Reclassification Deal Announced Today. URL: https: //www . schumer . senate . gov/newsroom/press - releases/schumer-demands orange - and - dutchess - county - hospitals - be - included - in - hospital reclassification-deal-announced-today.

Oliver, Thomas R., Philip R. Lee, and Helene L. Lipton (2004). “A Political History of Medicare and Prescription Drug Coverage". In: The Milbank Quarterly 82.2, pp. $283-$ 354.

Pear, Robert (1999). Health Industry Sees Wish List Made Into Law. The New York Times. Pope, Devin G. (2009). "Reacting to Rankings: Evidence from “America's Best Hospitals'”. In: Journal of Health Economics 28.6, pp. 1154-1165.

Powell, Lynda W. (2014). "The Influence of Campaign Contributions on the Legislative Process". In: Duke Journal of Constitutional Law and Public Policy 9.1, pp. 75-101.

Rocca, Michael S. and Stacy B Gordon (2013). "Earmarks as a Means and an End: The Link Between Earmarks and Campaign Contributions in the US House of Representatives". In: Journal of Politics 75.1, pp. 241-253.

Shepsle, Kenneth A. and Barry R. Weingast (1982). "Structure-Induced Equilibrium and Legislative Choice". In: Public Choice 27.3, pp. 503-519.

Smith, Sheila, Joseph P. Newhouse, and Mark S. Freeland (2009). "Income, Insurance, and Technology: Why Does Health Spending Outpace Economic Growth?" In: Health Affairs 28.5, pp. 1276-1284. 
Starr, Paul (1983). The Social Transformation of American Medicine. Basic Books.

Stratmann, Thomas (2005). "Some talk: Money in politics. A (partial) review of the literature". In: Public Choice 124, pp. 135-156.

The Center for Responsive Politics (2019a). URL: https : / /www . opensecrets . org/ federal-lobbying/industries?cycle $=2006$.

- (2019b). URL: https://www . opensecrets . org/orgs/lobby . php?id=D000000116.

- (2019c). Client Profile: Section 508 Coalition. URL: https : //www . opensecrets . org/federal-lobbying/clients/summary?cycle=2012\&id=D000056560.

Vladeck, Bruce C. (1999). “The Political Economy Of Medicare: Medicare Reform Requires Political Reform." In: Health Affairs 18.1, pp. 22-36.

Weingast, Barry R. (1979). “A Rational Choice Perspective on Congressional Norms”. In: American Journal of Political Science 23.2, pp. 245-262.

Weingast, Barry R., Kenneth A. Shepsle, and Christopher Johnsen (1981). "The Political Economy of Benefits and Costs: A Neoclassical Approach to Distributive Politics". In: Journal of Political Economy 89.4, pp. 642-664. 


\section{Appendix - For Online Publication}




\section{Appendix A Description of Data and Data Cleaning}

\section{A.1 Datasets and Sources}

American Hospital Association Annual Survey: We obtained data on hospital staffing, payroll, technology adoption, and other hospital characteristics from the American Hospital Association (AHA) annual survey. The AHA has surveyed hospitals annually since 1946. More information on the AHA survey data can be viewed at: http: //www . ahadataviewer . com/book-cd-products/AHA-Survey/.

American Hospital Directory Data: We use data on hospitals' Medicare activity that we obtained from the American Hospital Directory (AHD). The AHD is a for-profit data vendor that sells cleaned Medicare claims data derived from the Medicare Provider Analysis and Review limited access database. This includes claims records for $100 \%$ of Medicare fee-for-service inpatient claims. Details on the AHD data can be found at www. ahd . com.

Center for Responsive Politics Data: We identified the Section 508 Coalition via data on congressional lobbying presented by the Center for Responsive Politics https: //www . opensecrets. org/lobby/clientsum . php?id=D000056560\&year=2009.

CMS Inpatient PPS Impact Files: We accessed historical Impact Files from the Centers for Medicare \& Medicaid Services (CMS). These files list the parameters affecting each hospital's inpatient PPS payments for each fiscal year (e.g., hospital wage indices). We use these files to calculate Medicare inpatient PPS operating and capital payments as described in Appendix A.2. The files and more information are available at: https://www.cms.gov/Medicare/Medicare-Fee-for-Service-Payment/ AcuteInpatientPPS/Historical-Impact-Files-for-FY-1994-through-Present.

Database on Ideology, Money in Politics, and Elections (DIME): We accessed data on campaign contributions from the DIME database. The database was constructed by Adam 
Bonica. More information on the data is available at https://data.stanford.edu/dime. Their information on campaign contributions was collected from the Federal Election Commission. To calculate campaign contributions to a candidate, we remove transactions identified by FEC transaction type codes as loan repayments (codes starting with 16, 20 and 22), refunds (codes starting with 17 and 23), expenditures against the candidate (24A, $24 \mathrm{~N}$ ), contributions from the candidate themselves (15C), and other miscellaneous codes. In addition to direct contributions to candidates' campaigns, we include "independent expenditure[s] advocating election of [the] candidate" (code 24E), in-kind contributions (codes $15 \mathrm{Z}$ and 24Z), and communication/electioneering expenses (codes $24 \mathrm{~F}$ and 29). A full list of FEC transaction type codes is available at https://www.fec.gov/campaign-finance-data/ transaction-type-code-descriptions/.

Federal Register: We extracted data on Medicare labor market area (i.e., CBSA) wage indexes from the annual Hospital Inpatient Prospective System (IPPS) Final Rules published in the Federal Register. These wage indexes are typically listed in Tables $4 \mathrm{~A}$ and $4 \mathrm{~B}$ of the final rule for each fiscal year. We used these to estimate what each Section 508 hospital's wage index (and thus IPPS payment rate) would have been without its labor market reclassification under Section 508. The Federal Register files are available at: https ://www . cms.gov/Medicare/Medicare-Fee-for-Service-Payment/AcuteInpatientPPS/ IPPS-Regulations-and-Notices. The wage index tables for 2007-2010 are also available at: https://www.cms.gov/Medicare/Medicare-Fee-for-Service-Payment/ AcuteInpatientPPS/Acute-Inpatient-Files-for-Download.

Freedom of Information Act Request: We filed a Freedom of Information Act (FOIA) request to the Centers for Medicare and Medicaid Services to obtain a list of hospitals that applied for a Section 508 waiver, a list of applications that had their applications approved, and the criteria on which hospitals' applications were judged. Our FOIA request was filed 
on December 1, 2014. We received a reply on March 3, 2015.

RAND Hospital Data: We accessed data on hospitals' total revenue, Medicare prospective payment system (PPS) payments, and Medicare inpatient discharges from the RAND Corporation, which sells cleaned Medicare Cost Reports (HCRIS) data. We use federal fiscal year-level year data with error corrections by RAND. More information on the data is available at: https://www . hospitaldatasets .org.

Voteview Database: We accessed data on the votes by members of Congress for the Medicare Modernization Act from the Voteview database. The database includes roll call votes for every vote taken by Congress and can be accessed at voteview.com. The database is hosted and maintained by UCLA's Department of Political Science.

\section{A.2 Calculating Medicare Inpatient PPS Payment Rates}

To calculate payments, we followed payment rules outlined each year in the Federal Register. We began by calculating the inpatient PPS operating payments and capital payments, which were adjusted using the hospital operating wage index, labor and non-labor shares, operating cost-of-living adjustment, disproportionate share payments, indirect medical education payments, geographic adjustment factors, and capital cost-of-living adjustments. We then used diagnosis related group (DRG) weights to calculate the standard payment amount for each inpatient case exclusive of outlier payments. Outlier payments are additional payments made to hospitals if specific cases involve atypically long stays in the hospital.

\section{A.3 Identifying the Industry of a Donor}

For identifying the industry of employment of the donor/contributor, we primarily use the contributor categorization code in the DIME database. Details on categorization can be found at https://www . opensecrets.org/downloads/crp/CRP_Categories.txt. We 
supplement this categorization by looking for specific words in the contributors' employer and organization field. For example, we categorized contributors to the hospital industry by looking for words "hospital", "healthcare system", "health system" and "medical center" in the employer and the organization field. We repeat the same procedure for other industries. 
Table A.1: Hospital Characteristics

\begin{tabular}{|c|c|c|c|c|c|c|c|c|c|c|}
\hline & \multicolumn{2}{|c|}{$\begin{array}{c}\text { All } 508 \\
\text { Hospitals }\end{array}$} & \multicolumn{2}{|c|}{$\begin{array}{c}\text { Applied and } \\
\text { Rejected }\end{array}$} & \multicolumn{2}{|c|}{$\begin{array}{l}\text { Eligible But } \\
\text { Didn't Apply }\end{array}$} & \multicolumn{2}{|c|}{ Ineligible } & \multicolumn{2}{|c|}{$\begin{array}{l}\text { All AHA } \\
\text { Hospitals }\end{array}$} \\
\hline & Mean & Std. Dev. & Mean & Std. Dev. & Mean & Std. Dev. & Mean & Std. Dev. & Mean & Std. Dev \\
\hline Medicare Discharges & 5,022 & 4,198 & 5,498 & 4,190 & 4,258 & 3,951 & $3,853 * *$ & 3,074 & 4,245 & 3,688 \\
\hline Medicaid Discharges & 1,681 & 1,959 & $2,105^{*}$ & 2,071 & 1,937 & 2,497 & 1,638 & 2,022 & 1,825 & 2,261 \\
\hline For-Profit Hospital & 0.06 & 0.23 & $0.21 * * *$ & 0.41 & $0.13 * * *$ & 0.34 & $0.18 * * *$ & 0.38 & 0.16 & 0.36 \\
\hline Not-for-Profit Hospital & 0.88 & 0.33 & $0.69 * * *$ & 0.46 & $0.64 * * *$ & 0.48 & $0.65 * * *$ & 0.48 & 0.66 & 0.48 \\
\hline Teaching Hospital & 0.40 & 0.49 & 0.38 & 0.49 & $0.29 *$ & 0.46 & $0.23 * * *$ & 0.42 & 0.28 & 0.45 \\
\hline Beds & 235 & 184 & $274 *$ & 210 & 226 & 203 & $194 * *$ & 164 & 218 & 190 \\
\hline Urban Area & 0.81 & 0.40 & 0.79 & 0.41 & 0.73 & 0.44 & $0.57 * * *$ & 0.50 & 0.68 & 0.47 \\
\hline Member Voted Yea - MMA & \multicolumn{2}{|c|}{0.61} & \multicolumn{2}{|c|}{$0.49 *$} & \multicolumn{2}{|c|}{$0.51 *$} & \multicolumn{2}{|c|}{0.53} & \multicolumn{2}{|c|}{0.52} \\
\hline $\mathrm{N}$ & \multicolumn{2}{|c|}{88} & \multicolumn{2}{|c|}{284} & \multicolumn{2}{|c|}{1.278} & \multicolumn{2}{|c|}{1.125} & \multicolumn{2}{|c|}{2,775} \\
\hline
\end{tabular}

Notes: All statistics (except MMA votes) are calculated using 2004 AHA Annual Hospital Survey data. We exclude Critical Access Hospitals, hospitals that are not registered with the AHA for all of 2001 to 2010, and hospitals that are not in our sample for all of 2001 to 2010. Asterisks indicate that the group's mean is statistically significantly different from the 508 hospitals' mean based on a t-test $(* * * \mathrm{p}<0.01, * * \mathrm{p}<0.05, * \mathrm{p}<0.1)$. We do not conduct t-tests for the "All AHA Hospitals" group. 
Table A.2: Distribution of Predicted Gains in IPPS Rates and Simulated IPPS Payments from the 508 Waiver Program

\begin{tabular}{|c|c|c|c|c|c|c|c|c|c|c|}
\hline & Mean & S.D. & Min. & P5 & P10 & $\mathbf{P 2 5}$ & Median & P75 & P90 & Max. \\
\hline Predicted Gain in IPPS Payment Rate for Hospitals $(\$)$ & 426.70 & 247.45 & 0 & 74.20 & 105.33 & 252.75 & 401.32 & 554.34 & 802.81 & $1,008.18$ \\
\hline Predicted Gain in Total IPPS Payments for Hospitals (\$ Millions) & 2.64 & 4.05 & 0 & 0.06 & 0.16 & 0.51 & 1.52 & 2.89 & 5.90 & 27.04 \\
\hline Predicted Gain in Total IPPS Payments for Congressional Districts (\$ Millions) & 5.54 & 7.70 & 0.08 & 0.12 & 0.28 & 0.77 & 3.09 & 6.24 & 10.74 & 38.19 \\
\hline
\end{tabular}

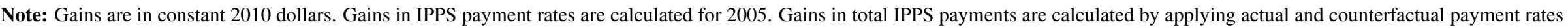

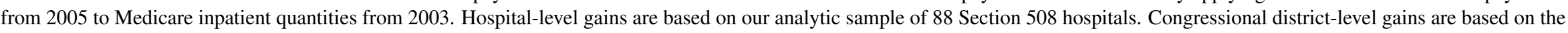
same sample of Section 508 hospitals, aggregated to the district level. 
Table A.3: Distribution of the Number of Hospitals Per Congressional District

\begin{tabular}{|c|c|c|c|c|c|c|c|c|c|c|c|}
\hline A. All Hospitals & & & & & & & & & & & \\
\hline & Obs. & Mean & S.D. & Min. & P5 & $\mathbf{P 1 0}$ & $\mathbf{P} 25$ & P50 & P75 & P90 & Max. \\
\hline Total Hospitals Per C.D. & 414 & 6.70 & 3.58 & 1 & 2 & 3 & 4 & 6 & 8 & 12 & 21 \\
\hline \multicolumn{12}{|l|}{ B. 508-Recipient Hospitals } \\
\hline & Obs. & Mean & S.D. & Min. & P5 & $\mathbf{P 1 0}$ & $\mathbf{P} 25$ & P50 & P75 & P90 & Max. \\
\hline 508 Hospitals Per C.D. & 414 & 0.21 & 0.86 & 0 & 0 & 0 & 0 & 0 & 0 & 1 & 9 \\
\hline 508 Hospitals Per Treated C.D. & 42 & 2.10 & 1.85 & 1 & 1 & 1 & 1 & 1 & 3 & 4 & 9 \\
\hline \multicolumn{12}{|l|}{ C. Non-508-Recipient Hospitals } \\
\hline & Obs. & Mean & S.D. & Min. & P5 & $\mathbf{P 1 0}$ & $\mathbf{P 2 5}$ & P50 & P75 & P90 & Max. \\
\hline Non-508 Hospitals Per C.D. & 414 & 6.49 & 3.56 & 0 & 2 & 3 & 4 & 6 & 8 & 11 & 21 \\
\hline Non-508 Hospitals Per Treated C.D. & 42 & 6.12 & 4.56 & 0 & 0 & 1 & 3 & 5 & 9 & 12 & 18 \\
\hline
\end{tabular}

Notes: Observations are congressional districts. Treated congressional districts are those with at least one hospital who received a Section 508 waiver. Hospitals are only counted if they are in our balanced analytic sample. 
Table A.4: The Impact of the Re-Authorization of the Section 508 Program on Campaign Contributions

\begin{tabular}{|c|c|c|c|c|c|c|}
\hline \multirow{3}{*}{$\begin{array}{c}\text { Campaign } \\
\text { Contributions } \\
\text { From: }\end{array}$} & \multirow{3}{*}{$\begin{array}{c}\text { All } \\
\text { Donors } \\
\text { Nationwide } \\
\text { (\$ Thousands) } \\
(1)\end{array}$} & \multirow{3}{*}{$\begin{array}{c}\text { Individual } \\
\text { Donors } \\
\text { Nationwide } \\
\text { (\$ Thousands) } \\
\text { (2) }\end{array}$} & \multicolumn{4}{|c|}{ Individual Donors in Same State } \\
\hline & & & $\begin{array}{c}\text { All } \\
\text { Industries } \\
\text { (\$ Thousands) }\end{array}$ & $\begin{array}{c}\text { Hospitals } \\
\text { (\$) }\end{array}$ & $\begin{array}{c}\text { Crop } \\
\text { Production } \\
\text { \& Basic } \\
\text { Processing } \\
(\$)\end{array}$ & $\begin{array}{c}\text { Oil \& Gas } \\
(\$)\end{array}$ \\
\hline & & & (3) & (4) & $(5)$ & (6) \\
\hline 2001-Q1*Treated & -11.44 & -1.51 & $11.24 *$ & 126.70 & -71.71 & 282.04 \\
\hline Group & $(19.76)$ & $(10.76)$ & $(6.51)$ & $(137.62)$ & $(199.37)$ & $(345.84)$ \\
\hline 2001-Q2*Treated & $-80.10 * * *$ & $-34.86 * * *$ & $-20.84 * *$ & -159.36 & $-673.34 * *$ & -281.26 \\
\hline Group & $(28.88)$ & $(12.31)$ & $(9.34)$ & $(179.71)$ & $(263.30)$ & $(255.83)$ \\
\hline 2001-Q3*Treated & -15.95 & -9.44 & 3.83 & 54.47 & 64.32 & -154.35 \\
\hline Group & $(21.98)$ & $(9.18)$ & $(9.75)$ & $(203.92)$ & $(279.62)$ & $(253.62)$ \\
\hline 2001-Q4*Treated & -28.68 & -11.58 & -1.19 & -181.62 & -280.84 & -261.29 \\
\hline Group & $(22.40)$ & $(13.84)$ & $(9.89)$ & $(177.87)$ & (196.64) & $(204.74)$ \\
\hline 2002-Q1*Treated & 0.40 & 1.82 & 6.24 & 36.25 & 30.38 & 166.41 \\
\hline Group & $(23.36)$ & (13.99) & $(8.92)$ & $(188.30)$ & $(356.44)$ & $(329.26)$ \\
\hline 2002-Q2*Treated & 14.64 & 5.02 & -3.14 & -90.47 & $-1,070.39 * *$ & 195.86 \\
\hline Group & $(41.91)$ & $(29.62)$ & $(17.95)$ & $(321.83)$ & $(536.31)$ & $(355.46)$ \\
\hline 2002-Q3*Treated & -37.45 & $-38.59 * *$ & $-24.79 *$ & -107.79 & $-913.88 * *$ & 63.23 \\
\hline Group & $(32.79)$ & $(18.43)$ & $(14.21)$ & $(258.58)$ & $(429.60)$ & $(410.75)$ \\
\hline 2002-Q4*Treated & -9.20 & -1.85 & -0.55 & -48.85 & $-502.45 * *$ & -290.63 \\
\hline Group & $(40.56)$ & $(19.00)$ & $(12.07)$ & $(206.00)$ & $(216.71)$ & $(256.47)$ \\
\hline 2003-Q1*Treated & -21.49 & -8.57 & 3.68 & 121.00 & -10.10 & 88.29 \\
\hline Group & $(19.78)$ & $(10.78)$ & $(6.77)$ & (128.58) & $(170.56)$ & $(303.29)$ \\
\hline 2003-Q2*Treated & -23.14 & -17.99 & -11.72 & -76.12 & $-518.18 * *$ & -280.78 \\
\hline Group & $(23.15)$ & $(13.62)$ & $(10.58)$ & (180.64) & $(229.45)$ & $(239.60)$ \\
\hline 2003-Q3*Treated & -17.93 & -14.96 & -3.61 & -111.19 & -344.10 & -160.83 \\
\hline Group & $(22.20)$ & $(13.33)$ & $(9.49)$ & (221.09) & $(219.80)$ & $(261.84)$ \\
\hline 2003-Q4*Treated & -19.94 & -6.41 & -2.63 & 206.74 & -230.08 & -147.79 \\
\hline Group & $(18.80)$ & $(9.35)$ & $(8.83)$ & (388.34) & $(243.02)$ & $(233.61)$ \\
\hline 2004-Q1*Treated & -20.00 & -16.85 & -8.01 & 148.05 & -619.92 & 64.89 \\
\hline Group & $(21.44)$ & (11.03) & $(9.45)$ & $(241.80)$ & $(381.50)$ & $(296.93)$ \\
\hline
\end{tabular}


Table A.4: The Impact of the Re-Authorization of the Section 508 Program on Campaign Contributions

\begin{tabular}{|c|c|c|c|c|c|c|}
\hline & (1) & (2) & (3) & (4) & (5) & (6) \\
\hline $\begin{array}{l}\text { 2004-Q2*Treated } \\
\text { Group }\end{array}$ & $\begin{array}{l}-23.08 \\
(23.75)\end{array}$ & $\begin{array}{l}-10.86 \\
(15.55)\end{array}$ & $\begin{array}{c}0.34 \\
(12.66)\end{array}$ & $\begin{array}{c}-60.43 \\
(349.89)\end{array}$ & $\begin{array}{l}-574.20 * \\
(315.73)\end{array}$ & $\begin{array}{c}-35.23 \\
(294.49)\end{array}$ \\
\hline \multicolumn{7}{|c|}{ Section 508 Payments Took Effect on April 1, 2004} \\
\hline 2004-Q3*Treated & -17.16 & -3.72 & 7.97 & -164.60 & -330.91 & 372.67 \\
\hline Group & $(30.98)$ & $(20.90)$ & (16.99) & $(240.40)$ & (397.61) & $(327.57)$ \\
\hline 2004-Q4*Treated & -5.24 & -16.12 & -1.82 & 416.98 & -393.90 & -186.57 \\
\hline Group & $(48.73)$ & $(14.48)$ & $(10.62)$ & $(340.77)$ & $(261.25)$ & $(236.61)$ \\
\hline 2005-Q1*Treated & -25.30 & -3.12 & 5.62 & 314.36 & -163.99 & 125.71 \\
\hline Group & (19.53) & (10.94) & $(5.99)$ & $(215.93)$ & (188.59) & $(261.54)$ \\
\hline 2005-Q2*Treated & -11.42 & -9.10 & -10.20 & 0.53 & -304.78 & -362.53 \\
\hline Group & $(23.59)$ & $(13.18)$ & $(9.59)$ & $(266.95)$ & (332.28) & $(247.43)$ \\
\hline 2005-Q3*Treated & -23.15 & -18.70 & -10.18 & -2.49 & -149.40 & 240.46 \\
\hline Group & $(19.26)$ & $(12.34)$ & $(10.16)$ & (354.68) & (389.89) & $(435.96)$ \\
\hline 2005-Q4*Treated & 3.24 & 10.61 & -1.31 & 209.28 & -319.19 & -183.34 \\
\hline Group & $(40.67)$ & $(31.60)$ & $(12.49)$ & $(266.85)$ & $(233.53)$ & $(247.17)$ \\
\hline 2006-Q1*Treated & -0.99 & 3.95 & 1.52 & -109.48 & -381.76 & 256.86 \\
\hline Group & $(27.22)$ & $(17.96)$ & $(12.02)$ & $(297.26)$ & $(290.23)$ & $(330.88)$ \\
\hline 2006-Q2*Treated & 4.10 & 0.89 & 4.29 & 214.87 & -386.53 & -100.95 \\
\hline Group & $(31.65)$ & $(20.48)$ & $(14.00)$ & $(315.31)$ & $(266.29)$ & $(353.34)$ \\
\hline 2006-Q3*Treated & -7.30 & -25.03 & -10.03 & 391.35 & $-528.63 * *$ & -44.96 \\
\hline Group & $(39.01)$ & $(20.63)$ & $(15.27)$ & $(400.95)$ & $(216.59)$ & $(436.55)$ \\
\hline 2006-Q4*Treated & -8.18 & -10.11 & 5.61 & -286.43 & -165.87 & 227.02 \\
\hline Group & $(31.50)$ & $(18.93)$ & (12.08) & (226.99) & $(226.95)$ & (392.10) \\
\hline \multicolumn{7}{|c|}{ 2007-Q1 - Omitted Category } \\
\hline 2007-Q2*Treated & -11.56 & -14.33 & -7.00 & 227.32 & $-397.48 *$ & 7.94 \\
\hline Group & $(22.05)$ & $(10.46)$ & (7.16) & $(243.80)$ & $(218.73)$ & $(271.06)$ \\
\hline 2007-Q3*Treated & -12.82 & -12.91 & -4.02 & 89.35 & -579.80 & -155.44 \\
\hline Group & $(17.64)$ & $(10.93)$ & $(9.60)$ & $(254.21)$ & $(375.31)$ & (293.39) \\
\hline 2007-Q4*Treated & -18.29 & -17.51 & -7.91 & 700.51 & 184.78 & 119.75 \\
\hline Group & $(27.41)$ & (15.19) & (11.16) & $(445.31)$ & $(459.41)$ & (319.03) \\
\hline
\end{tabular}


Table A.4: The Impact of the Re-Authorization of the Section 508 Program on Campaign Contributions

\begin{tabular}{|c|c|c|c|c|c|c|}
\hline & $(1)$ & (2) & (3) & (4) & $(5)$ & (6) \\
\hline \multicolumn{7}{|c|}{ Section 508 Program Reauthorized on December 19, 2007} \\
\hline 2008-Q1*Treated & $44.55^{*}$ & 20.88 & $22.24 * *$ & 164.06 & -271.06 & -126.63 \\
\hline Group & $(23.46)$ & $(15.51)$ & $(10.48)$ & $(217.03)$ & $(261.00)$ & $(241.16)$ \\
\hline 2008-Q2*Treated & 18.35 & 3.04 & 5.94 & -54.52 & -280.92 & -81.12 \\
\hline Group & $(31.32)$ & $(23.81)$ & $(17.45)$ & $(226.10)$ & $(231.79)$ & $(273.56)$ \\
\hline 2008-Q3*Treated & $190.56 * *$ & $34.60^{*}$ & $32.70 * *$ & 509.26 & -14.27 & 153.53 \\
\hline Group & $(85.53)$ & $(20.13)$ & $(15.29)$ & $(331.50)$ & $(350.77)$ & $(529.35)$ \\
\hline 2008-Q4*Treated & 48.90 & -5.29 & 4.48 & 45.04 & -101.87 & -234.11 \\
\hline Group & $(58.52)$ & $(16.76)$ & $(10.81)$ & (201.08) & $(172.07)$ & $(248.65)$ \\
\hline 2009-Q1*Treated & -26.69 & -11.05 & 0.39 & 111.60 & -74.32 & -117.54 \\
\hline Group & $(20.95)$ & $(12.38)$ & $(6.97)$ & $(161.32)$ & (192.14) & $(208.16)$ \\
\hline 2009-Q2*Treated & -4.92 & -7.20 & -2.12 & -36.31 & -297.43 & -197.09 \\
\hline Group & $(27.90)$ & $(15.60)$ & $(10.02)$ & $(217.37)$ & $(206.87)$ & $(227.79)$ \\
\hline 2009-Q3*Treated & -17.83 & -12.65 & -6.80 & 325.48 & 205.61 & 145.75 \\
\hline Group & $(27.64)$ & $(13.38)$ & $(9.06)$ & (198.69) & $(568.22)$ & $(398.80)$ \\
\hline 2009-Q4*Treated & -44.38 & -31.83 & -21.21 & -256.73 & 58.97 & -264.75 \\
\hline Group & $(33.52)$ & $(20.71)$ & $(15.79)$ & $(268.76)$ & $(381.23)$ & (307.49) \\
\hline 2010-Q1*Treated & -10.35 & -13.75 & -4.41 & 229.12 & 64.86 & -223.11 \\
\hline Group & $(25.67)$ & $(14.54)$ & $(8.47)$ & (191.09) & $(331.95)$ & $(279.67)$ \\
\hline 2010-Q2*Treated & 16.15 & 1.15 & 2.68 & 99.62 & 40.72 & -51.05 \\
\hline Group & $(32.18)$ & $(17.38)$ & $(11.08)$ & $(323.66)$ & $(278.72)$ & (266.99) \\
\hline 2010-Q3*Treated & 22.15 & -3.71 & 0.11 & 110.51 & 340.44 & -164.31 \\
\hline Group & $(54.71)$ & $(19.57)$ & $(11.84)$ & $(344.94)$ & $(957.01)$ & $(370.95)$ \\
\hline 2010-Q4*Treated & 4.65 & -3.46 & 4.98 & 179.38 & -217.23 & -165.51 \\
\hline Group & $(44.41)$ & (17.10) & (10.84) & $(272.69)$ & $(274.16)$ & $(240.21)$ \\
\hline Candidate F.E.s & $\mathrm{X}$ & $\mathrm{X}$ & $\mathrm{X}$ & $X$ & $X$ & $\mathrm{X}$ \\
\hline Year-Quarter F.E.s & $\mathrm{X}$ & $\mathrm{X}$ & X & X & X & X \\
\hline $\mathrm{N}$ & 6,080 & 6,080 & 6,080 & 6,080 & 6,080 & 6,080 \\
\hline \multicolumn{7}{|c|}{ Mean of the Dependent Variable in 2007-Q1 } \\
\hline Treated Candidates & 148.89 & 51.93 & 25.47 & 153.12 & 296.97 & 352.65 \\
\hline Control Candidates & 136.31 & 44.74 & 31.92 & 396.92 & 318.73 & 214.47 \\
\hline
\end{tabular}

Notes: $* \mathrm{p}<0.10, * * \mathrm{p}<0.05, * * \mathrm{p}<0.01$. This table presents estimates of Equation (3) where we regress campaign contributions (in constant 2010 dollars) on a vector of candidate fixed effects, quarter dummies, and interactions between the treated candidate indicator and quarter dummies. 2007-Q1 is our omitted category. Wild-bootstrapped standard errors clustered around candidates are in parentheses. Observations (N) are candidate-quarters. Control candidates are those with at least one hospital in their district that applied for a Section 508 waiver but was rejected. 


\section{Figure A.1: The Impact of Section 508 Waivers on Hospitals' Medicare and Total Revenue}

\section{Panel A: Medicare Inpatient + Outpatient PPS Payments (\$ Millions, 2010 Dollars)}
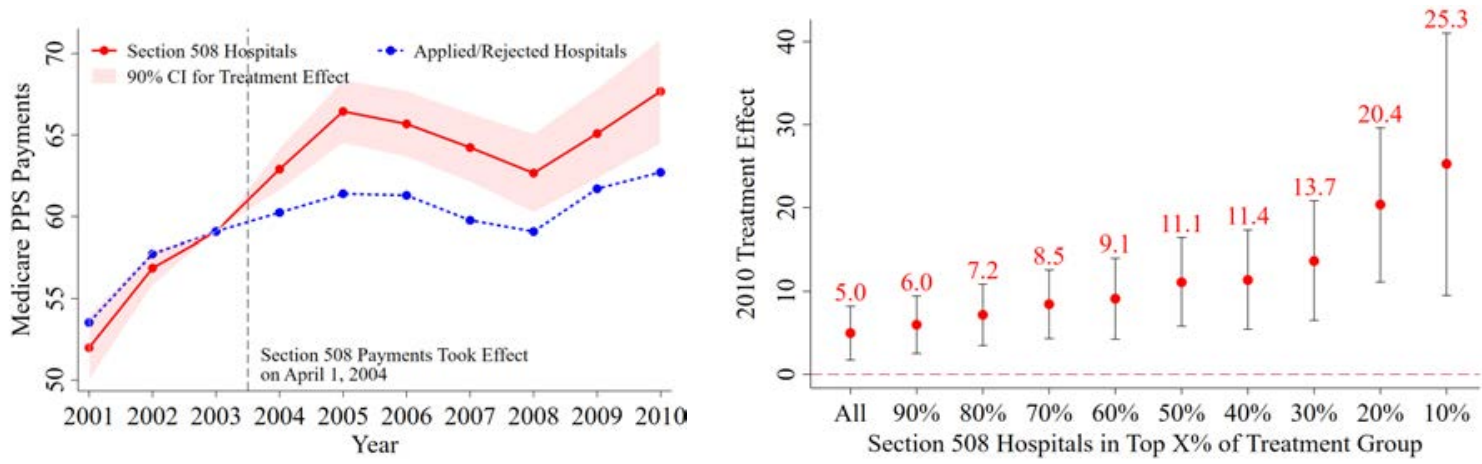

Panel B: Total Net Patient Revenue (\$ Millions, 2010 Dollars)

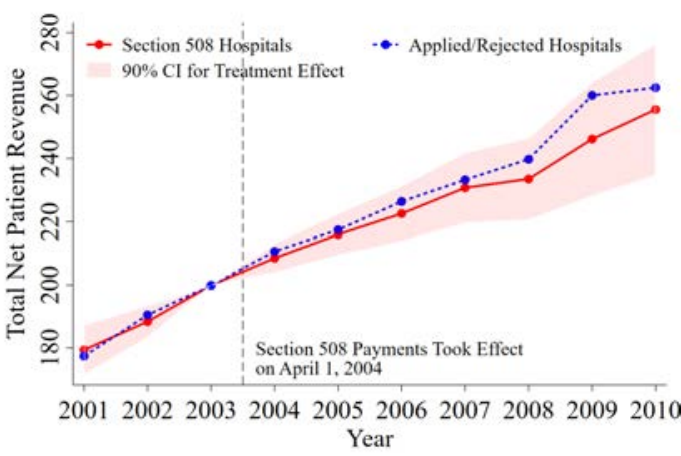

Panel C: Total Net Patient Revenue (\$ Millions, 2010 Dollars), Treated=Top 50\%

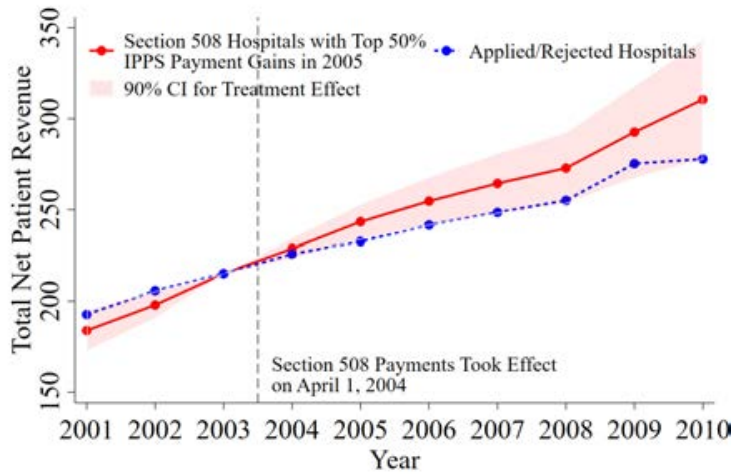

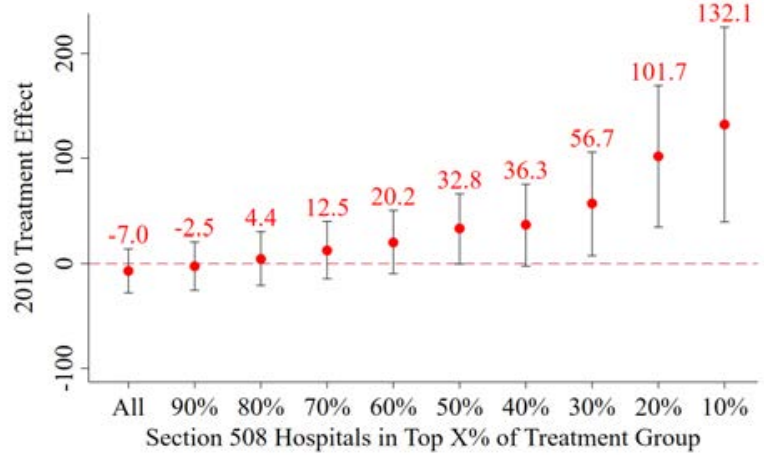

Panel D: Total Net Patient Revenue (\$ Millions, 2010 Dollars), Treated=Top $20 \%$

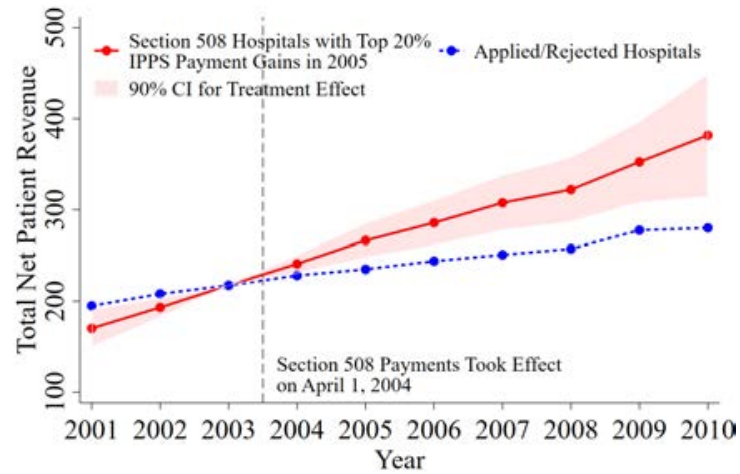

Notes: These panels present estimates of Equation (1) where we regress hospital outcomes on a vector of hospital fixed effects, year dummies, and interactions between the Section 508-recipient hospital indicator and year dummies. 2003 is our omitted year. $90 \%$ confidence intervals are based on wild-bootstrapped standard errors clustered around hospitals. Control hospitals include those that applied for the Section 508 waiver but were rejected. The rightmost figures plot the coefficient of the 2010 interaction term from Equation (1) as we vary the definition of the treatment group. Moving left to right in each figure, each specification involves a treated group composed of hospitals that received increasingly large gains in total IPPS payments (based on quantities in 2003 and actual and counterfactual payment rates in 2005) due to the Section 508 program. Outcome measures are from the RAND Medicare Cost Reports (HCRIS) data. Panel A uses the sum of Medicare payments under the inpatient and outpatient prospective payment systems. Panels B, C, and D use "net patient revenue (charges minus contractual allowances and discounts)." 


\title{
Figure A.2: The Impact of Section 508 Waivers on Hospitals' Inpatient Medicare Admissions, Inpatient Medicare Spending, Payroll, Personnel, and Technology Adoption (Unbalanced Panel)
}

\author{
Panel A: Medicare Inpatient Admissions
}
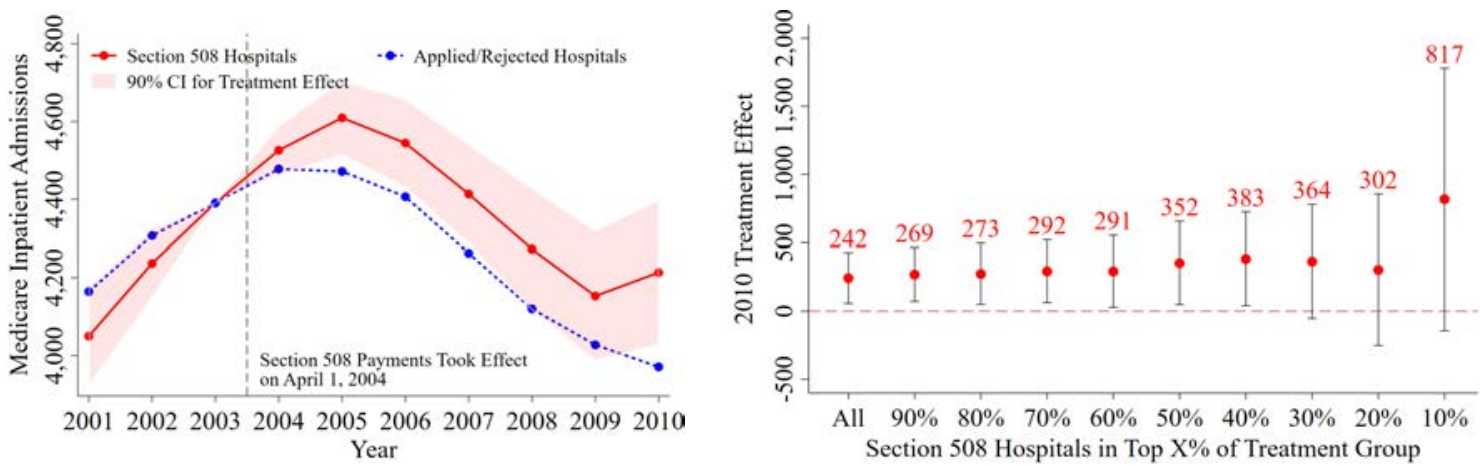

Panel B: Medicare Inpatient PPS Payments (\$ Millions, 2010 Dollars)
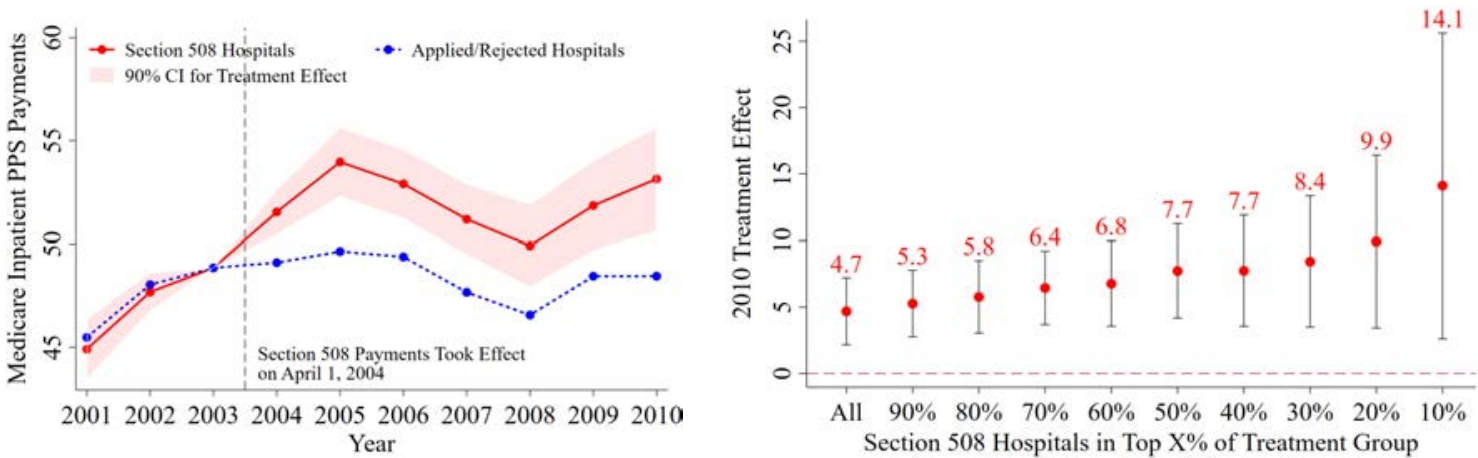

Panel C: Total Facility Payroll Expenses (\$ Millions, 2010 Dollars)
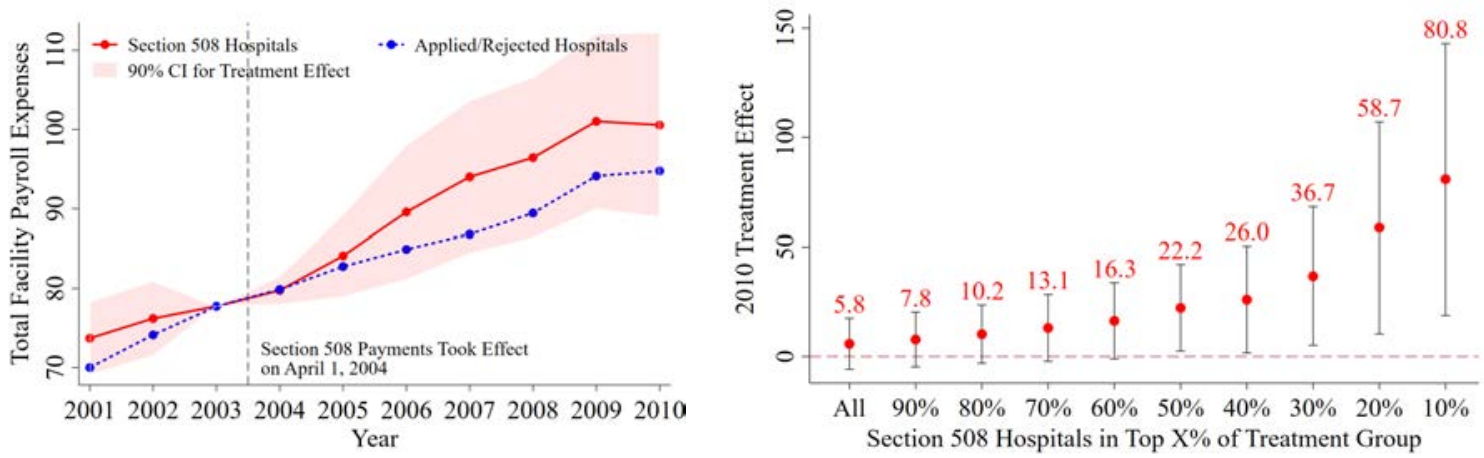

Notes: These panels present estimates of Equation (1) where we regress hospital outcomes on a vector of hospital fixed effects, year dummies, and interactions between the Section 508-recipient hospital indicator and year dummies. 2003 is our omitted year. 90\% confidence intervals are based on wild-bootstrapped standard errors clustered around hospitals. Control hospitals include those that applied for the Section 508 waiver but were rejected. The rightmost figures plot the coefficient of the 2010 interaction term from Equation (1) as we vary the definition of the treatment group. Moving left to right in each figure, each specification involves a treated group composed of hospitals that received increasingly large gains in total IPPS payments (based on quantities in 2003 and actual and counterfactual payment rates in 2005) due to the Section 508 program. We limit our sample to hospitals that were registered with the AHA and not classified as a Critical Access Hospital for at least 1 year before and after the Section 508 program took effect in 2004. Medicare inpatient admissions and PPS payments are from the RAND Medicare Cost Reports (HCRIS) data. Payroll expenses, full-time personnel, and technology counts are derived from the American Hospital Association's Annual Survey data. 


\section{Figure A.2: The Impact of Section 508 Waivers on Hospitals' Inpatient Medicare Admissions, Inpatient Medicare Spending, Payroll, Personnel, and Technology Adoption (Unbalanced Panel) [Contd.]}

\section{Panel D: Full-Time Total Personnel}
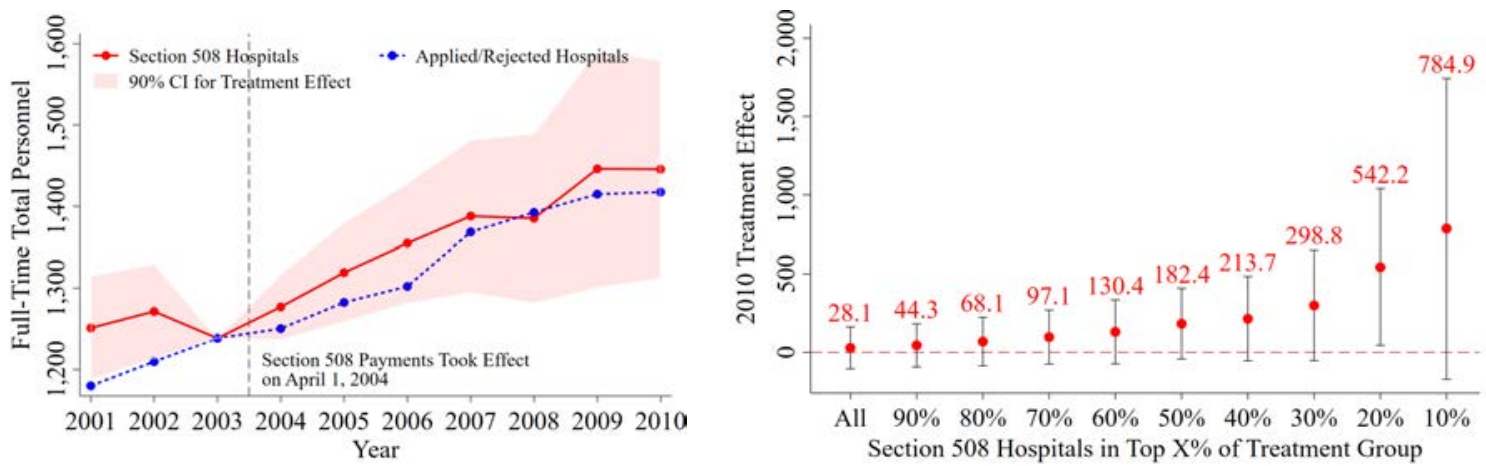

Panel E: Number of Technologies
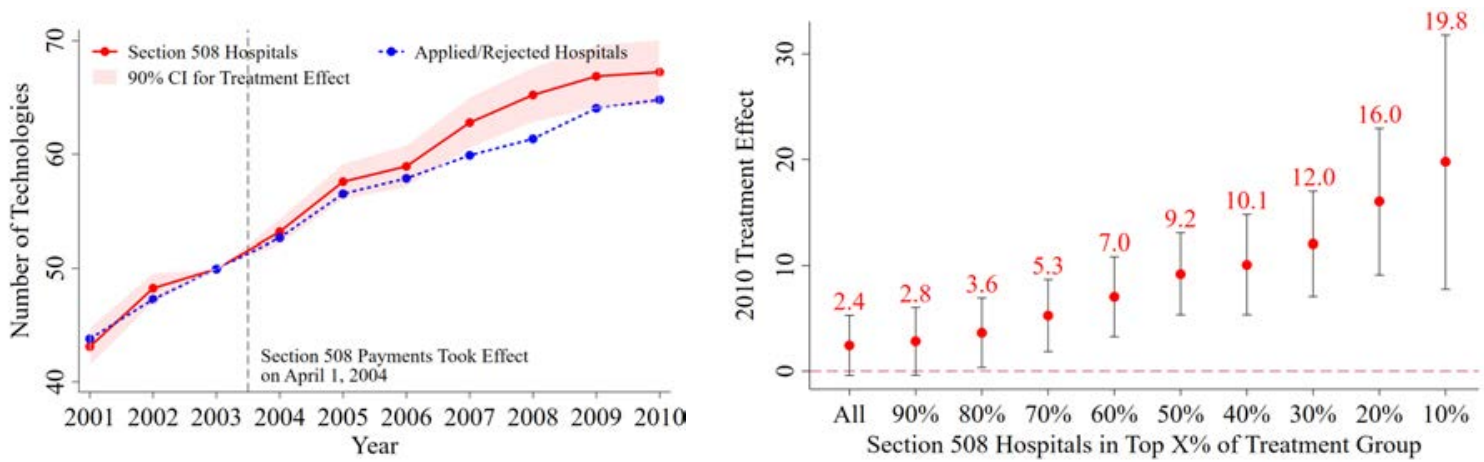

Notes: These panels present estimates of Equation (1) where we regress hospital outcomes on a vector of hospital fixed effects, year dummies, and interactions between the Section 508-recipient hospital indicator and year dummies. 2003 is our omitted year. 90\% confidence intervals are based on wild-bootstrapped standard errors clustered around hospitals. Control hospitals include those that applied for the Section 508 waiver but were rejected. The rightmost figures plot the coefficient of the 2010 interaction term from Equation (1) as we vary the definition of the treatment group. Moving left to right in each figure, each specification involves a treated group composed of hospitals that received increasingly large gains in total IPPS payments (based on quantities in 2003 and actual and counterfactual payment rates in 2005) due to the Section 508 program. We limit our sample to hospitals that were registered with the AHA and not classified as a Critical Access Hospital for at least 1 year before and after the Section 508 program took effect in 2004. Medicare inpatient admissions and PPS payments are from the RAND Medicare Cost Reports (HCRIS) data. Payroll expenses, full-time personnel, and technology counts are derived from the American Hospital Association's Annual Survey data. 


\section{Figure A.3: The Impact of Section 508 Waivers on Hospitals' Inpatient Medicare Admissions, Inpatient Medicare Spending, Payroll, Personnel, and Technology Adoption (Control: Eligible But Didn’t Apply)}

\section{Panel A: Medicare Inpatient Admissions}
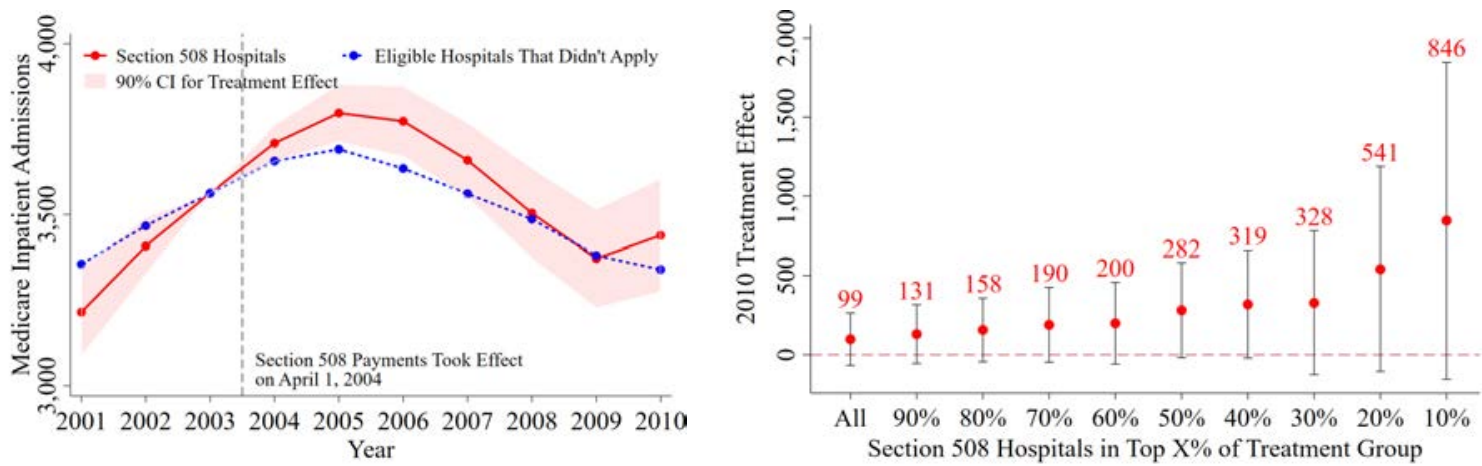

Panel B: Medicare Inpatient PPS Payments (\$ Millions, 2010 Dollars)
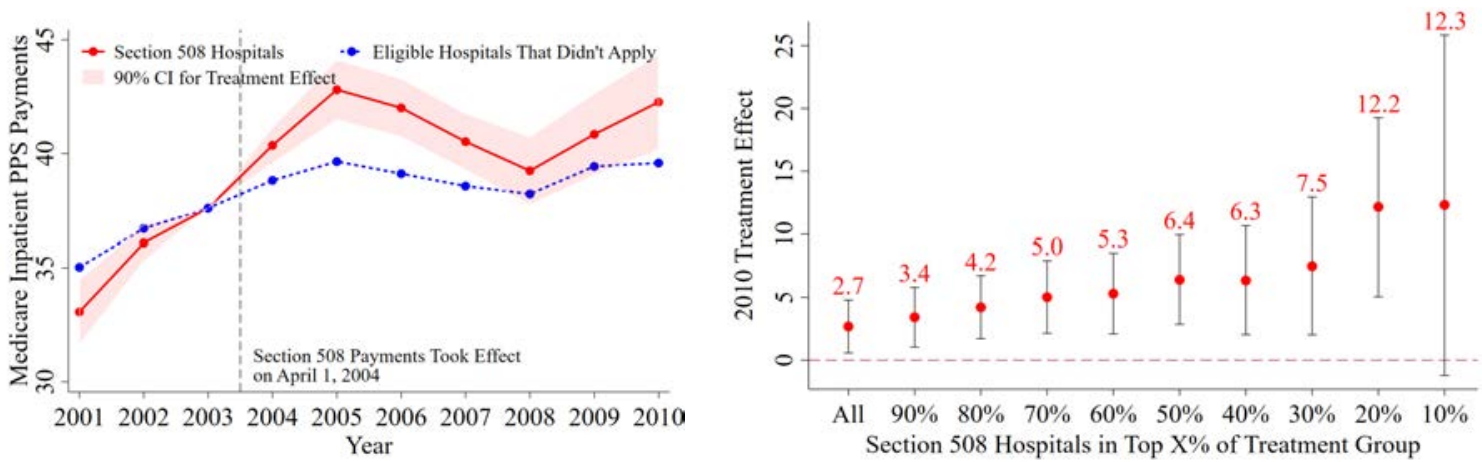

Panel C: Total Facility Payroll Expenses (\$ Millions, 2010 Dollars)
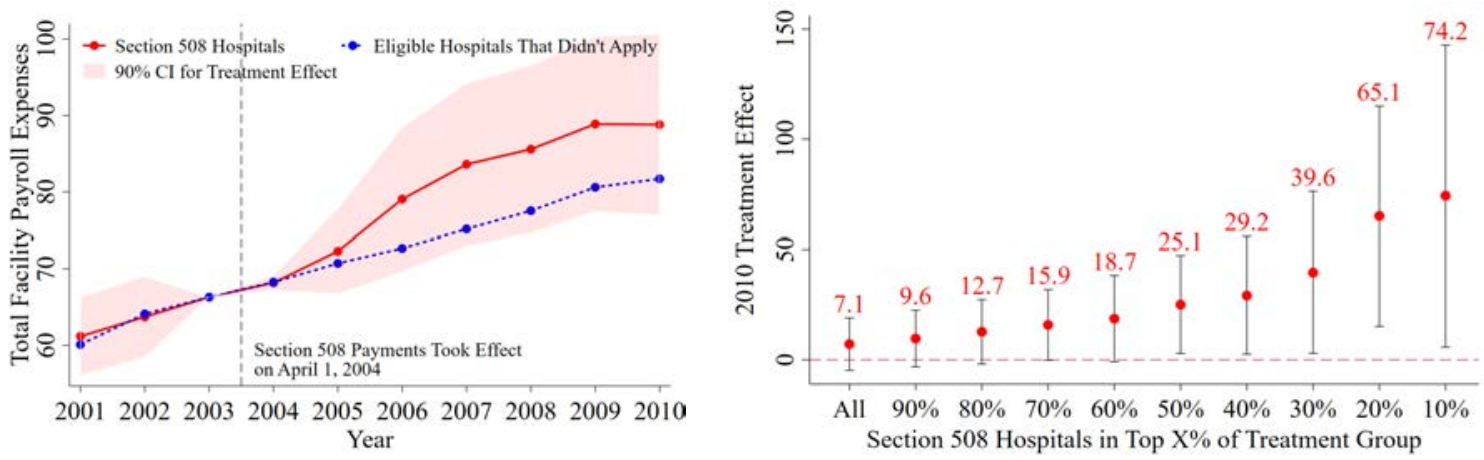

Notes: These panels present estimates of Equation (1) where we regress hospital outcomes on a vector of hospital fixed effects, year dummies, and interactions between the Section 508-recipient hospital indicator and year dummies. 2003 is our omitted year. $90 \%$ confidence intervals are based on wild-bootstrapped standard errors clustered around hospitals. Control hospitals include those that were eligible for a 508 waiver but did not apply. The rightmost figures plot the coefficient of the 2010 interaction term from Equation (1) as we vary the definition of the treatment group. Moving left to right in each figure, each specification involves a treated group composed of hospitals that received increasingly large gains in total IPPS payments (based on quantities in 2003 and actual and counterfactual payment rates in 2005) due to the Section 508 program. Medicare inpatient admissions and PPS payments are from the RAND Medicare Cost Reports (HCRIS) data. Payroll expenses, full-time personnel, and technology counts are derived from the American Hospital Association's Annual Survey data. 


\section{Figure A.3: The Impact of Section 508 Waivers on Hospitals' Inpatient Medicare Admissions, Inpatient Medicare Spending, Payroll, Personnel, and Technology Adoption (Control: Eligible But Didn't Apply) [Contd.]}

\section{Panel D: Full-Time Total Personnel}
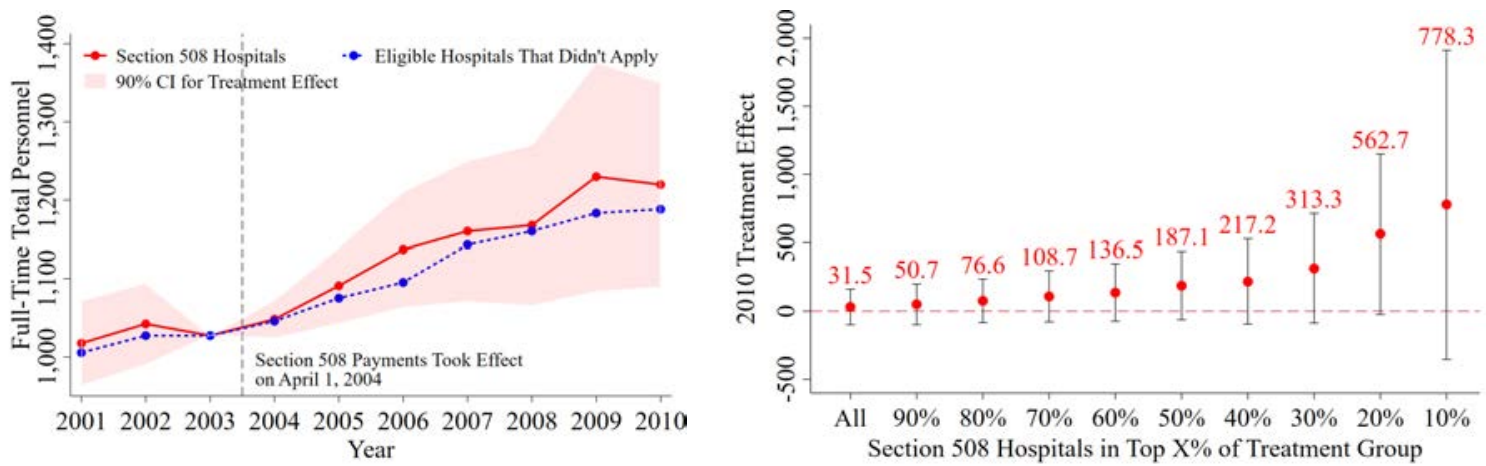

Panel E: Number of Technologies
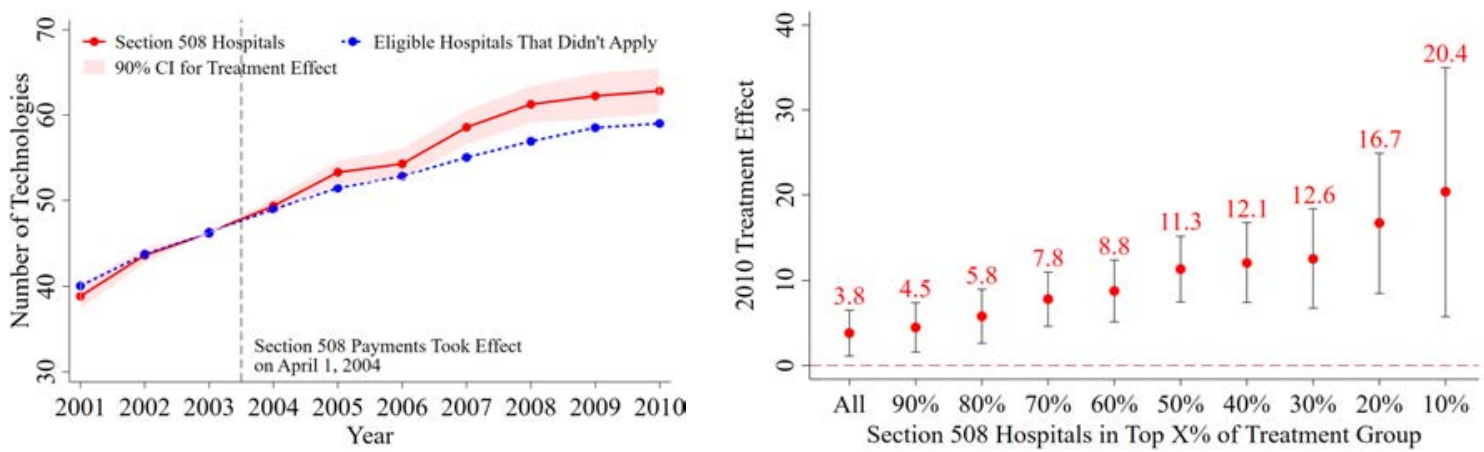

Notes: These panels present estimates of Equation (1) where we regress hospital outcomes on a vector of hospital fixed effects, year dummies, and interactions between the Section 508-recipient hospital indicator and year dummies. 2003 is our omitted year. 90\% confidence intervals are based on wild-bootstrapped standard errors clustered around hospitals. Control hospitals include those that were eligible for a 508 waiver but did not apply. The rightmost figures plot the coefficient of the 2010 interaction term from Equation (1) as we vary the definition of the treatment group. Moving left to right in each figure, each specification involves a treated group composed of hospitals that received increasingly large gains in total IPPS payments (based on quantities in 2003 and actual and counterfactual payment rates in 2005) due to the Section 508 program. Medicare inpatient admissions and PPS payments are from the RAND Medicare Cost Reports (HCRIS) data. Payroll expenses, full-time personnel, and technology counts are derived from the American Hospital Association's Annual Survey data. 


\section{Figure A.4: The Impact of Section 508 Waivers on Hospitals' Inpatient Medicare Admissions, Inpatient Medicare Spending, Payroll, Personnel, and Technology Adoption (Control: Ineligible)}

\section{Panel A: Medicare Inpatient Admissions}
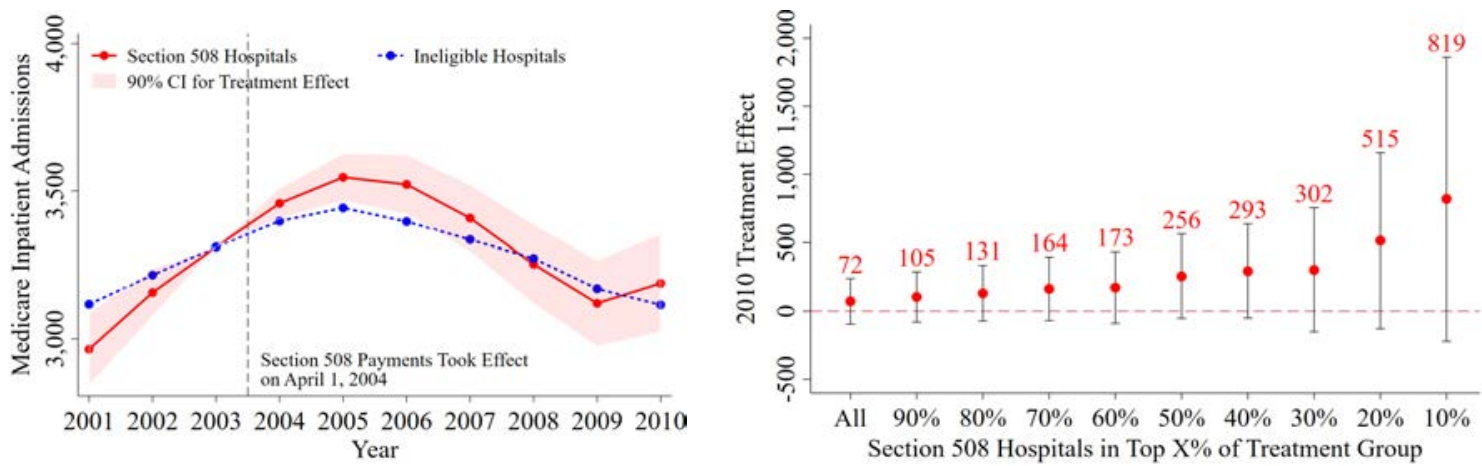

Panel B: Medicare Inpatient PPS Payments (\$ Millions, 2010 Dollars)
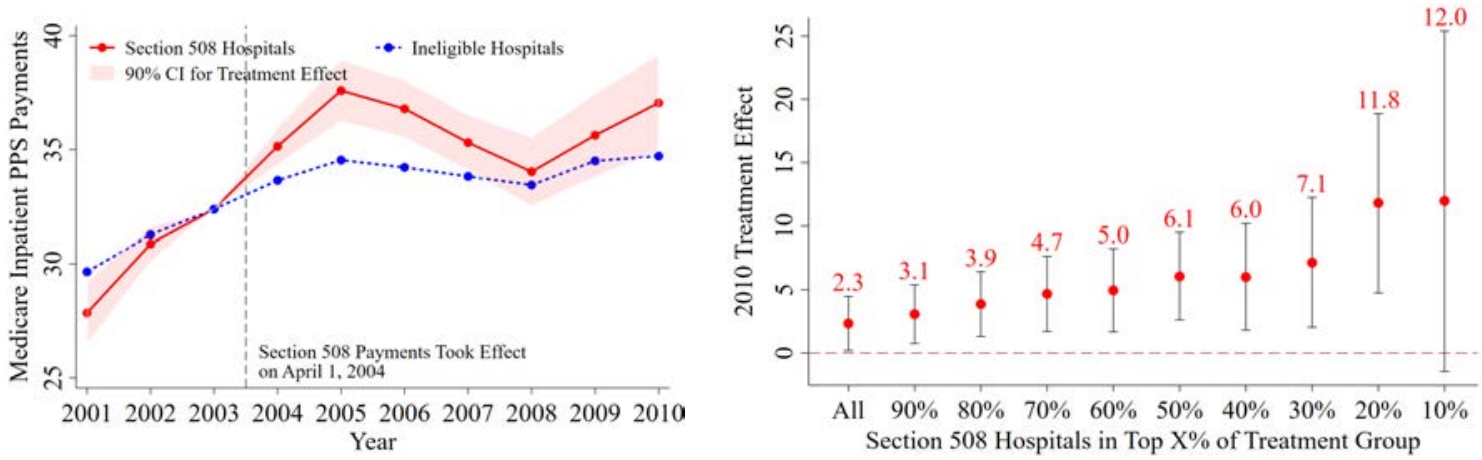

Panel C: Total Facility Payroll Expenses (\$ Millions, 2010 Dollars)
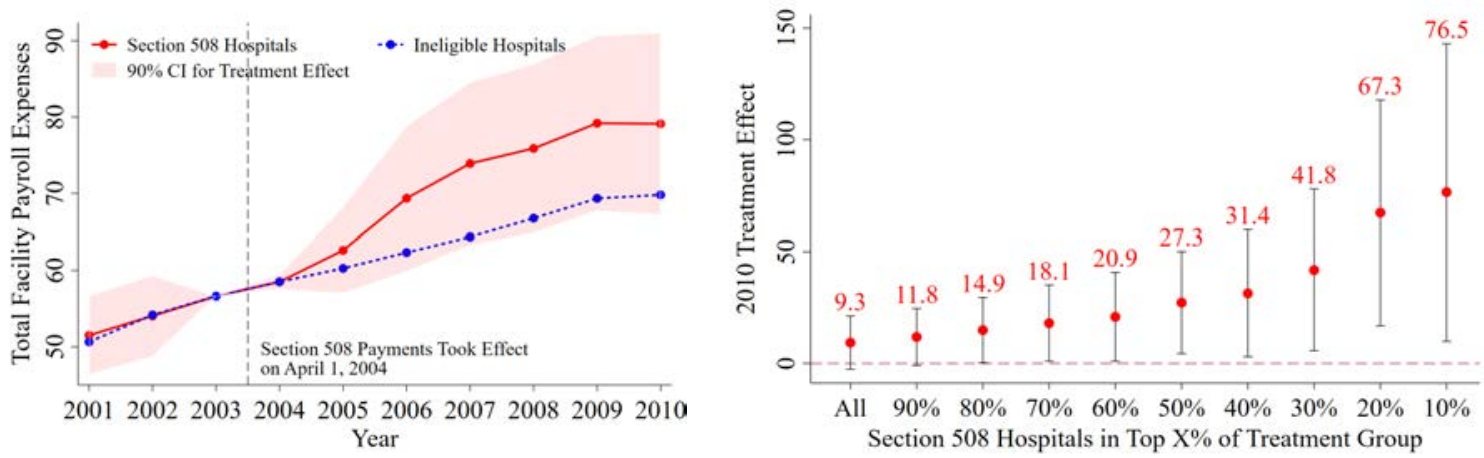

Notes: These panels present estimates of Equation (1) where we regress hospital outcomes on a vector of hospital fixed effects, year dummies, and interactions between the Section 508-recipient hospital indicator and year dummies. 2003 is our omitted year. $90 \%$ confidence intervals are based on wild-bootstrapped standard errors clustered around hospitals. Control hospitals include those that were not eligible for the Section 508 waiver. The rightmost figures plot the coefficient of the 2010 interaction term from Equation (1) as we vary the definition of the treatment group. Moving left to right in each figure, each specification involves a treated group composed of hospitals that received increasingly large gains in total IPPS payments (based on quantities in 2003 and actual and counterfactual payment rates in 2005) due to the Section 508 program. Medicare inpatient admissions and PPS payments are from the RAND Medicare Cost Reports (HCRIS) data. Payroll expenses, full-time personnel, and technology counts are derived from the American Hospital Association's Annual Survey data. 


\section{Figure A.4: The Impact of Section 508 Waivers on Hospitals' Inpatient Medicare Admissions, Inpatient Medicare Spending, Payroll, Personnel, and Technology Adoption (Control: Ineligible) [Contd.]}

\section{Panel D: Full-Time Total Personnel}
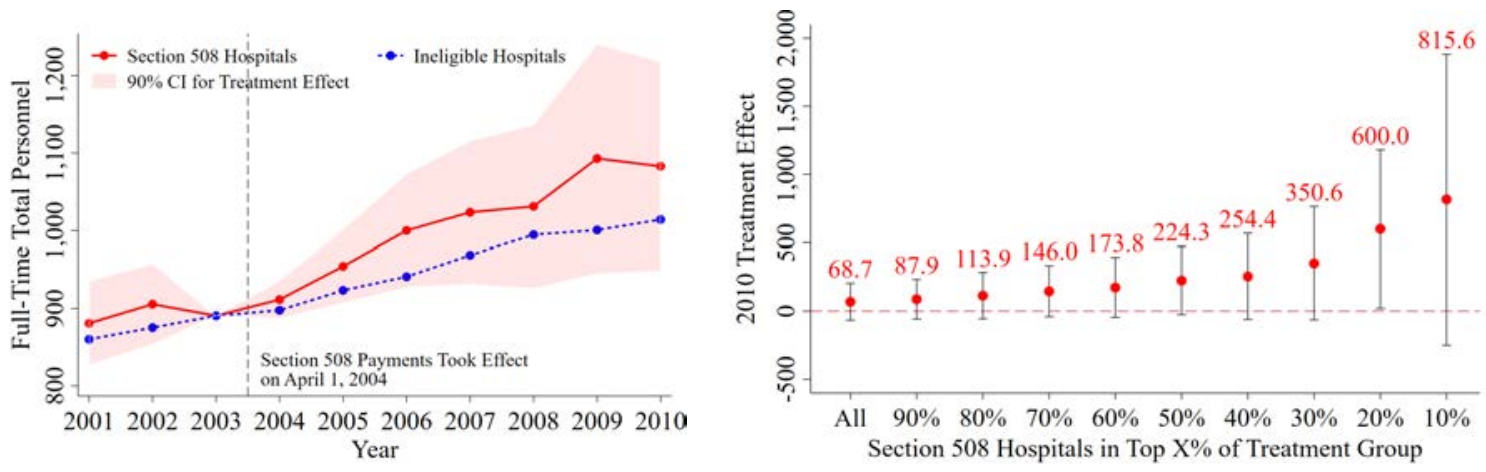

Panel E: Number of Technologies
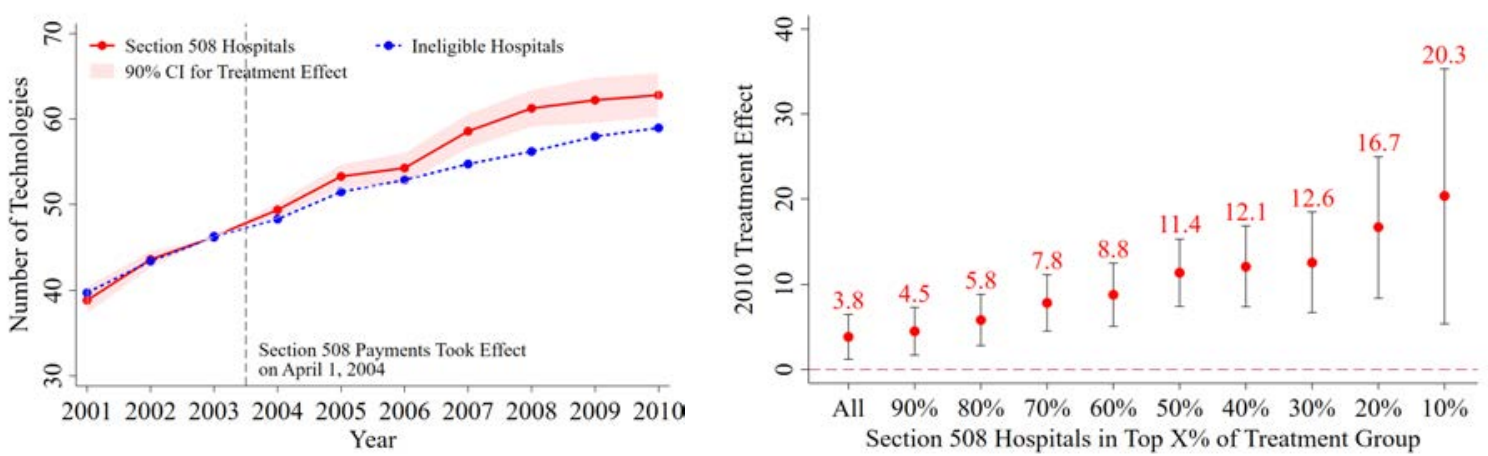

Notes: These panels present estimates of Equation (1) where we regress hospital outcomes on a vector of hospital fixed effects, year dummies, and interactions between the Section 508-recipient hospital indicator and year dummies. 2003 is our omitted year. 90\% confidence intervals are based on wild-bootstrapped standard errors clustered around hospitals. Control hospitals include those that were not eligible for the Section 508 waiver. The rightmost figures plot the coefficient of the 2010 interaction term from Equation (1) as we vary the definition of the treatment group. Moving left to right in each figure, each specification involves a treated group composed of hospitals that received increasingly large gains in total IPPS payments (based on quantities in 2003 and actual and counterfactual payment rates in 2005) due to the Section 508 program. Medicare inpatient admissions and PPS payments are from the RAND Medicare Cost Reports (HCRIS) data. Payroll expenses, full-time personnel, and technology counts are derived from the American Hospital Association's Annual Survey data. 


\section{Figure A.5: The Impact of Section 508 Waivers on Hospitals' Inpatient Medicare Admissions, Inpatient Medicare Spending, Payroll, Personnel, and Technology Adoption (Control: All Non-508 Recipients)}

Panel A: Medicare Inpatient Admissions
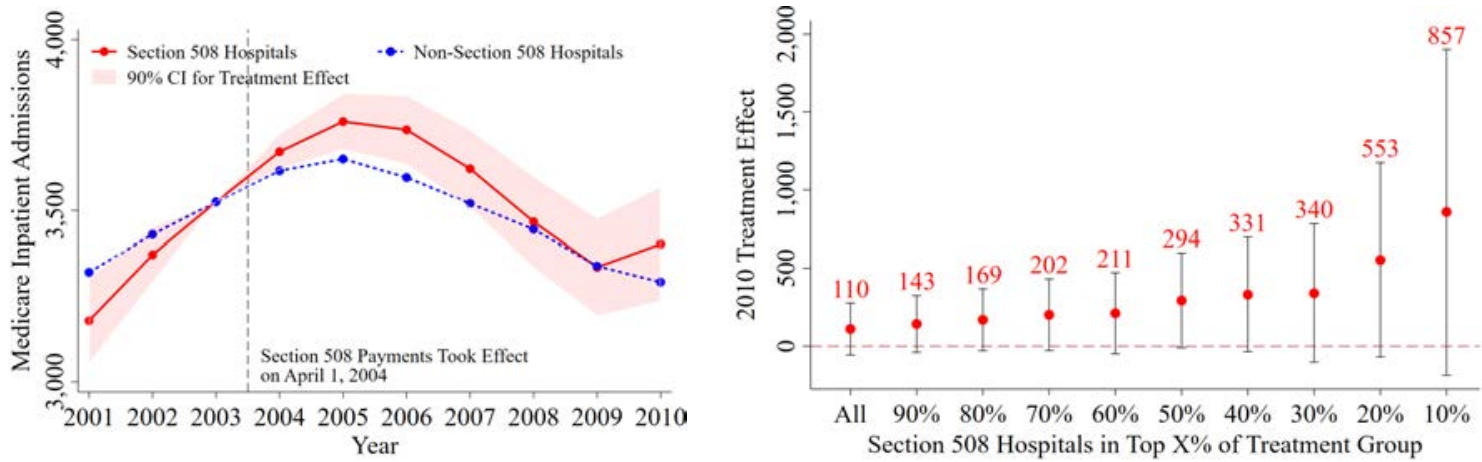

Panel B: Medicare Inpatient PPS Payments (\$ Millions, 2010 Dollars)
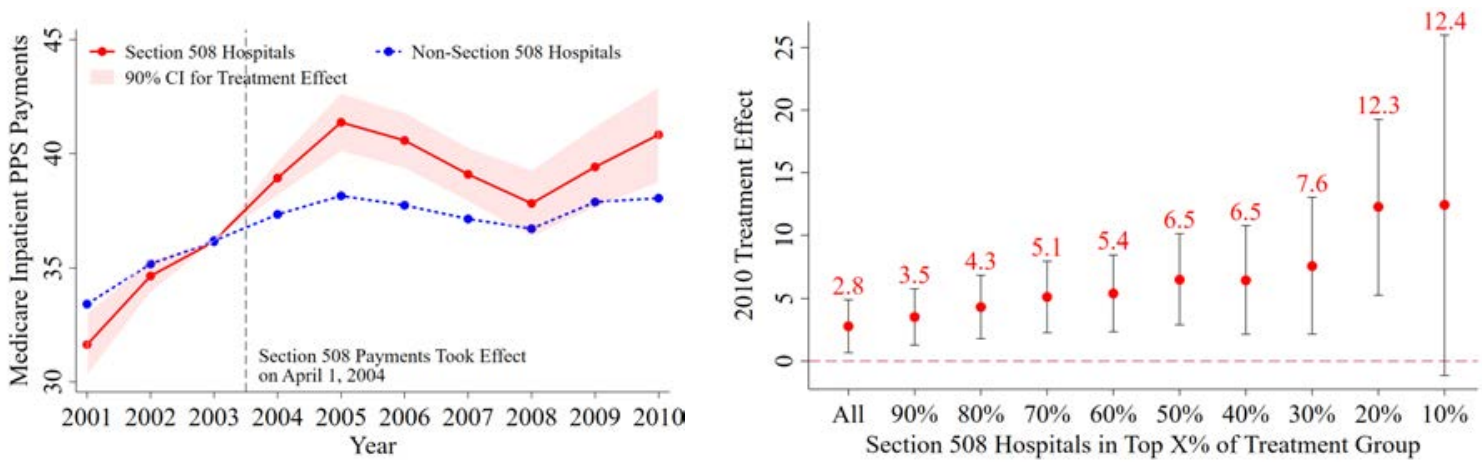

Panel C: Total Facility Payroll Expenses (\$ Millions, 2010 Dollars)
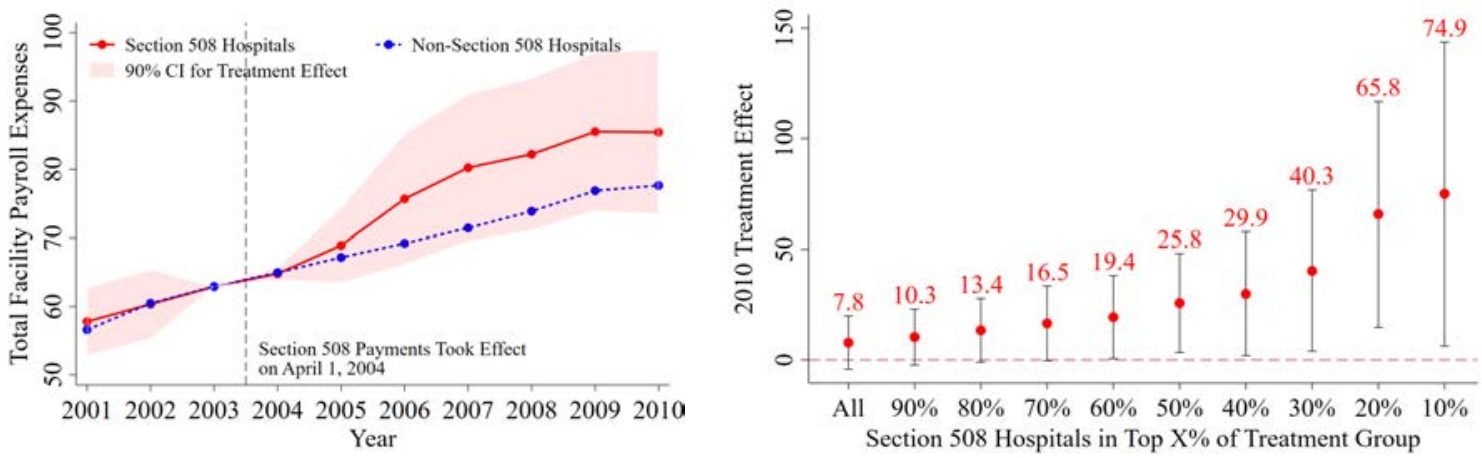

Notes: These panels present estimates of Equation (1) where we regress hospital outcomes on a vector of hospital fixed effects, year dummies, and interactions between the Section 508-recipient hospital indicator and year dummies. 2003 is our omitted year. $90 \%$ confidence intervals are based on wild-bootstrapped standard errors clustered around hospitals. Control hospitals include all hospitals that did not receive a 508 waiver. The rightmost figures plot the coefficient of the 2010 interaction term from Equation (1) as we vary the definition of the treatment group. Moving left to right in each figure, each specification involves a treated group composed of hospitals that received increasingly large gains in total IPPS payments (based on quantities in 2003 and actual and counterfactual payment rates in 2005) due to the Section 508 program. Medicare inpatient admissions and PPS payments are from the RAND Medicare Cost Reports (HCRIS) data. Payroll expenses, full-time personnel, and technology counts are derived from the American Hospital Association's Annual Survey data. 


\section{Figure A.5: The Impact of Section 508 Waivers on Hospitals' Inpatient Medicare Admissions, Inpatient Medicare Spending, Payroll, Personnel, and Technology Adoption (Control: All Non-508 Recipients) [Contd.]}

\section{Panel D: Full-Time Total Personnel}
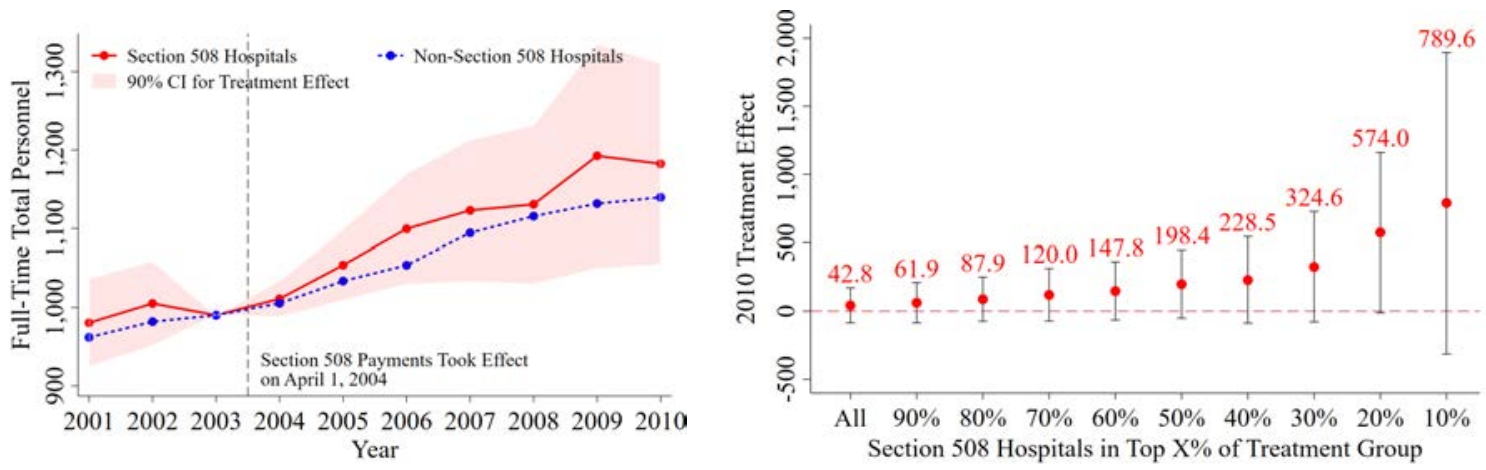

Panel E: Number of Technologies
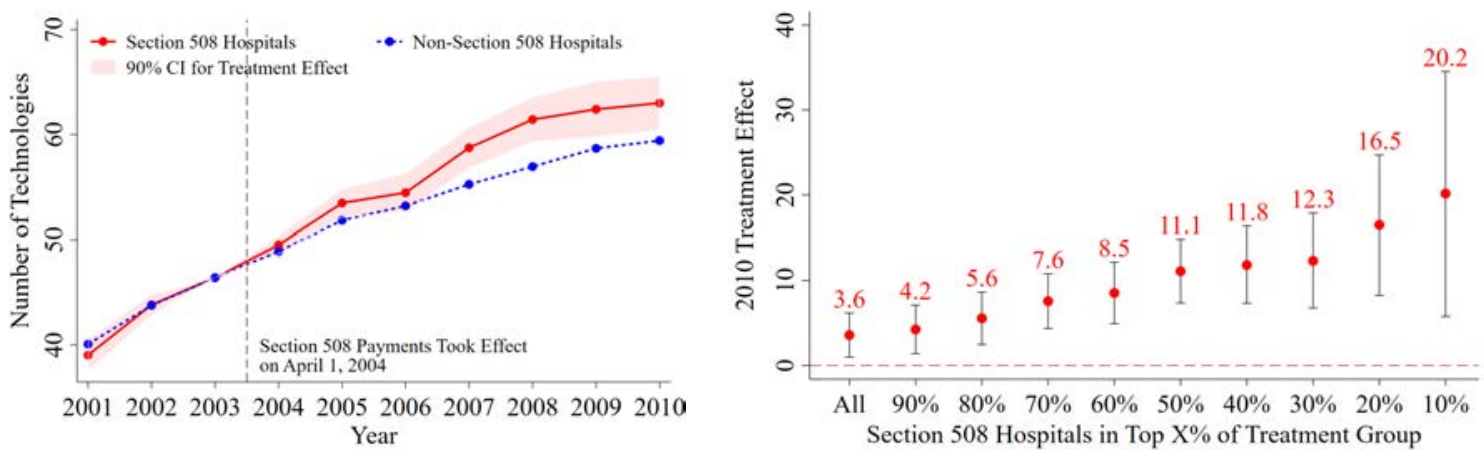

Notes: These panels present estimates of Equation (1) where we regress hospital outcomes on a vector of hospital fixed effects, year dummies, and interactions between the Section 508-recipient hospital indicator and year dummies. 2003 is our omitted year. 90\% confidence intervals are based on wild-bootstrapped standard errors clustered around hospitals. Control hospitals include all hospitals that did not receive a 508 waiver. The rightmost figures plot the coefficient of the 2010 interaction term from Equation (1) as we vary the definition of the treatment group. Moving left to right in each figure, each specification involves a treated group composed of hospitals that received increasingly large gains in total IPPS payments (based on quantities in 2003 and actual and counterfactual payment rates in 2005) due to the Section 508 program. Medicare inpatient admissions and PPS payments are from the RAND Medicare Cost Reports (HCRIS) data. Payroll expenses, full-time personnel, and technology counts are derived from the American Hospital Association's Annual Survey data. 


\section{Figure A.6: The Impact of Section 508 Waivers on Hospitals' Inpatient Medicare Admissions, Inpatient Medicare Spending, Payroll, Personnel, and Technology Adoption (Control: Propensity Score Matched Hospitals)}

Panel A: Medicare Inpatient Admissions
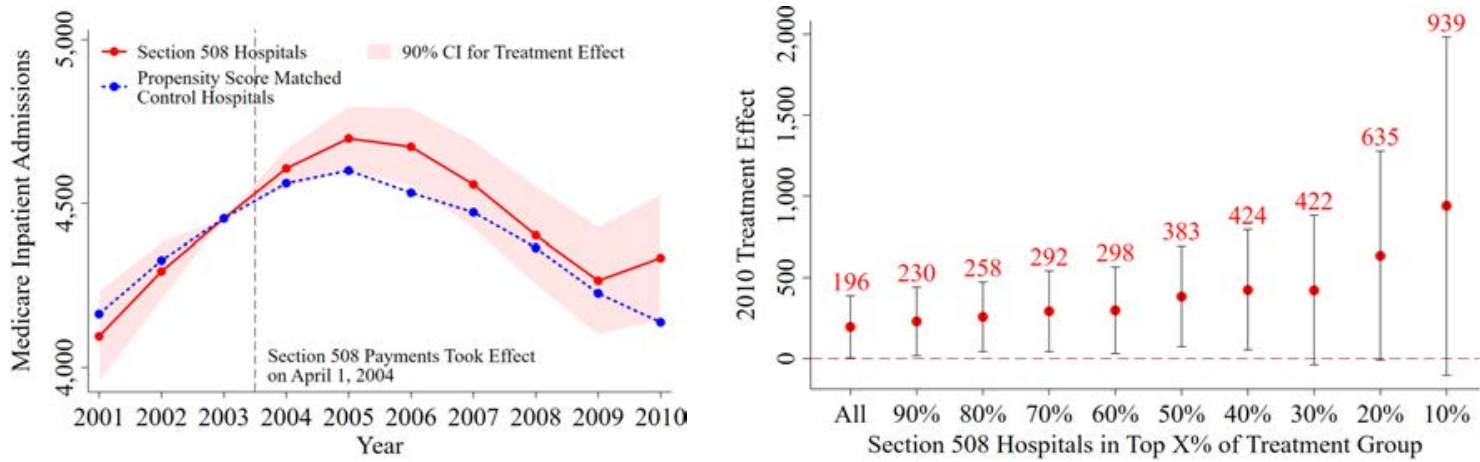

Panel B: Medicare Inpatient PPS Payments (\$ Millions, 2010 Dollars)
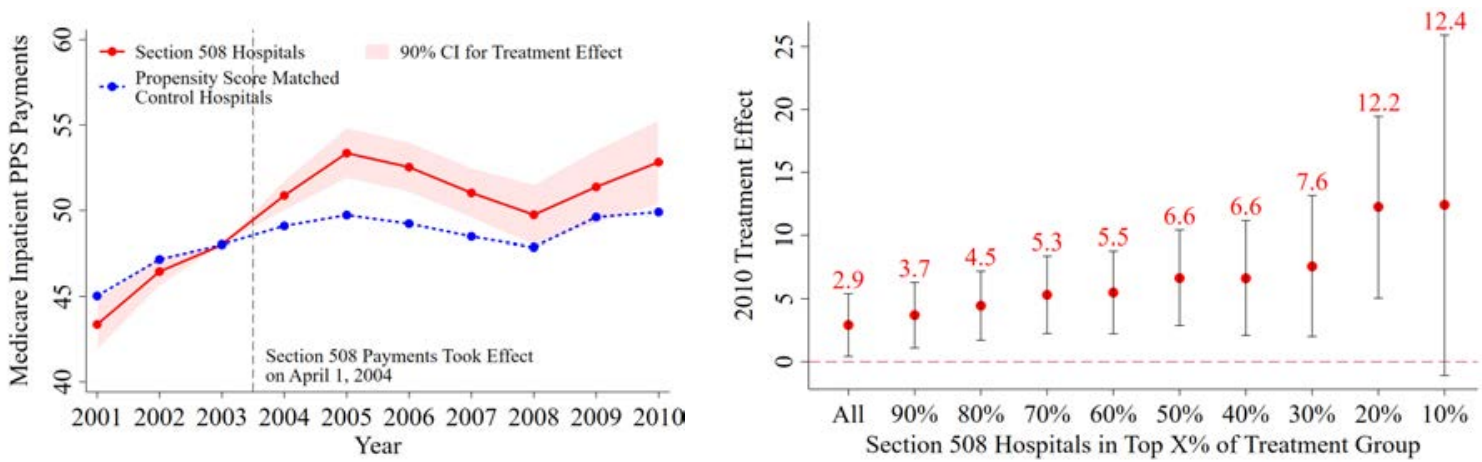

Panel C: Total Facility Payroll Expenses (\$ Millions, 2010 Dollars)
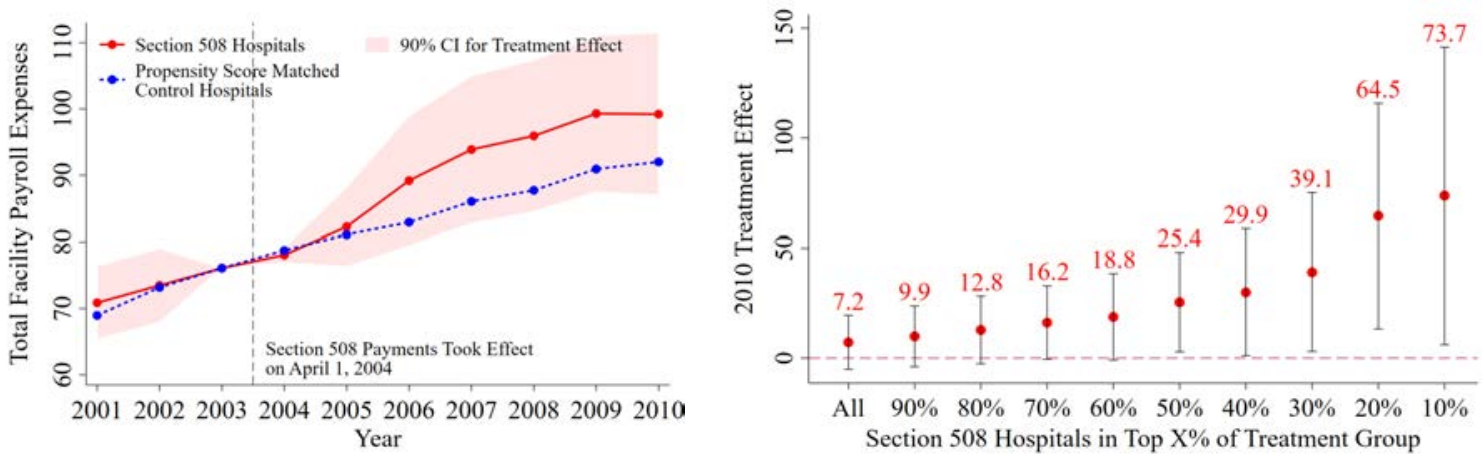

Notes: These panels present estimates of Equation (1) where we regress hospital outcomes on a vector of hospital fixed effects, year dummies, and interactions between the Section 508-recipient hospital indicator and year dummies. 2003 is our omitted year. $90 \%$ confidence intervals are based on wild-bootstrapped standard errors clustered around hospitals. Control hospitals include the 10 nearest neighbors according to the probit model of propensity score matching. The rightmost figures plot the coefficient of the 2010 interaction term from Equation (1) as we vary the definition of the treatment group. Moving left to right in each figure, each specification involves a treated group composed of hospitals that received increasingly large gains in total IPPS payments (based on quantities in 2003 and actual and counterfactual payment rates in 2005) due to the Section 508 program. Medicare inpatient admissions and PPS payments are from the RAND Medicare Cost Reports (HCRIS) data. Payroll expenses, full-time personnel, and technology counts are derived from the American Hospital Association's Annual Survey data. 


\section{Figure A.6: The Impact of Section 508 Waivers on Hospitals' Inpatient Medicare Admissions, Inpatient Medicare Spending, Payroll, Personnel, and Technology Adoption (Control: Propensity Score Matched Hospitals) [Contd.]}

\section{Panel D: Full-Time Total Personnel}
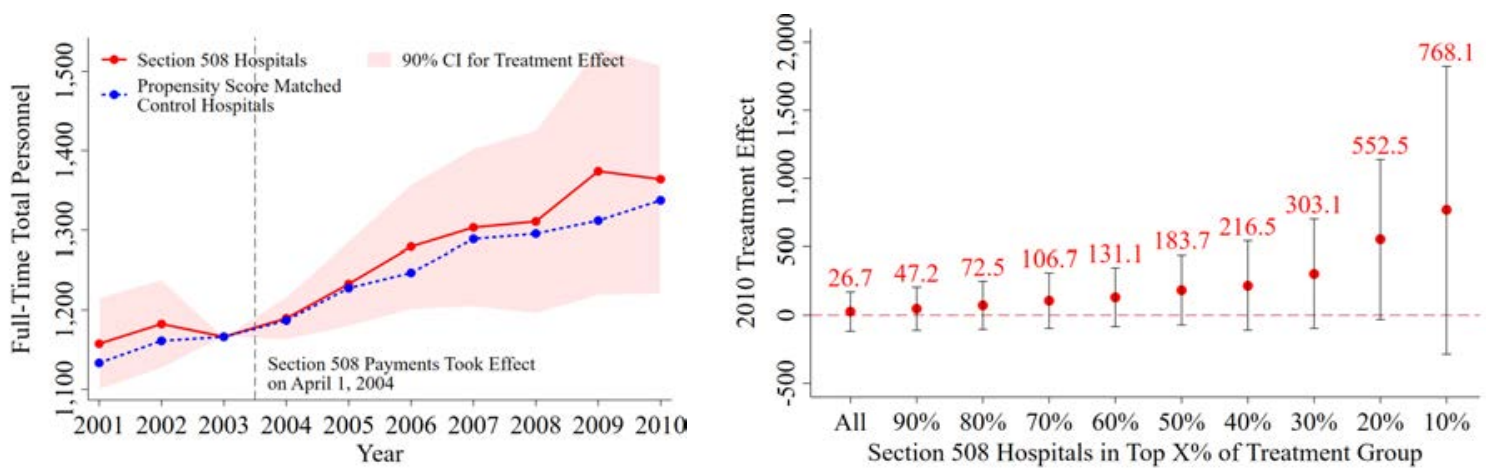

Panel E: Number of Technologies
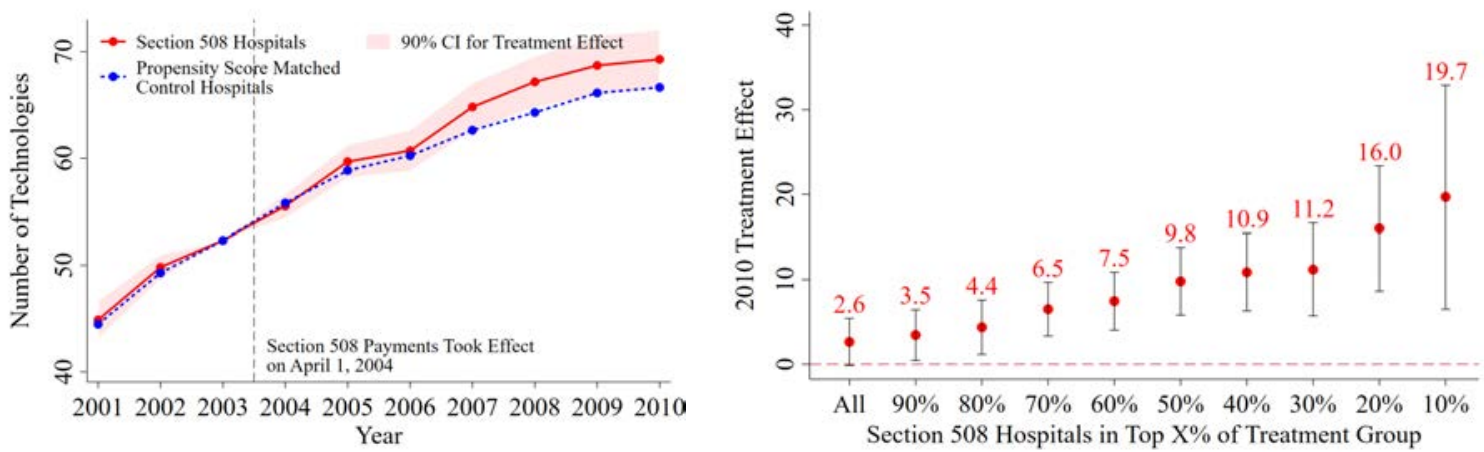

Notes: These panels present estimates of Equation (1) where we regress hospital outcomes on a vector of hospital fixed effects, year dummies, and interactions between the Section 508-recipient hospital indicator and year dummies. 2003 is our omitted year. 90\% confidence intervals are based on wild-bootstrapped standard errors clustered around hospitals. Control hospitals include the 10 nearest neighbors according to the probit model of propensity score matching. The rightmost figures plot the coefficient of the 2010 interaction term from Equation (1) as we vary the definition of the treatment group. Moving left to right in each figure, each specification involves a treated group composed of hospitals that received increasingly large gains in total IPPS payments (based on quantities in 2003 and actual and counterfactual payment rates in 2005) due to the Section 508 program. Medicare inpatient admissions and PPS payments are from the RAND Medicare Cost Reports (HCRIS) data. Payroll expenses, full-time personnel, and technology counts are derived from the American Hospital Association's Annual Survey data. 


\section{Figure A.7: The Impact of the Section 508 Program on Congressional District-Level Hospital Revenue}

\section{Panel A: Total Net Patient Revenue (\$ Millions, 2010 Dollars)}
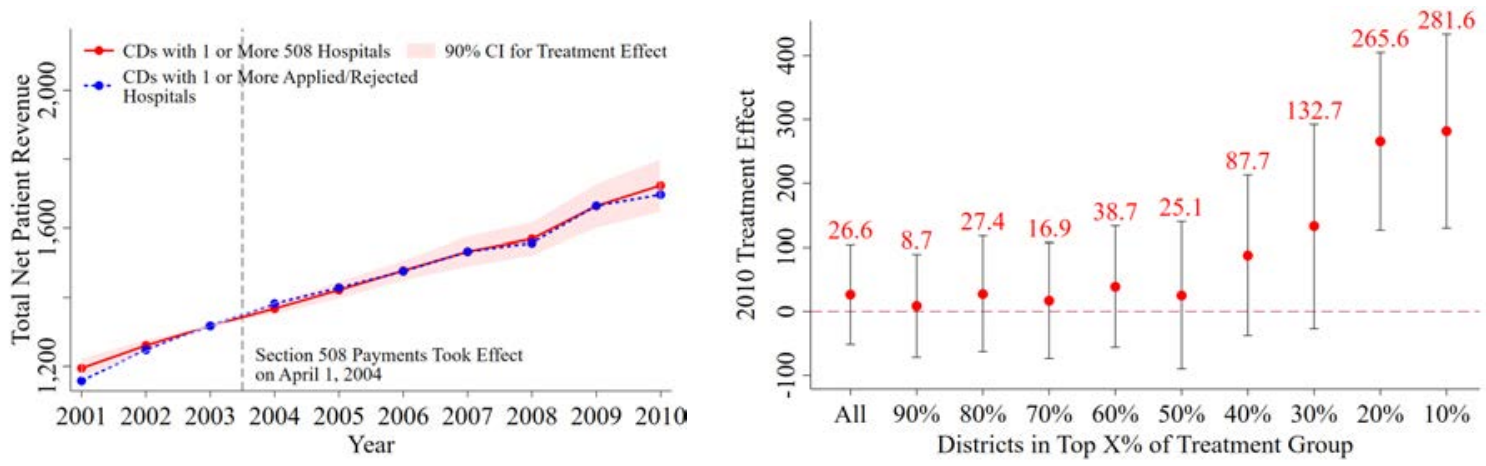

\section{Panel B: Total Net Patient Revenue (\$ Millions, 2010 Dollars), Treated=Top $20 \%$}

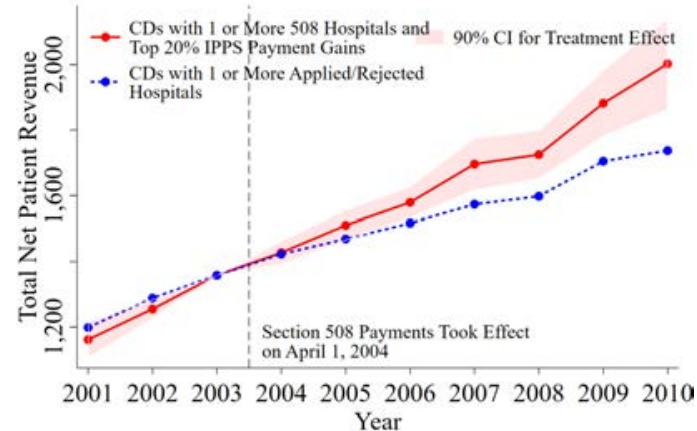

Notes: These figures present estimates of Equation (2) where we regress congressional district outcomes on a vector of congressional district fixed effects, year dummies, and interactions between the treated congressional district indicator and year dummies. 2003 is our omitted year. Control congressional districts are those with one or more hospitals that applied for a Section 508 waiver but were rejected. 90\% confidence intervals are based on wild-bootstrapped standard errors clustered around congressional districts. The rightmost figure in Panel A plots the coefficient of the 2010 interaction term from Equation (2) as we vary the definition of the treatment group. Moving left to right in that figure, each specification involves a treated group composed of congressional districts with increasingly large gains in total IPPS payments (based on quantities in 2003 and actual and counterfactual payment rates in 2005) due to the Section 508 program. We calculate CD-level total net patient revenue by aggregating hospital-level data on "net patient revenue (charges minus contractual allowances and discounts)” from the RAND Medicare Cost Reports (HCRIS) data. 


\section{Figure A.8: The Impact of the Section 508 Program on Congressional District-Level Inpatient Medicare Spending, Hospital Personnel, and Hospital Payroll (Control=Eligible \& Didn't Apply)}

\section{Panel A: Medicare Inpatient PPS Payments (\$ Millions, 2010 Dollars)}
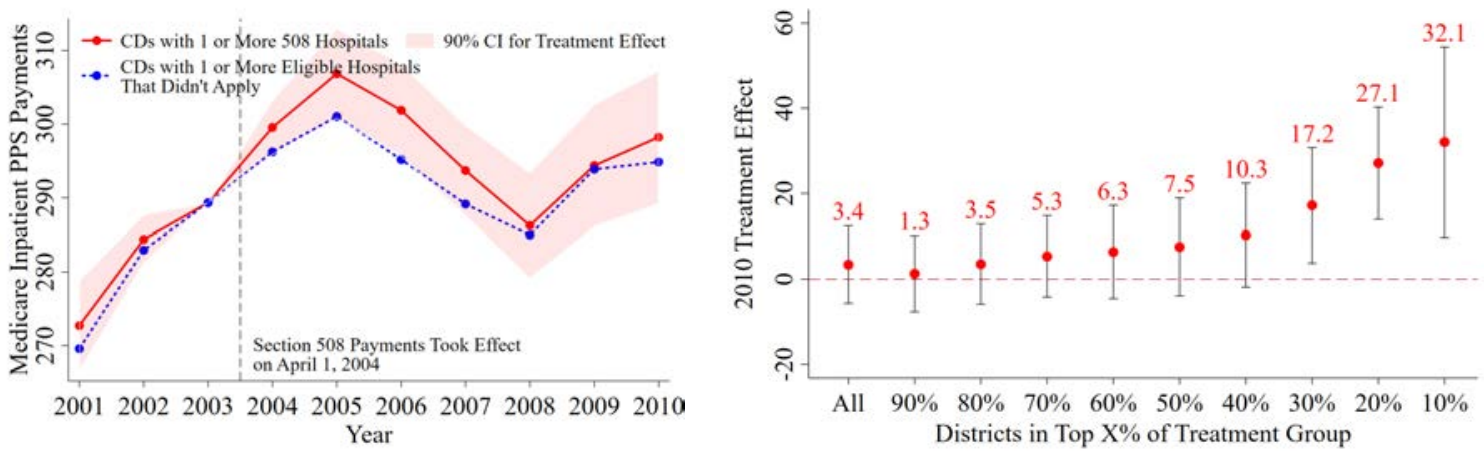

Panel B: Full-Time Total Personnel

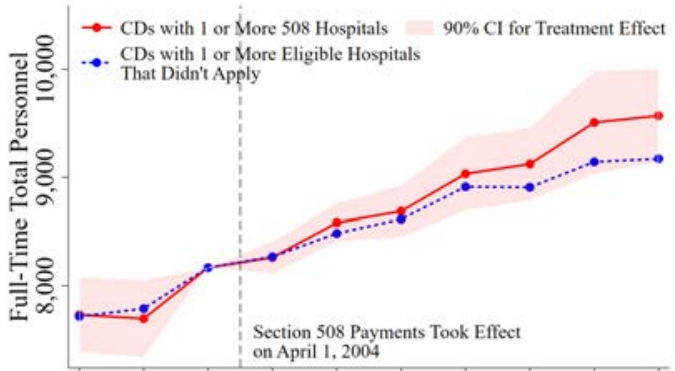

2001200220032004200520062007200820092010 Year

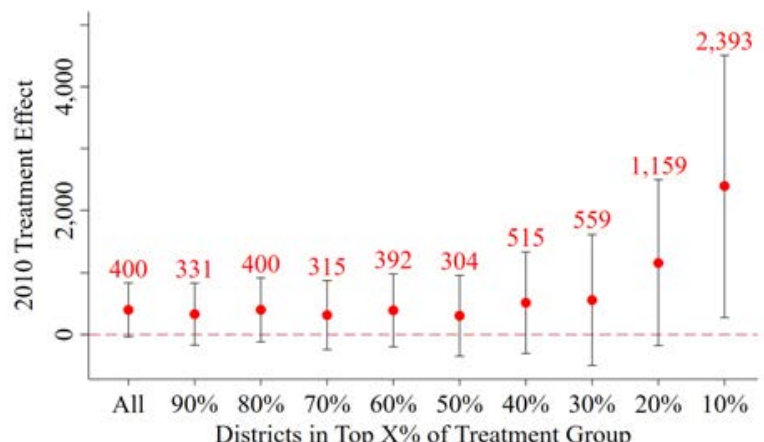

Panel C: Total Facility Payroll Expenses (\$ Millions, 2010 Dollars)
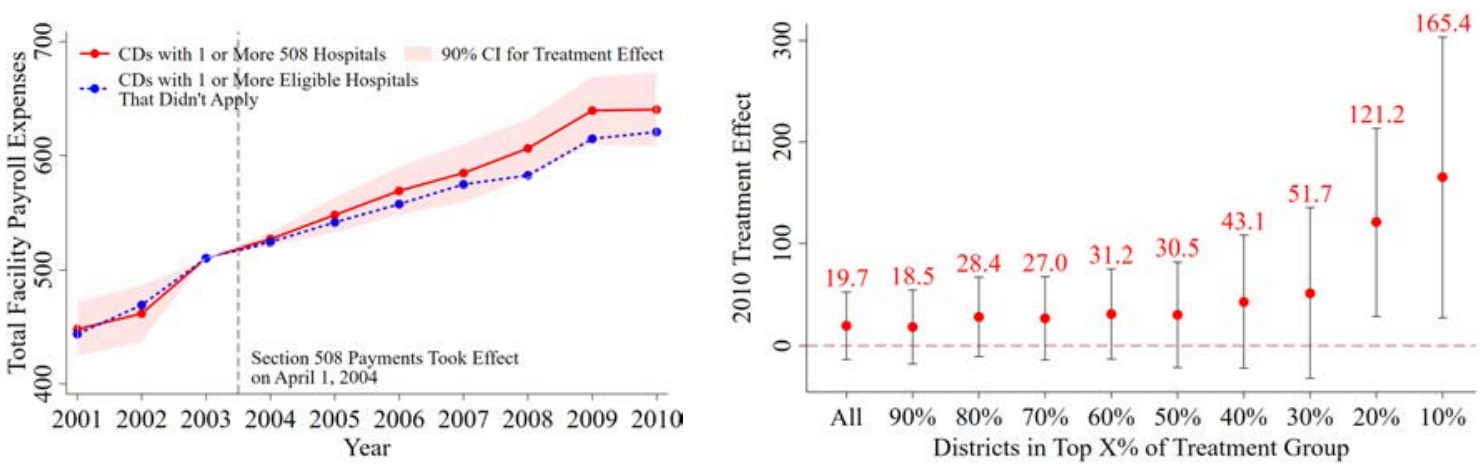

Notes: These figures present estimates of Equation (2) where we regress congressional district outcomes on a vector of congressional district fixed effects, year dummies, and interactions between the treated congressional district indicator and year dummies. 2003 is our omitted year. Control congressional districts are those with at least one hospital that was eligible for a Section 508 waiver but did not apply. 90\% confidence intervals are based on wild-bootstrapped standard errors clustered around congressional districts. The rightmost figures plot the coefficient of the 2010 interaction term from Equation (2) as we vary the definition of the treatment group. Moving left to right in each figure, each specification involves a treated group composed of congressional districts with increasingly large gains in total IPPS payments (based on quantities in 2003 and actual and counterfactual payment rates in 2005) due to the Section 508 program. Medicare inpatient PPS payments are derived from the RAND Medicare Cost Reports (HCRIS) data. Payroll expenses and full-time personnel are derived from the American Hospital Association's Annual Survey data. 


\section{Figure A.9: The Impact of the Section 508 Program on Congressional District-Level Inpatient Medicare Spending, Hospital Personnel, and Hospital Payroll (Control=Ineligible)}

\section{Panel A: Medicare Inpatient PPS Payments (\$ Millions, 2010 Dollars)}
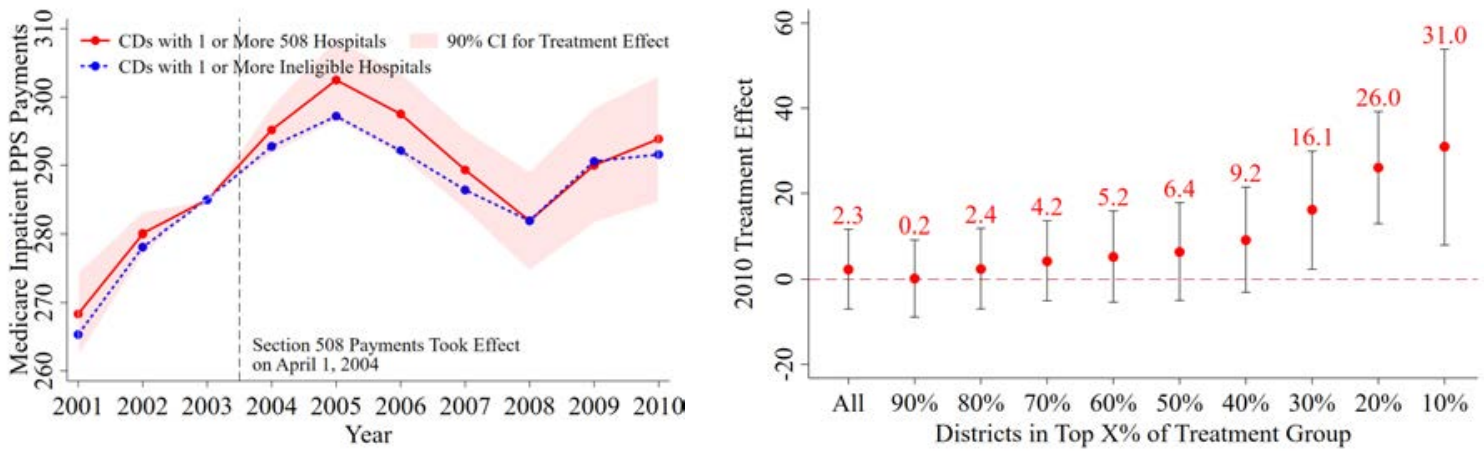

Panel B: Full-Time Total Personnel

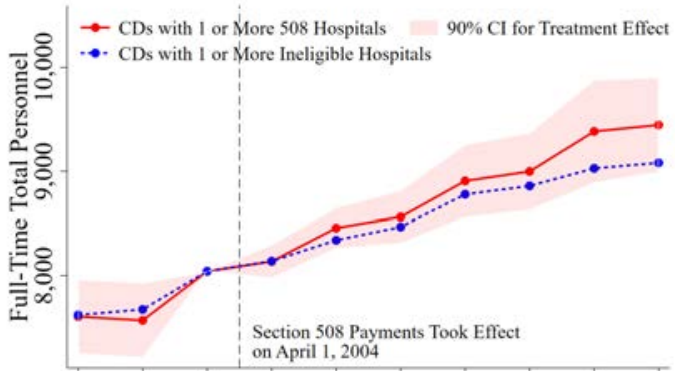

2001200220032004200520062007200820092010 Year

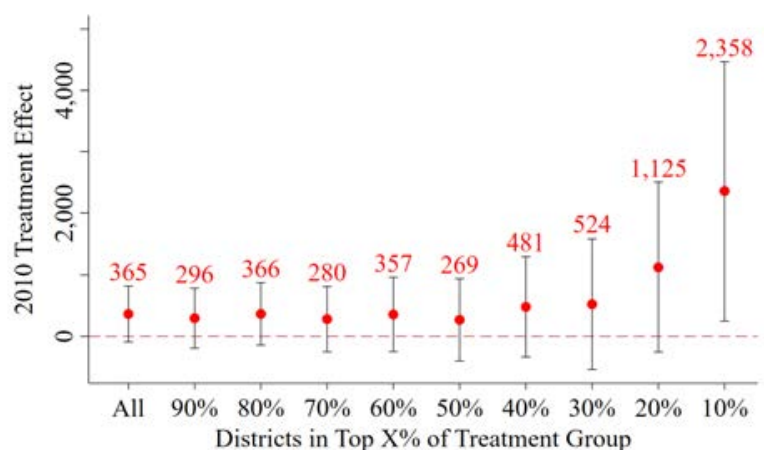

Districts in Top X\% of Treatment Group

Panel C: Total Facility Payroll Expenses (\$ Millions, 2010 Dollars)
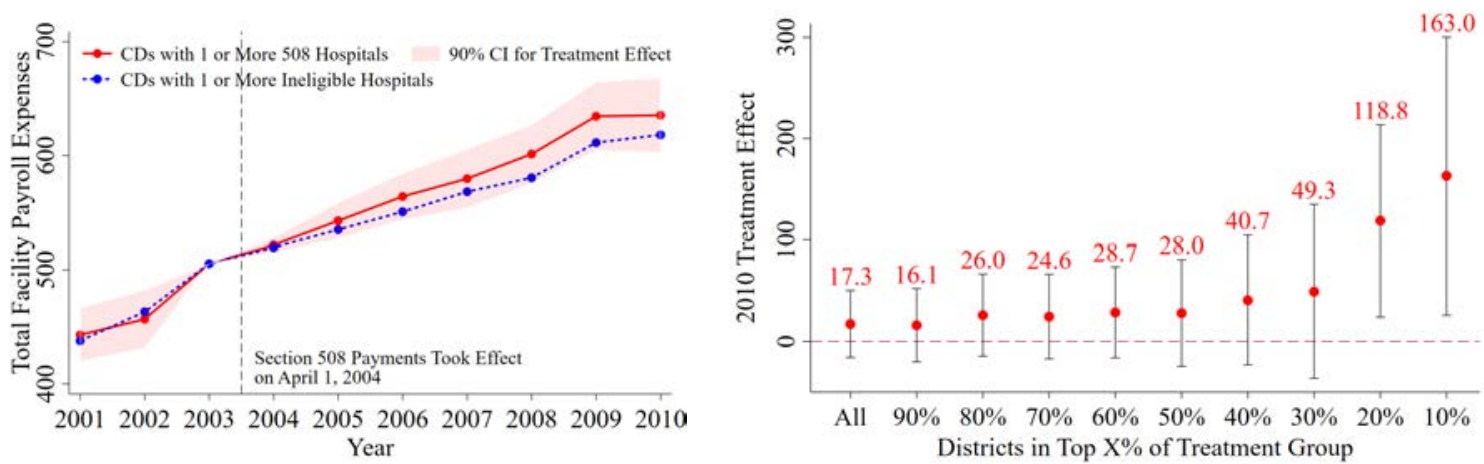

Notes: These figures present estimates of Equation (2) where we regress congressional district outcomes on a vector of congressional district fixed effects, year dummies, and interactions between the treated congressional district indicator and year dummies. 2003 is our omitted year. Control congressional districts are those with at least one hospital that was ineligible for a Section 508 waiver. $90 \%$ confidence intervals are based on wild-bootstrapped standard errors clustered around congressional districts. The rightmost figures plot the coefficient of the 2010 interaction term from Equation (2) as we vary the definition of the treatment group. Moving left to right in each figure, each specification involves a treated group composed of congressional districts with increasingly large gains in total IPPS payments (based on quantities in 2003 and actual and counterfactual payment rates in 2005) due to the Section 508 program. Medicare inpatient PPS payments are derived from the RAND Medicare Cost Reports (HCRIS) data. Payroll expenses and full-time personnel are derived from the American Hospital Association's Annual Survey data. 
Figure A.10: The Impact of the Section 508 Program on Congressional District-Level Inpatient Medicare Spending, Hospital Personnel, and Hospital Payroll

(Control=All Non-508 CDs)

\section{Panel A: Medicare Inpatient PPS Payments (\$ Millions, 2010 Dollars)}
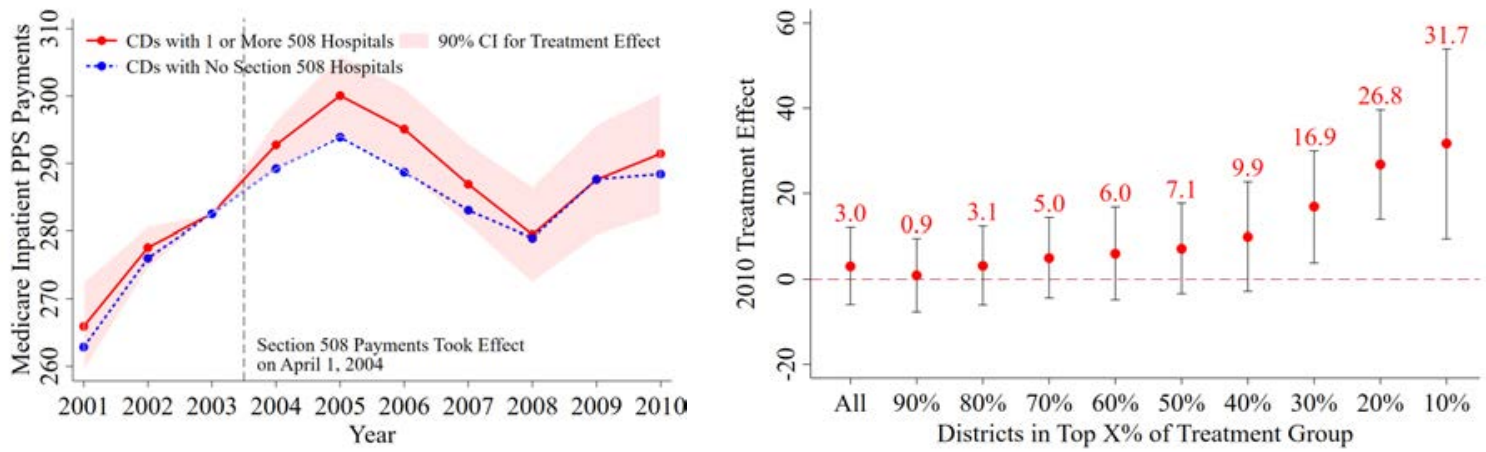

Panel B: Full-Time Total Personnel

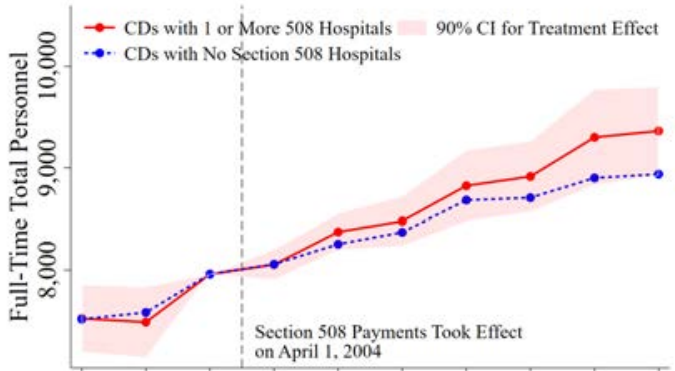

2001200220032004200520062007200820092010 Year

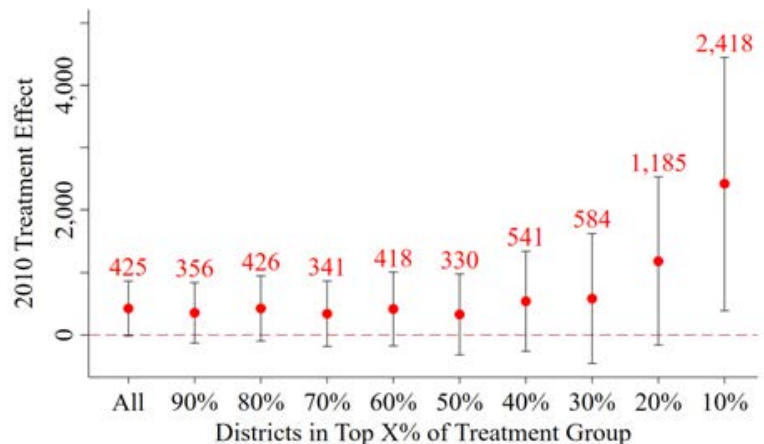

Panel C: Total Facility Payroll Expenses (\$ Millions, 2010 Dollars)
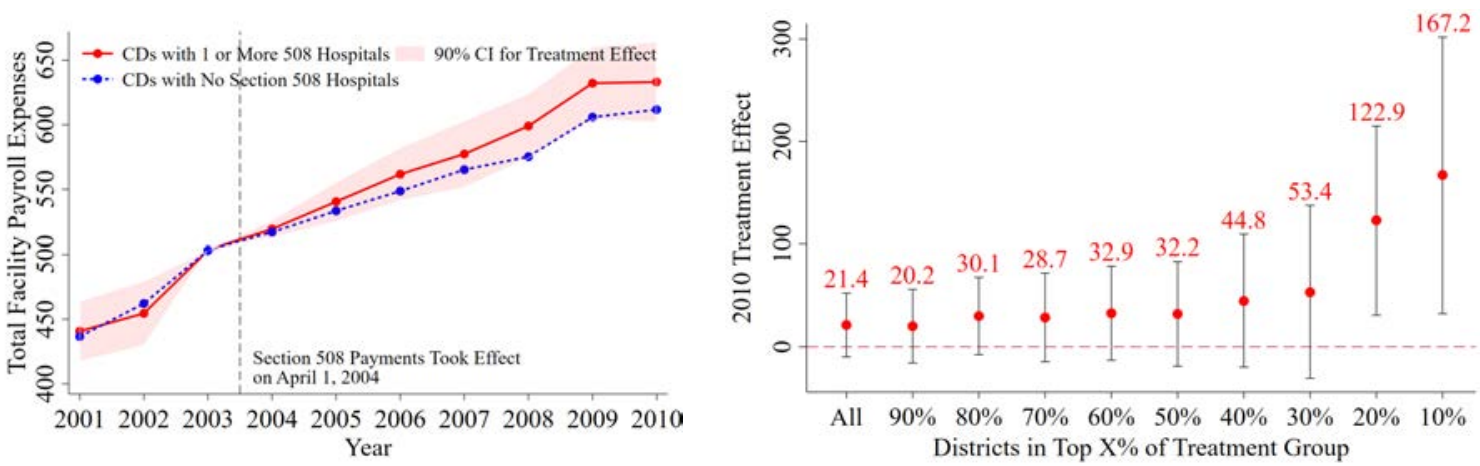

Notes: These figures present estimates of Equation (2) where we regress congressional district outcomes on a vector of congressional district fixed effects, year dummies, and interactions between the treated congressional district indicator and year dummies. 2003 is our omitted year. Control congressional districts are those with no Section 508-recipient hospitals. 90\% confidence intervals are based on wild-bootstrapped standard errors clustered around congressional districts. The rightmost figures plot the coefficient of the 2010 interaction term from Equation (2) as we vary the definition of the treatment group. Moving left to right in each figure, each specification involves a treated group composed of congressional districts with increasingly large gains in total IPPS payments (based on quantities in 2003 and actual and counterfactual payment rates in 2005) due to the Section 508 program. Medicare inpatient PPS payments are derived from the RAND Medicare Cost Reports (HCRIS) data. Payroll expenses and full-time personnel are derived from the American Hospital Association's Annual Survey data. 
Figure A.11: The Impact of the Section 508 Program on Congressional District-Level Inpatient Medicare Spending, Hospital Personnel, and Hospital Payroll (Control: Propensity Score Matched CDs)

Panel A: Medicare Inpatient PPS Payments (\$ Millions, 2010 Dollars)
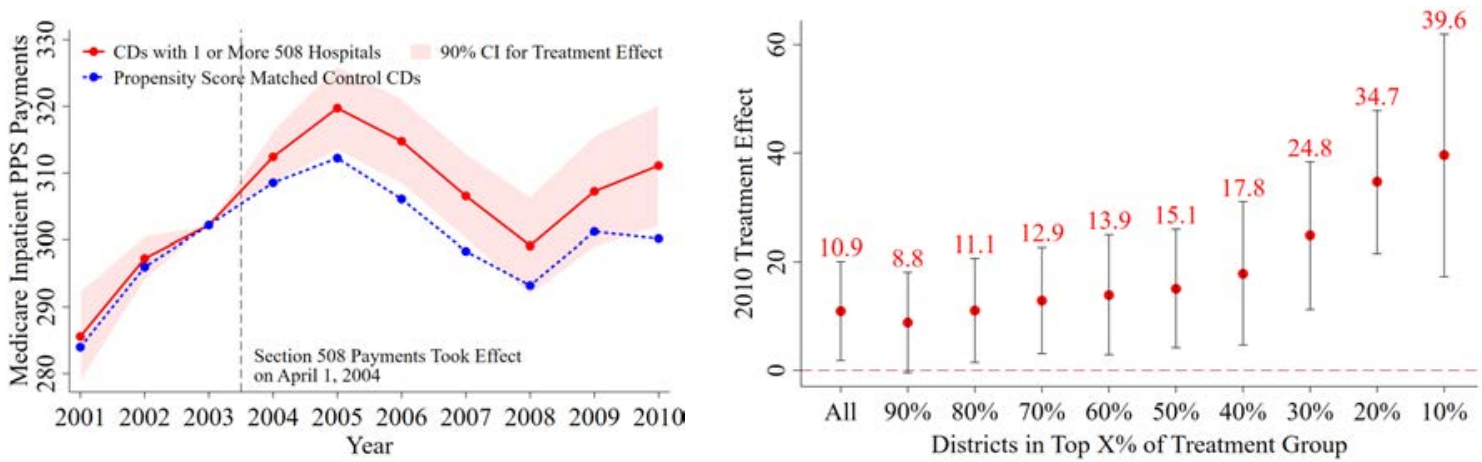

Panel B: Full-Time Total Personnel

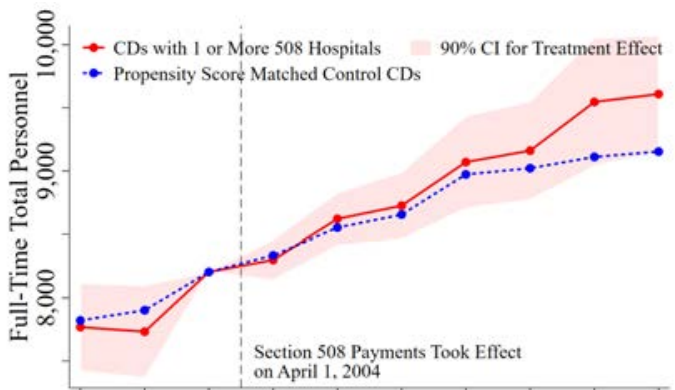

2001200220032004200520062007200820092010

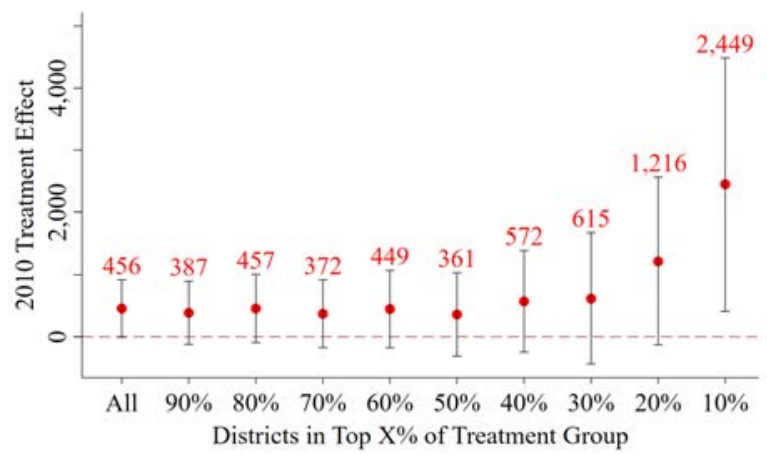

Panel C: Total Facility Payroll Expenses (\$ Millions, 2010 Dollars)
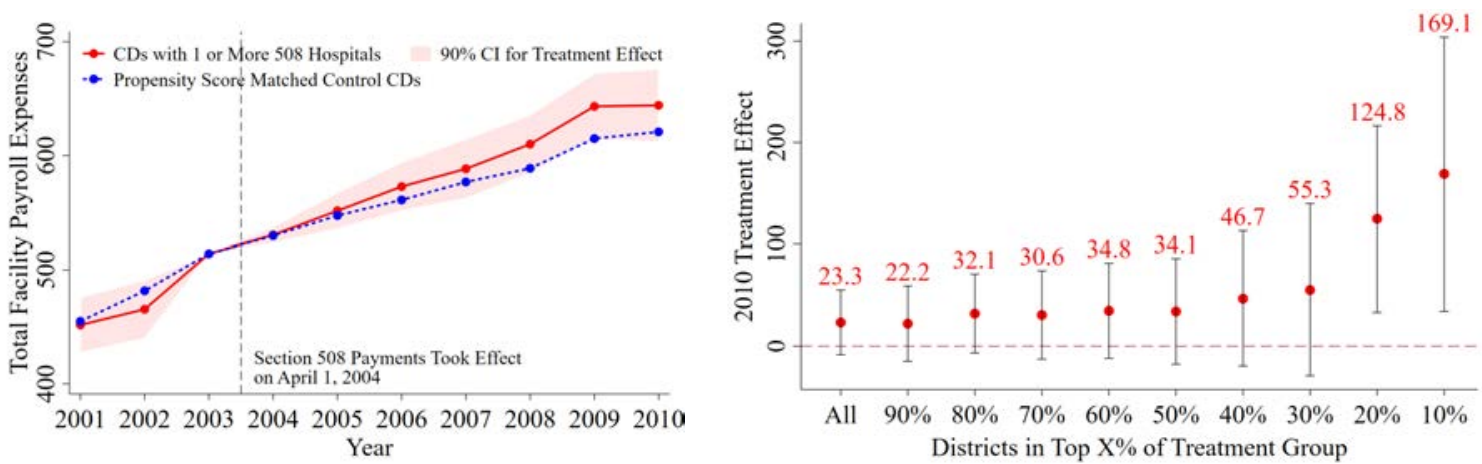

Notes: These figures present estimates of Equation (2) where we regress congressional district outcomes on a vector of congressional district fixed effects, year dummies, and interactions between the treated congressional district indicator and year dummies. 2003 is our omitted year. Control congressional districts are the 10 nearest neighbors according to the probit model of propensity score matching. $90 \%$ confidence intervals are based on wild-bootstrapped standard errors clustered around congressional districts. The rightmost figures plot the coefficient of the 2010 interaction term from Equation (2) as we vary the definition of the treatment group. Moving left to right in each figure, each specification involves a treated group composed of congressional districts with increasingly large gains in total IPPS payments in 2005 due to the Section 508 program. Medicare inpatient PPS payments are derived from the RAND Medicare Cost Reports (HCRIS) data. Payroll expenses and full-time personnel are derived from the American Hospital Association's Annual Survey data. 


\section{Figure A.12: Annual Lobbying Dollars from Section 508 Coalition}

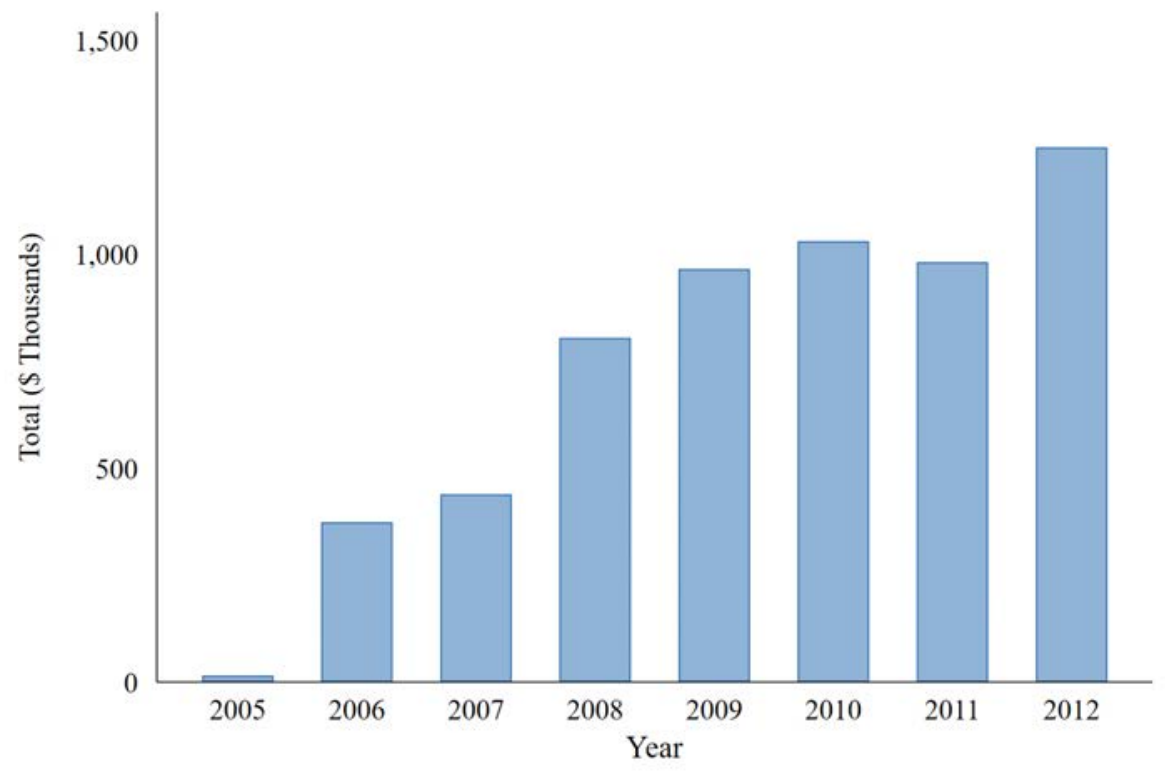

Notes: This figure presents the annual dollars spent lobbying by the Section 508 Coalition. Data was obtained from the Center for Responsive Politics. 


\section{Figure A.13: The Impact of the Re-Authorization of the Section 508 Program on Campaign Contributions from All Donors Nationwide (Dose Responses)}

Panel A: 2007-Quarter 2

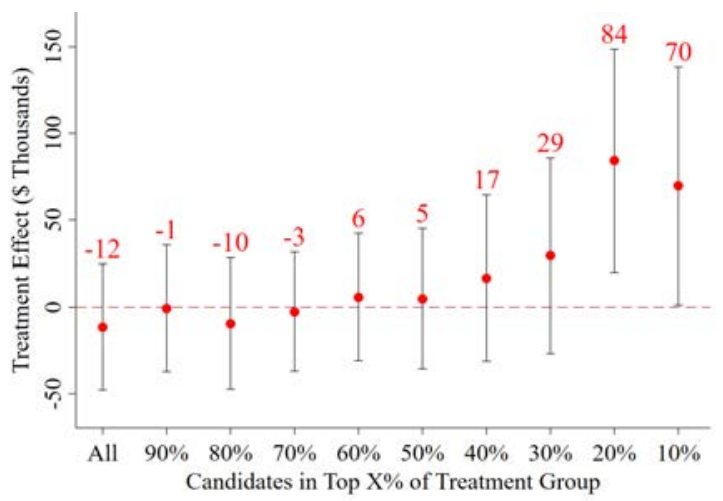

Panel C: 2007-Quarter 4

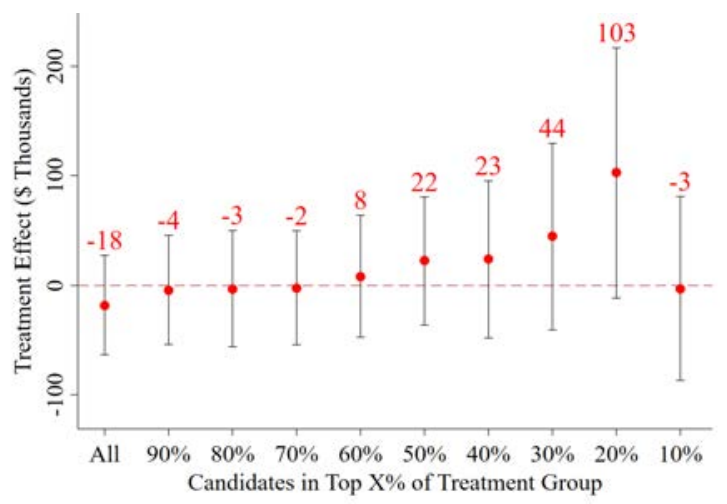

Panel E: 2008-Quarter 2

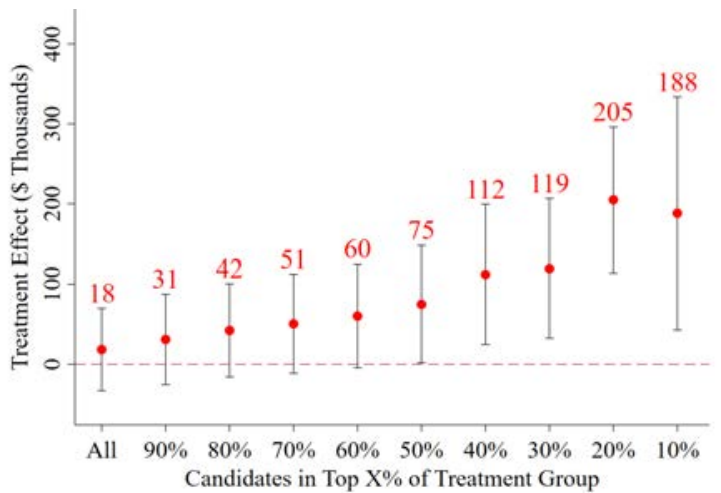

Panel B: 2007-Quarter 3

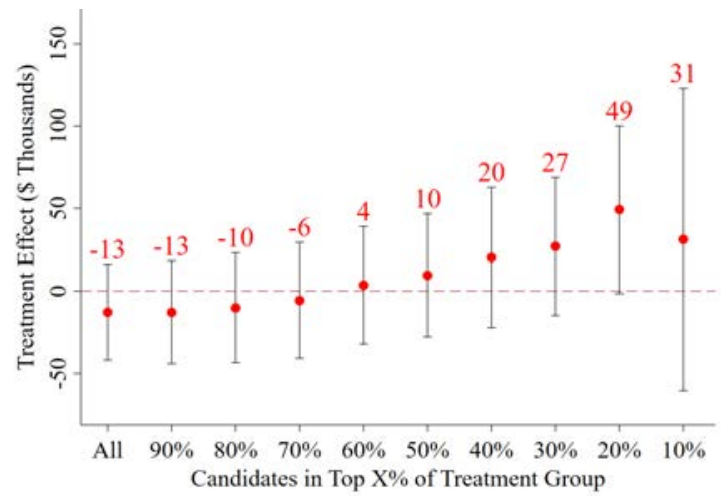

Panel D: 2008-Quarter 1

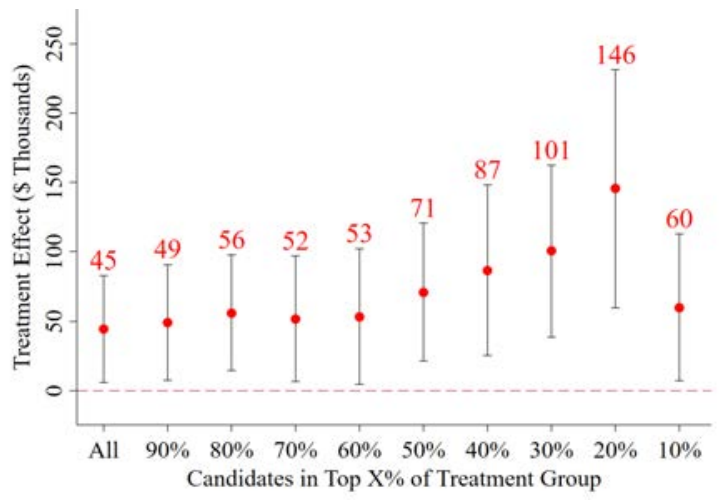

Panel F: 2008-Quarter 3

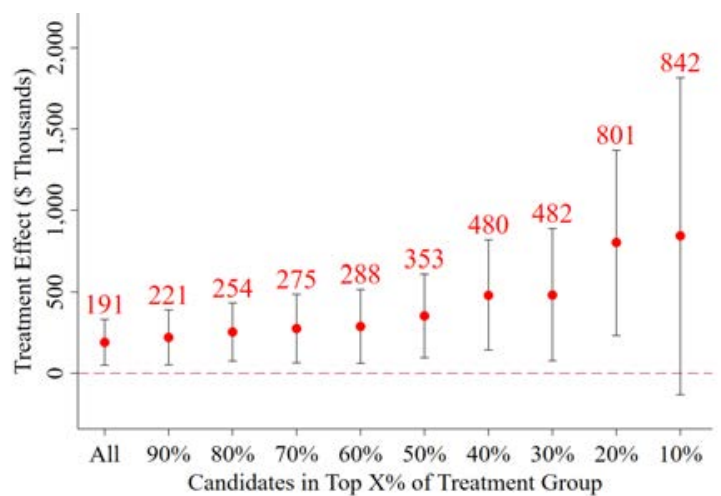

Notes: These figures plot the coefficient of the interactions between the treated candidate indicator and quarter dummies for all quarters in years 2007 and 2008 from Equation (3) as we vary the definition of the treatment group. Moving left to right in each figure, each specification involves a treated group composed of candidates from congressional districts with increasingly large gains in total IPPS payments in 2005 (based on quantities in 2003 and actual and counterfactual payment rates in 2005) due to the Section 508 program. Control candidates are those with one or more hospitals in their district that applied for a Section 508 waiver but were rejected. 2007-Q1 is our omitted time period. $90 \%$ confidence intervals are based on wild-bootstrapped standard errors clustered around candidates. Campaign contributions are in thousands of constant 2010 dollars. 
Figure A.13: The Impact of the Re-Authorization of the Section 508 Program on Campaign Contributions from All Donors Nationwide (Dose Responses) [Contd.]

\section{Panel G: 2008-Quarter 4}

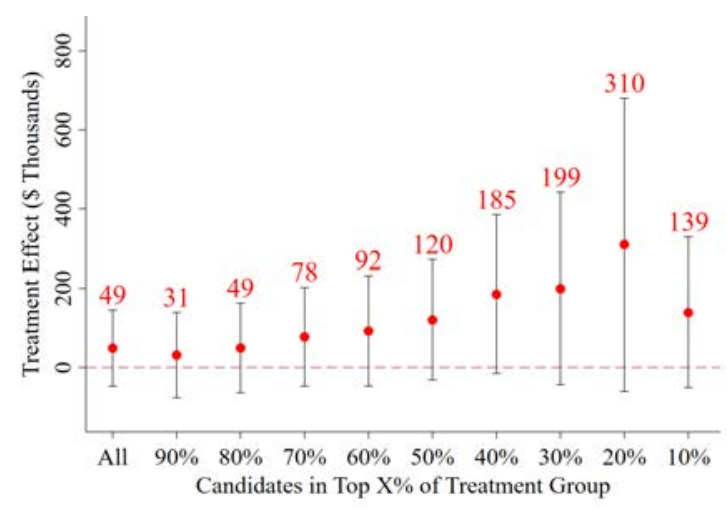

Notes: These figures plot the coefficient of the interactions between the treated candidate indicator and quarter dummies for all quarters in years 2007 and 2008 from Equation (3) as we vary the definition of the treatment group. Moving left to right in each figure, each specification involves a treated group composed of candidates from congressional districts with increasingly large gains in total IPPS payments in 2005 (based on quantities in 2003 and actual and counterfactual payment rates in 2005) due to the Section 508 program. Control candidates are those with one or more hospitals in their district that applied for a Section 508 waiver but were rejected. 2007-Q1 is our omitted time period. 90\% confidence intervals are based on wild-bootstrapped standard errors clustered around candidates. Campaign contributions are in thousands of constant 2010 dollars. 


\section{Figure A.14: The Impact of the Re-Authorization of the Section 508 Program on Campaign Contributions}

\section{Panel A: Campaign Contributions from All Donors in Same State}
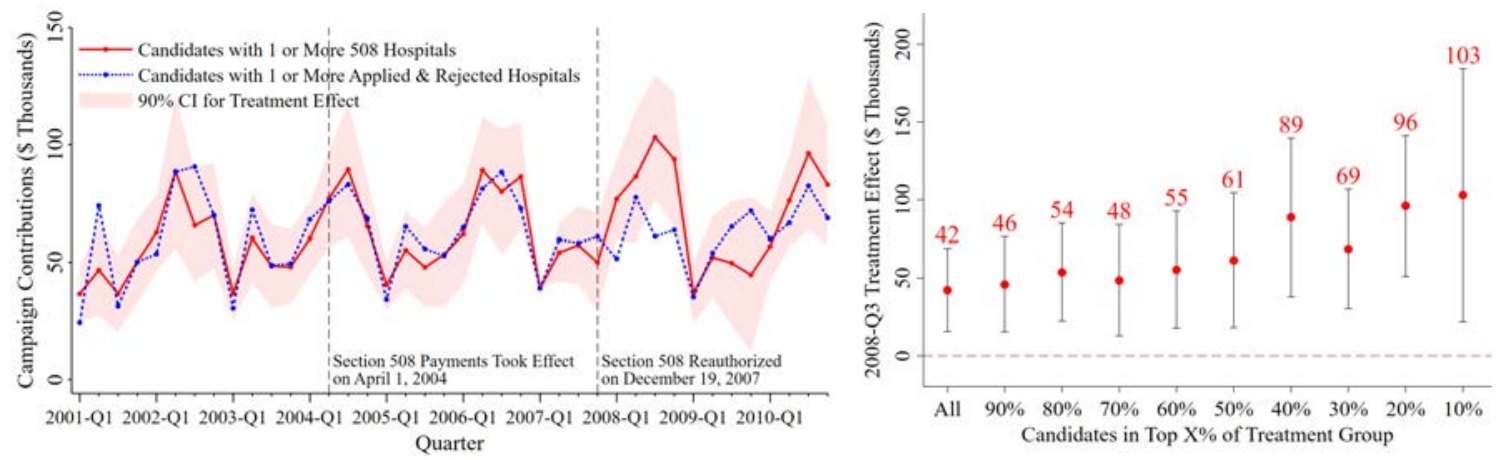

Panel B: Campaign Contributions from Individual Donors Nationwide
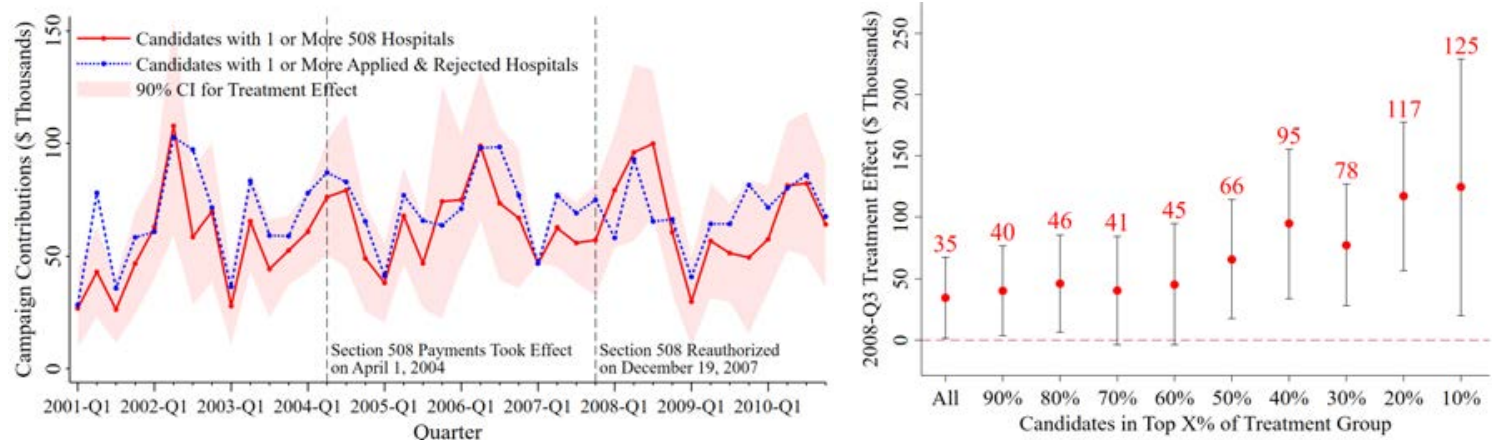

Panel C: Campaign Contributions from Individual Donors in Same State
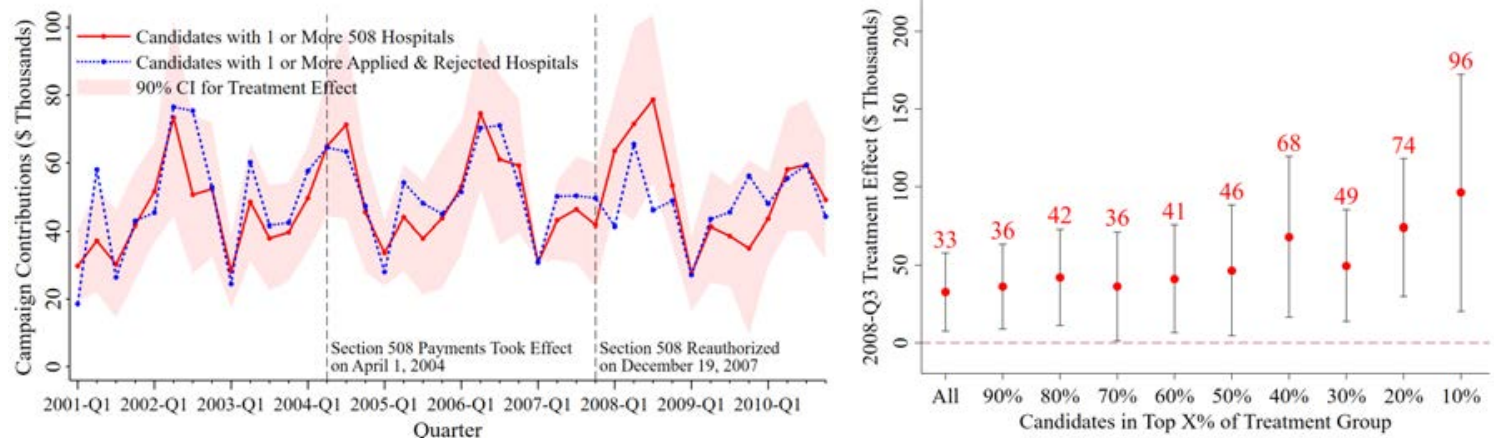

Notes: These panels present estimates of Equation (3) where we regress campaign contributions (in thousands of constant 2010 dollars) on a vector of candidate fixed effects, quarter dummies, and interactions between the treated candidate indicator and quarter dummies. Control candidates are those that have one or more hospitals in their district that applied for a Section 508 waiver but were rejected. 2007-Q1 is our omitted time period. $90 \%$ confidence intervals are based on wild-bootstrapped standard errors clustered around candidates. The rightmost figures plot the coefficient of the 2008-Q3 interaction term from Equation (3) as we vary the definition of the treatment group. Moving left to right in each figure, each specification involves a treated group composed of candidates from congressional districts with increasingly large gains in total IPPS payments in 2005 (based on quantities in 2003 and actual and counterfactual payment rates in 2005) due to the Section 508 program. 


\section{Figure A.14: The Impact of the Re-Authorization of the Section 508 Program on Campaign Contributions [Contd.]}

\section{Panel D: Campaign Contributions from Committee/Organization Donors Nationwide}
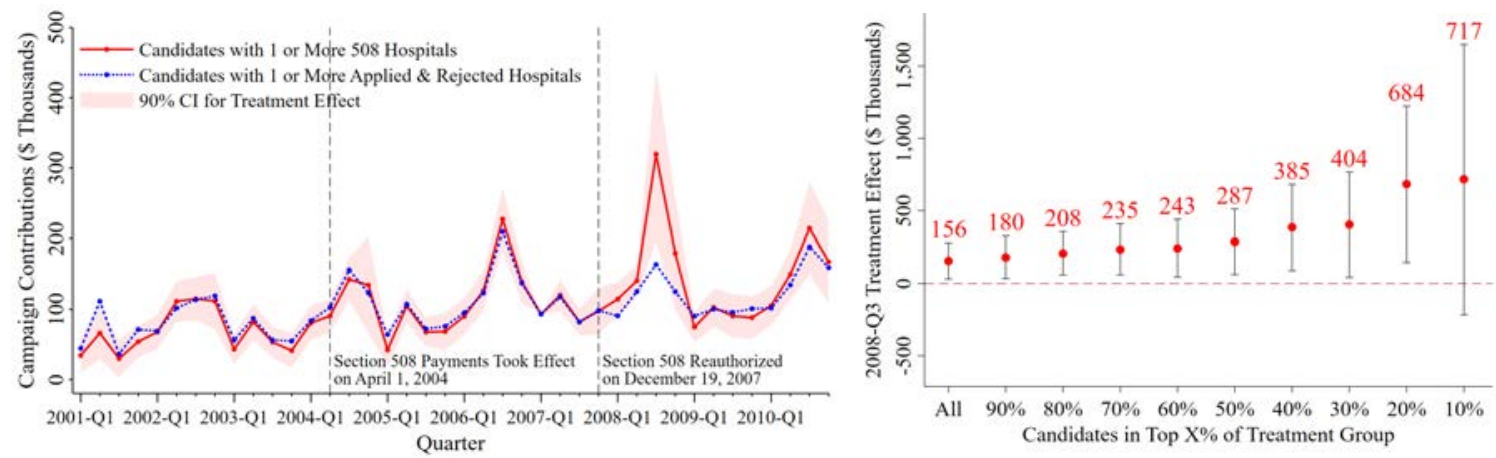

Notes: These panels present estimates of Equation (3) where we regress campaign contributions (in thousands of constant 2010 dollars) on a vector of candidate fixed effects, quarter dummies, and interactions between the treated candidate indicator and quarter dummies. Control candidates are those that have one or more hospitals in their district that applied for a Section 508 waiver but were rejected. 2007-Q1 is our omitted time period. 90\% confidence intervals are based on wild-bootstrapped standard errors clustered around candidates. The rightmost figures plot the coefficient of the 2008-Q3 interaction term from Equation (3) as we vary the definition of the treatment group. Moving left to right in each figure, each specification involves a treated group composed of candidates from congressional districts with increasingly large gains in total IPPS payments in 2005 (based on quantities in 2003 and actual and counterfactual payment rates in 2005) due to the Section 508 program. 


\section{Figure A.15: The Impact of the Re-Authorization of the Section 508 Program on Campaign Contributions from All Donors Nationwide}

\section{Panel A: Candidates in Office in 2007 (Control=Applied But Rejected)}
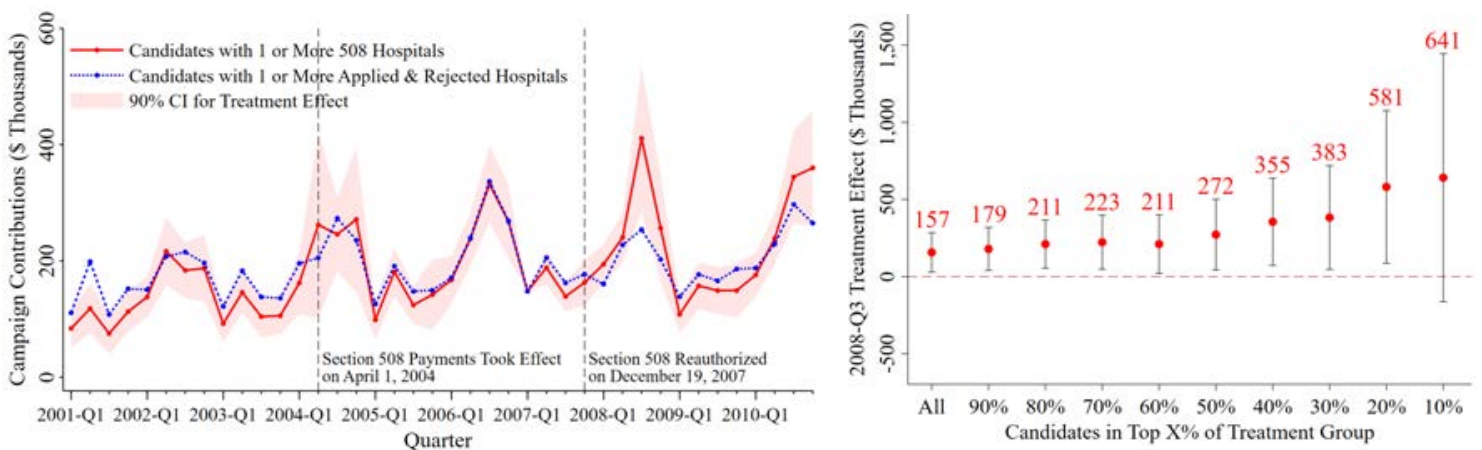

\section{Panel B: Control=All Non-508 Candidates}
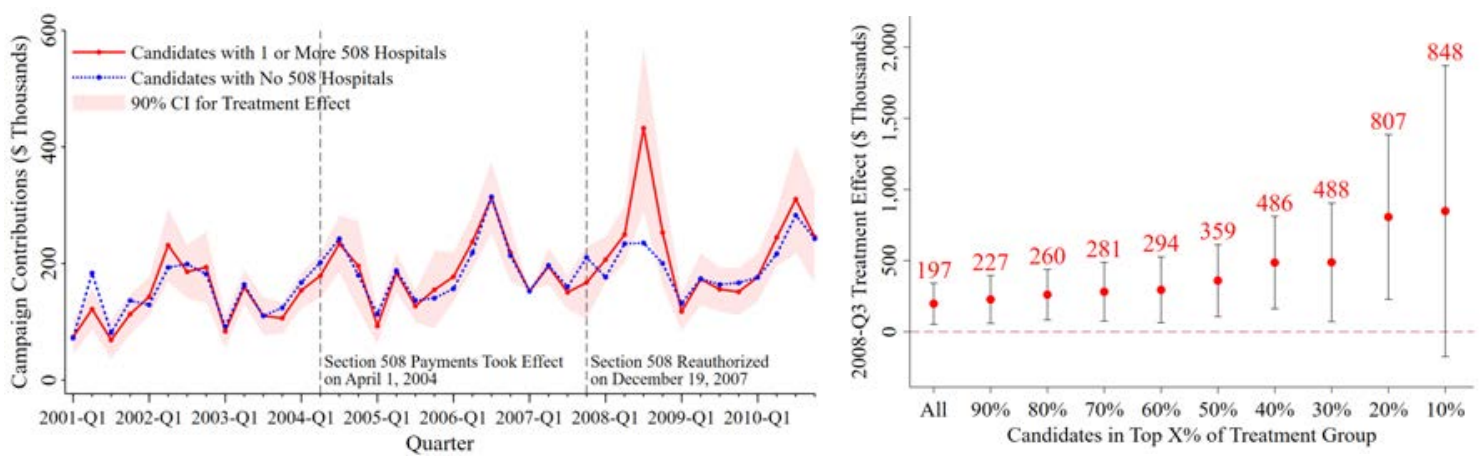

Panel C: Control=Eligible \& Didn’t Apply
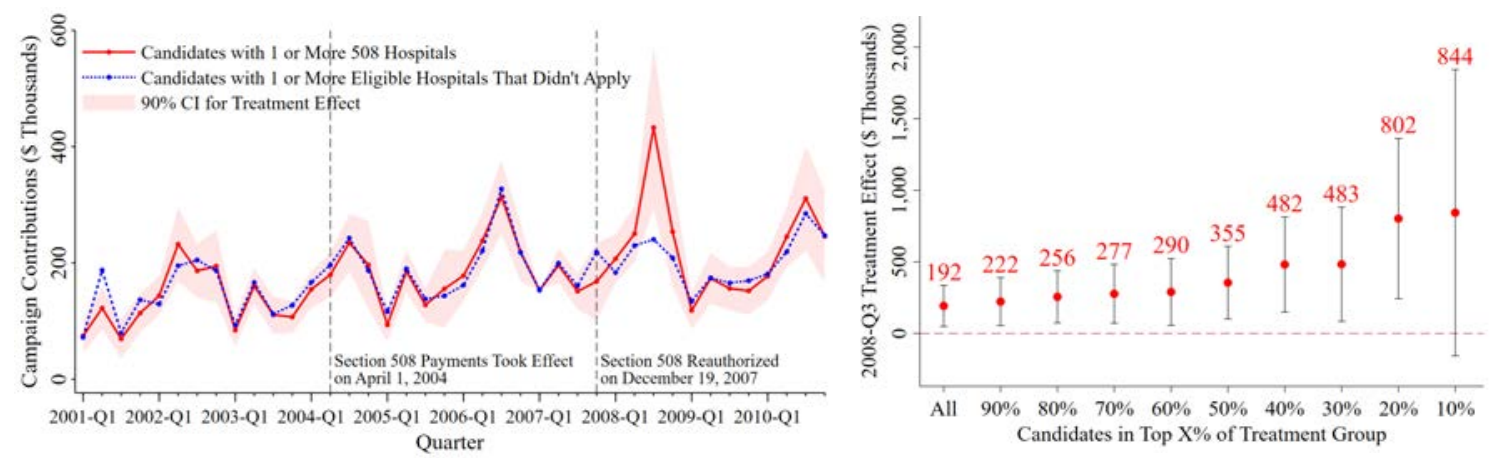

Notes: These panels present estimates of Equation (3) where we regress campaign contributions from all donors nationwide (in thousands of constant 2010 dollars) on a vector of candidate fixed effects, quarter dummies, and interactions between the treated candidate indicator and quarter dummies. 2007-Q1 is our omitted time period. 90\% confidence intervals are based on wild-bootstrapped standard errors clustered around candidates. The rightmost figures plot the coefficient of the 2008-Q3 interaction term from Equation (3) as we vary the definition of the treatment group. Moving left to right in each figure, each specification involves a treated group composed of candidates from congressional districts with increasingly large gains in total IPPS payments in 2005 (based on quantities in 2003 and actual and counterfactual payment rates in 2005) due to the Section 508 program. Panel A relaxes the requirement that candidates are in office in both 2003 and 2007, and only requires candidates to be in office in 2007. Panels B to E change the control group to candidates with no Section 508-recipient hospitals in their district; candidates with one or more hospitals in their district that were eligible for a Section 508 waiver but didn't apply; candidates with one or more hospitals in their district that were ineligible for a Section 508 waiver; and candidates that are 10 nearest neighbors according to our probit model of propensity score matching, respectively. 


\section{Figure A.15: The Impact of the Re-Authorization of the Section 508 Program on Campaign Contributions from All Donors Nationwide [Contd.]}

\section{Panel D: Control=Ineligibles}

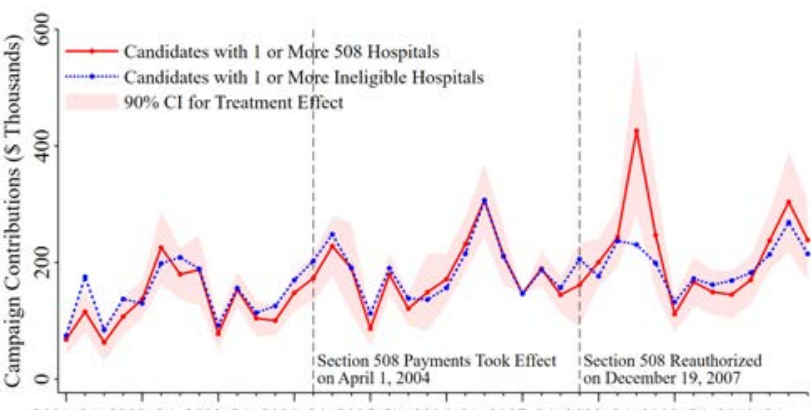

2001-Q1 2002-Q1 2003-Q1 2004-Q1 2005-Q1 2006-Q1 2007-Q1 2008-Q1 2009-Q1 2010-Q1

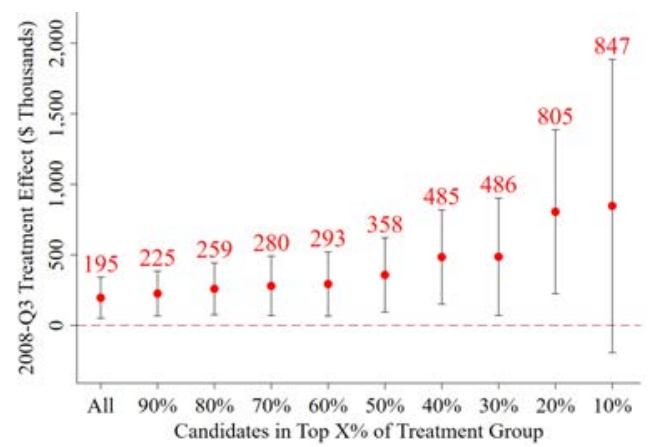

Candidates in Top X\% of Treatment Group

\section{Panel E: Control=Propensity Score Matched Candidates}

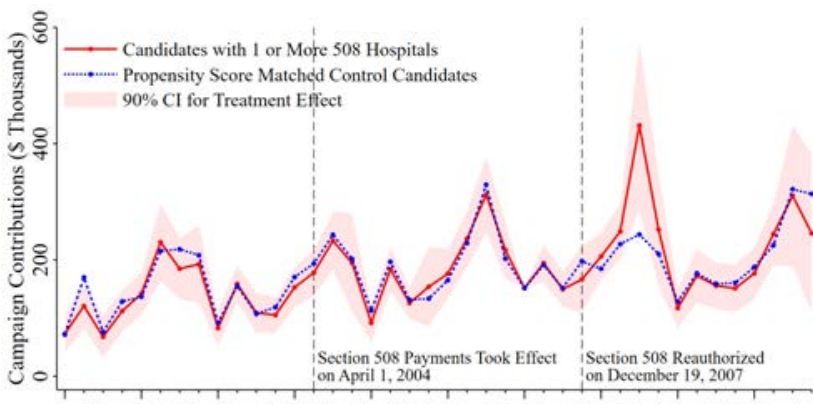

2001-Q1 2002-Q1 2003-Q1 2004-Q1 2005-Q1 2006-Q1 2007-Q1 2008-Q1 2009-Q1 2010-Q1

Quarter

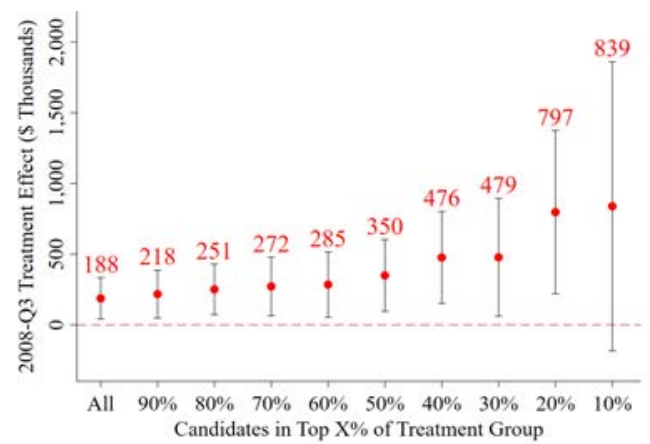

Notes: These panels present estimates of Equation (3) where we regress campaign contributions from all donors nationwide (in thousands of constant 2010 dollars) on a vector of candidate fixed effects, quarter dummies, and interactions between the treated candidate indicator and quarter dummies. 2007-Q1 is our omitted time period. 90\% confidence intervals are based on wild-bootstrapped standard errors clustered around candidates. The rightmost figures plot the coefficient of the 2008-Q3 interaction term from Equation (3) as we vary the definition of the treatment group. Moving left to right in each figure, each specification involves a treated group composed of candidates from congressional districts with increasingly large gains in total IPPS payments in 2005 (based on quantities in 2003 and actual and counterfactual payment rates in 2005) due to the Section 508 program. Panel A relaxes the requirement that candidates are in office in both 2003 and 2007, and only requires candidates to be in office in 2007. Panels B to E change the control group to candidates with no Section 508-recipient hospitals in their district; candidates with one or more hospitals in their district that were eligible for a Section 508 waiver but didn't apply; candidates with one or more hospitals in their district that were ineligible for a Section 508 waiver; and candidates that are 10 nearest neighbors according to our probit model of propensity score matching, respectively. 